NBER WORKING PAPER SERIES

\title{
INTRAHOUSEHOLD CONSUMPTION ALLOCATION AND DEMAND FOR AGENCY: A TRIPLE EXPERIMENTAL INVESTIGATION
}

\author{
Uzma Afzal \\ Giovanna D'Adda \\ Marcel Fafchamps \\ Farah Said \\ Working Paper 24977 \\ http://www.nber.org/papers/w24977 \\ NATIONAL BUREAU OF ECONOMIC RESEARCH
1050 Massachusetts Avenue
Cambridge, MA 02138
August 2018
}

We thank Doug Bernheim, Muriel Niederle, Glenn Harrison, John Quiggin, Emily Breza, Giacomo De Giorgi, Pedro Vicente, Catia Batista, James Berry, Silvia Prina, and Erlend Berg for their useful comments. We also benefitted from comments from participants to the CIRPEE Workshop on Social Identity and Social Interactions in Economics (Quebec City, April 2016), and to the WZB "Field Days" Conference (Berlin, June 2016), as well as from seminar participants at Stanford University, Georgia State University, the University of Oregon, and Nova University in Lisbon. Funding for this study was provided by the International Growth Centre (IGC) and by the Economic and Social Research Council (ESRC). The views expressed herein are those of the authors and do not necessarily reflect the views of the National Bureau of Economic Research.

At least one co-author has disclosed a financial relationship of potential relevance for this research. Further information is available online at http://www.nber.org/papers/w24977.ack

NBER working papers are circulated for discussion and comment purposes. They have not been peer-reviewed or been subject to the review by the NBER Board of Directors that accompanies official NBER publications.

(C) 2018 by Uzma Afzal, Giovanna D'Adda, Marcel Fafchamps, and Farah Said. All rights reserved. Short sections of text, not to exceed two paragraphs, may be quoted without explicit permission provided that full credit, including $\odot$ notice, is given to the source. 
Intrahousehold Consumption Allocation and Demand for Agency: A Triple Experimental

Investigation

Uzma Afzal, Giovanna D'Adda, Marcel Fafchamps, and Farah Said

NBER Working Paper No. 24977

August 2018

JEL No. D13,D91,O12

\begin{abstract}
We conduct two lab experiments and one field experiment to investigate demand for consumption agency in married couples. The evidence we uncover is consistent across all three experiments. Subjects are often no better at guessing their spouse's preferences than those of a stranger, and many subjects disregard what they believe or know about others' preferences when assigning them a consumption bundle. This confers instrumental value to individual executive agency within the household. We indeed find significant evidence of demand for agency in all three experiments, and this demand varies with the cost and anticipated instrumental benefit of agency. But subjects often make choices incompatible with pure instrumental motives - e.g., paying for agency even when they know their partner assigned them their preferred choice. We also find female subjects to be quite willing to exert agency even though, based on survey responses, they have little executive agency within their household. We interpret this as suggestive of pent-up demand for agency, and indeed we find that female demand for agency falls as a result of an empowerment intervention.
\end{abstract}

Uzma Afzal

Lahore School of Economics

Lahore

Pakistan

uzmaafzal1@gmail.com

Giovanna D'Adda

Department of Economics, Management

and Quantitative Methods (DEMM)

University of Milan

Via Conservatorio 7

20122 Milan

Italy

giovanna.dadda@unimi.it
Marcel Fafchamps

Freeman Spogli Institute

Stanford University

616 Serra Street

Stanford, CA 94305

and NBER

fafchamp@stanford.edu

Farah Said

Lahore School of Economics

Lahore

Pakistan

farahz3@gmail.com 


\section{Introduction}

Much of the economic literature on intrahousehold consumption takes allocative efficiency between spouses as starting point. Without information on individual preferences over consumption bundles, however, it is difficult to test consumption efficiency directly. The collective model of the household (e.g., Chiappori 1997, Browning and Chiappori 1998) circumvents this difficulty by testing consumption efficiency using cross-equation restrictions on demand functions. The test ultimately relies on the idea that efficiency can be achieved by giving each spouse an individual budget they can spend as they like (e.g., Browning et al. 1994, 2010, 2013, 2014). Bargaining models of the household (e.g., McElroy and Horney 1981, Lundberg and Polak 1996) put more structure on the way by which a particular allocation of consumption is reached. By doing so they derive predictions about what extraneous factors determine the allocation of consumption between household members. ${ }^{1}$ They assume bargaining to be efficient, which ultimately requires that spouses are fully informed about each other's preferences, and that agreements between them are costlessly enforced.

In practice, the way by which households function departs from the organization structure that inspires both types of models: financial and real assets often are owned jointly, not individually; and consumption decisions are typically taken in a sequential and decentralized manner that opens the door to coordination issues. For instance, individuals encounter opportunities to make a consumption choice for another household member without necessarily knowing their preferences. This may arise either because the consumption good being offered is unfamiliar, the decision maker does not recall the preferences of others, or these preferences have changed. Similar opportunities for miscoordination occur within the household itself, e.g., someone prepares a family meal without knowing whether it will be appreciated or not. It is also conceivable that the decision maker knows the preferences of others but deliberately chooses to ignore them, either due to a paternalistic motive (e.g., 'this food is not good for you'), or out of disregards for others or a desire to impose one's will on them.

When other members of the household cannot be relied on to make decisions that maximize collective welfare, individual members may seek to gain agency over household consumption choices that affect them (e.g., Glennerster et al. 2018). To this effect, they may secure control over individual sources of income and saving (e.g., Anderson and Baland 2002), even if doing so is inefficent and involves dissimulation (e.g., Jakiela and Ozier 2015, Kebede et al. 2016). Alternatively, they may seek control over consumption purchases and household production activities. The latter strategies are particular relevant in less developed economies where households count many members engaged in a large range of home production activities (e.g., Fafchamps and Quisumbing 2008), in addition to having multiple sources of monetary income. Control over household decisions may take various forms, such as executive agency - making a decision alone - and consultative agency - being consulted on decisions made by others.

\footnotetext{
${ }^{1}$ E.g., distribution of assets upon divorce, control over household assets and finances, income earning opportunities.
} 
Unfortunately there is little or no literature investigating whether household members know each other's preferences, and whether they respect these preferences when making consumption choices for others. There is also little evidence regarding the demand for executive agency over own consumption within and outside the household. Others not respecting your preferences creates an instrumental motive for wanting agency. People may also value agency for its own sake, independently from instrumental motivations. One possibility, discussed in the empowerment literature, is that individuals - e.g., women have a pent-up demand for agency originating in their repressed desire to make their own choices.

The purpose of this paper is to offer new experimental evidence on these issues. We test three main hypotheses: (1) household members know each other's preferences over individual consumption goods; (2) household members respect the preferences of others when they are informed about them; and (3) individuals have a demand for agency, that is: are they willing to pay for the certainty of getting the consumption bundle of their choice; and does this demand increase with the risk of not getting one's choice, i.e., is demand for agency serving an instrumental motive.

We design an original experiment to test these hypotheses and we implement it in three different ways with Pakistani couples who have been married for some time. We find evidence against hypotheses 1 and 2: household members often do not know the preferences of their spouse or other household members; and even when they are informed about these preferences, they often choose to ignore them. We do find evidence of willingness to pay for agency, but demand for agency responds only weakly to the risk of not getting one's preferred consumption bundle. This suggests that demand for agency is not solely driven by an instrumental motive: some subjects seem to value agency for its own sake. The fact that informed subjects often make inefficient consumption choices for others similarly signals a demand for power, that is, a desire to make choices for others.

This paper is related to the existing literature in multiple ways. In addition to the literature already mentioned, a number of papers have experimentally examined willingness to pay for agency in games between spouses (e.g., Iversen et al. 2011, Jakiela and Ozier 2015, Mani 2011). In these experiments, agency has instrumental benefits and these studies do not focus on demand from pure agency. A related literature looks at preference for agency in decision-making processes outside of the household. Results suggests that individuals value their decision power beyond its instrumental value (Güth and WeckHannemann 1997, Fehr et al. 2013, Bartling et al. 2014, Owens et al. 2014). Individuals have also been shown to prefer fair decision processes, over and above the fairness of the allocation (Bolton et al. 2005). ${ }^{2}$ Our study is the first, to the best of our knowledge, to experimentally look at preference for agency within and across households.

A large related literature looks at the efficiency of household decisions. Many papers, relying on natural, field, and laboratory experiments, show that income pooling fails, a situation that implies inefficient consumption choices (Duflo and Udry 2004, Kebede et

\footnotetext{
${ }^{2}$ More generally, a large literature on incentives and sanctions demonstrate the presence of control aversion among some individuals (for an example, see Falk and Kosfeld, 2006).
} 
al. 2014, Castilla 2015, Chen 2013, Munro et al. 2008, Iverson et al. 2006). ${ }^{3}$ In the same vein, several experiments have varied the amount of information available to household members and found evidence of opportunism (Ambler 2015, Castilla and Walker 2012, Hoel 2015, de Laat 2014, Castilla 2014). ${ }^{4}$ A number of authors have documented the negative efficiency consequences of mismatched preferences between spouses (Schaener 2015, Ashraf et al. 2014, Carlsson et al. 2009, Fiala 2015). Our contribution to this literature is to identify another possible source of inefficiency, namely disregard for others' preferences within and across households.

Regarding procedural gender equality, a number of studies find that inefficiency in household decisions is lower when control over resources is more egalitarian between men and women (Deer and Twyman 2012, Fiala 2017, Ashraf 2009). In an experiment over risky decisions by spouses, de Palma et al. (2009) show that the balance of power within the household is malleable. On these themes, our contribution is twofold. First, we clarify that procedural equality is not just about bargaining weights per se; it is also related to the way agency is allocated within the household. Second, we offer a novel experimental design to investigate whether people value agency and why. The approach is designed to distinguish the different motives behind willingness to pay for agency. One such motive is others' imperfect knowledge of one's own preferences. We deal with this motive by varying the amount of information given to participants about their partner's preferences. Another motive is the partner's willingness to respect one own preferences, which lowers the need to pay for agency when the partner is informed. We tackle this issue by measuring these choices directly.

The paper is organized as follows. To provide a stronger motivation for our research, we start in Section 2 by offering evidence of the unequal distribution of executive and consultative agency within the households we study. We then detail in Section 3 the design of our sequence of experiments. We also describe our testing strategy, building on a simple model of instrumental demand for agency. Empirical evidence from two sets of experimental sessions is discussed in Section 4. Addtional evidence from a field experiment is presented in Section 5, while Section 6 concludes. A detailed description of the experimental protocols is given in the Online Appendix.

\section{Descriptive statistics on agency}

To better motivate our research, we begin by documenting how individual agency is distributed between married men and women in our study population. We select subjects whose livelihoods are broadly representative of the bulk of the population in developing

\footnotetext{
${ }^{3}$ Other income pooling tests are provided by Munro et al. (2008), Bobonis (2009), Robinson (2012), and de Brauw et al. (2014), among others.

${ }^{4}$ More generally, social preferences are shown to differ by gender. Eckel and Grossman (1998) provide experimental evidence that women are more selfless than men; that they exhibit solidarity and are even more generous when dealing with women than with men (Eckel and Grossman, 2001). Dasgupta and Mani (2015) find that while men feel entitled to use endowments they have earned for private consumption, women do not.
} 
countries, i.e., living in large households with multiple income generating activities but a relatively low level of consumption and income. In such populations, decisions over everyday consumption are likely to impact consumption welfare more than in prosperous societies where individual welfare depends more on durables and other large expenditures. To further strengthen the relevance of our findings, we focus on a country - Pakistan - where intrahousehold agency is often viewed as problematic and where women are traditionally destined to remain under the control of an adult male, typically their father or husband.

Survey questionnaires were administered to individuals from our experiments. The protocol used to recruit experimental subject will described in more details in Section 3.2. For now we simply present a few descriptive statistics on agency as a way of motivating the experimental design. ${ }^{5}$ The data we are presenting comes from questions administered to individual respondents by an independent enumerator firm. Due to the private and subjective nature of the questions being asked, interviews of female respondents were conducted face-to-face by female enumerators only. Care was taken to ensure that the respondents knew their responses would remain confidential.

We document the distribution of agency between men and women using questions aimed at capturing two different aspects: the power to make decisions autonomously, which we call executive agency; and being consulted in household decisions, which we call consultative agency. ${ }^{6}$ Consultative agency allows individuals to inform the decision maker about their preferences.

Executive agency is measured by asking whether the respondent has to ask for permission when making decisions ranging from small consumption choices - e.g., buying ice cream for children - to major financial decisions - e.g., purchasing a durable good. Consultative agency is measured by asking respondents the extent to which their preferences and opinions are taken into account when the household makes decisions ranging from children's education and social visits, to the purchase of household goods and investment decisions. For presentation purposes, they are grouped into categories based on similarity of the decision.

Figure A1 in Appendix A presents summary statistics on the need to ask for permission before making different types of decisions. Averages are given for women (Panel A and $\mathrm{B}$ ), and men (Panel C and D) for each of our two laboratory experiments - denoted as LAB1 and LAB2 in what follows. Each bar represents the share of respondents answering that they need to ask for permission before making a decision. Decisions are sorted by order of economic importance. Two main findings emerge from the Figures. First, there is a large difference in the need to ask for permission between men and women: $62 \%$ to $73 \%$ of women in the LAB1\&2 samples have to ask for permission, compared to only $6 \%$ and $45 \%$ of their male partners $(\mathrm{p}=.000)$. Second, the need to ask for permission is increasing

\footnotetext{
${ }^{5}$ For the purpose of another research project, we asked identical questions to non-experimental subjects from the same study population. Their answers, not reported here to save space, are very similar, suggesting that the details of the experimental recruitment process can be ignored for the sake of the descriptive statistics reported here.

${ }^{6}$ The full list of agency questions is presented in Appendix B. The table also specifies from which samples we collect each measure.
} 
in the importance of the decision: the proportion of affirmative answers increases by 67 percentage points for women in the LAB1\&2 samples. By comparison, the increase is only 13 percentage points for the men. We see similar patterns among the women who participated in the field experiment - the need to ask permission increases by more than 50 percentage points. These patterns support the idea that women have less executive agency than men, particularly for important decisions. ${ }^{7}$

Questions on consultative agency include the following decision categories: personal consumption or finance; children's education and health care; household investment; and family planning. Figure A2 in Appendix A displays average answers to these questions broken down by category. We see that women's opinion and preferences are taken into account to a lesser degree as the importance of the decision increases.

\section{$3 \quad$ Experimental design}

The logic behind our experimental design starts from standard economic theory. Individuals have preferences over consumption bundles, with $\bar{U}_{i}$ denoting the utility individual $i$ derives from their preferred bundle. When someone else, say $j$, chooses a bundle for $i$, the utility $\widetilde{U}_{i}$ that $i$ expects to receive depends on the probability that $j$ chooses $i$ 's preferred bundle. If $i$ is not certain to receive their preferred bundle, this creates an instrumental motive for $i$ to exercise agency: $i$ is willing to pay to obtain their preferred bundle instead of letting $j$ choose for them. ${ }^{8}$

To implement this idea, each subject $i$ is invited to select among possible consumption bundles, to be consumed on the spot. Another person $j$ is also invited to select a consumption bundle for $i$. Subject $i$ is then offered a chance to pay something to ensure that they receive their selection. We expect $i$ 's willingness to pay for agency to be higher when the instrumental value of agency is larger - e.g., when $j$ has little information about $i$ 's preferences and is less likely to respect those preferences.

To capture this variation, we first vary $j$ 's relationship with $i$. In some treatments, $j$ is a spouse or close household member; in others $j$ is a stranger. We expect a stranger to be less informed about $i$ 's preferences, and less concerned about choosing the wrong bundle for $i$. Second, we vary the information $j$ is given about $i$ 's preferences. We expect an informed $j$ to be more likely to accomodate $i$ 's preference when $j$ cares about $i-$ e.g., is a close relative or is otherwise altruistic. Hence the effect of information on accomodating $i$ 's stated preferences should be larger between close relatives than among strangers. The experiment is designed to test these intermediate predictions directly.

Demand for agency may, however, be repressed among certain individuals - e.g., women - either through the threat of retribution or through the internationalization of social norms. In the latter case, individuals internalize their dependent status and punish

\footnotetext{
${ }^{7}$ Regression analysis with individual fixed effects confirms that women are more likely to report having to ask for permission when decisions are more important.

${ }^{8}$ Note that risk aversion is not necessary to generate demand for agency: all that is needed is that consumption bundles are strictly ranked by $i$ - i.e., are not perfect substitutes.
} 
themselves for infringing them - e.g., through guilt or shame. Alternatively, repressed individuals may not even conceive that they could have their own free will, a phenomenon that leads to a failure of aspiration (e.g., Alan and Artac 2016). Many policies advocated to empower women seek to reduce the threat of retribution directly - e.g., by seeking to reduce domestic violence or by penalizing sexual harrassment and rape (e.g., biju rao papers, erica?). Others focus on changing social norms and aspirations through information campaigns (e.g., AEA paper on Turkish school intervention) or the media (e.g., La Ferrara telenovelas). ${ }^{9}$ What matters for our purpose is that, when certain individuals' agency is repressed, they will refrain from expressing a demand for agency. We test this idea by comparing willingness to pay for agency between men and women, within and across households. If women's agency is repressed, we expect them to be less willing to pay to get their own choice, irrespective of whether the instrumental value of agency is high or not.

It is also conceivable, however, that women have a pent-up demand for agency. This is more likely to occur if repression is not internalized but is due to the fear of retribution. If such case, removing the possibility of retribution may encourage women to demand more agency than men, as a way of compensating for otherwise repressed aspirations. Pent-up demand for agency may even lead women to insist on having their choice even when the instrumental value of that choice is nihil. To allow the expression of pent-up demand for agency, we design the experiment in such a way that $j$ does not know whether or not $i$ chooses to exert agency. To achieve this, we place male and female subjects in two different rooms with no communication between them during the whole duration of the experiment. Given that Pakistani society generally favors gender segregation, this turned out to be unproblematic. We also organize the experiment around the choice of a good - e.g., a food or drink or an individualized item - to be consumed by the subject alone. This precludes sharing the good with others within or outside the household, thereby making it impossible for subjects to compensate outside the lab for those decisions they made within it. It also makes it possible for subjects to hide, if they so wish, the nature of what they consumed - and thus whether or not they decided to overrule what $j$ had chosen for them.

By an inverse reasoning, individuals who have plenty of executive agency - e.g., male household heads in our study area - may insist on exerting power over others' consumption choices, even menial ones. This would lead them not to accomodate the preferences of their wife or female dependents, and of women more generally. To investigate this possibility, we compare $j$ 's failure to accomodate $i$ 's preferences between men and women, within and across households.

Having outlined the general principles behind our experimental design, we now discuss the details of each of the three specific implementations presented in this paper. The first two are laboratory experiments; the third is part of a randomized controlled trial.

\footnotetext{
${ }^{9}$ See also Krutikova and Dercon $(20 \mathrm{XX})$ and Dercon et al (20XX) on inteventions aimed at raising aspirations.
} 


\subsection{The first laboratory experiment}

The first experiment (LAB1) was conducted in April 2015 in the city of Chakwal, Pakistan. There were 15 sessions with a total of 336 subjects. We invited female participants in a microfinance RCT and some of their neighbor to come to a makeshift lab with their husband. Those who could not bring their husband were told to come accompanied by the adult male with the greatest power over her household's finances. $74.4 \%$ of the participants came with their spouse; $14.88 \%$ with their son and $10.72 \%$ with other male household members (for instance, brother, brother-in-law).

Upon arrival, men and women were sent to a separate room. Each male and female subject was then matched with a partner in the other room. Half of the women were matched with the male household member they came with; the other half were matched at random with a male participants coming from another household. Subject pairs assigned to a stranger partner are referred as part of the Stranger Match treatment; the others are referred to as the Family Match treatment. Subjects in the Stranger Match treatment are never told the identity of the person they are matched with.

Each subject is then invited to taste each of three possible fruit juices, upon which they rank them by order of preference and pick one to be their preferred choice. Subjects are then asked to guess how their partner ranked the three juices. Half of the subjects are then informed how their partner actually ranked the juices, and they are asked to pick a juice for the partner. The rest of the subjects are not told their partner's rankings and have to pick a juice without having that information. Subjects are then told that a coin flip would determine whether they receive the juice they picked, or the juice picked by their partner. Before tossing the coin, however, subjects are offered the opportunity to instead have half a glass of the juice they picked for themselves. To measure altruism between partners, we also conduct three standard redistributive games: a dictator game; an ultimatum game; and a reverse dictator game. We combine answers to the three games to construct an index of altruism towards the partner. Detailed experimental protocol is presented in the Online Appendix A1.

This design allows us to test the following hypotheses:

H1 Do subjects know the preferences of their partner? This is achieved by comparing actual juice rankings with those guessed by the partner.

H2a Do subjects respect the preferences of their partner? If they do not, this indicates a desire to override the partner's choice - i.e., a demand for power over the consumption of others. We investigate this in two ways: (1) we test whether uninformed subjects pick for their partner what they guess is their partner's preferred juice; and (2) we test whether informed subjects pick for their partner what they have been told is their partner's preferred juice. We also breakdown the marginal effect of information depending on whether the subject initially guessed correctly or not.

We can also test a series of hypotheses regarding demand for agency: 
H3a Do subjects have a demand for agency? We investigate this by observing what proportion of subjects elects to receive half a glass of their juice pick.

H3b Is there pent-up demand for agency or repressed demand for agency among women? This test is achieved by comparing demand for agency between men and women, within and across households. If female demand for agency is repressed by the husband or male head of household, but women have pent-up demand for agency, we should observe more willingness to pay for agency in the Stranger Match treatment since, in this case, retribution is less likely, given the physical separation of men and women in the experiment.

H3c Does the demand for agency increase with the risk of not getting one's choice? To test this hypothesis, we first predict the probability that the subject's ranking will be respected by their partner (i.e., H2a). Predictors include the various treatments - e.g., Stranger Match, Informed treatment - as well as the nature of the relationship between subject and partner - e.g., spouse or other relative. We then test whether there is more demand for agency when the predicted probability of getting one's preferred pick is low.

\subsection{The second laboratory experiment}

The second lab experiment (LAB2) was conducted in April 2017 in 15 different villages in Faisalabad district in Pakistan. A total of 30 lab sessions were conducted with 358 married couples.

The design and general testing strategy remained the same as LAB1. However, a number of modifications were introduced to verify the robustness of our initial findings and to introduce other sources of exogenous variation for identification purposes. The details of the experimental protocol are given in the Online Appendix A2. The main modifications are the following:

1. The consumption bundle was expanded to include three food items and three beverages. The purpose of expanding the number of choices was to increase statistical power. Furthermore, the range of foods and beverages on offer was more varied than in the first experiment, so as to increase the utility cost of not getting one's choice.

2. Unlike in the first experiment, we no longer asked subjects to rank the available options and separately pick a consumption bundle - the top ranked item was taken as the subject's choice. The purpose of this modification was to simplify this part of the experimental design so as to make time for other features.

3. We diversified Stranger Matches to also include Same Sex partners and matching with the Computer.

4. All subjects played two games: one with their family partner; and one with one of the three stranger categories - e.g., Opposite Sex Stranger (OSS); Same Sex 
Stranger (SSS); or Computer Match (CM). In half of the sessions subjects start with the Family Match; the other half starts with the Stranger Match. One third of the subjects are assigned to OSS, one third to SSS, and one third to CM. At the end of the session, we used a coin toss to randomly select one of the two games to determine what the subject consumes. A second coin toss determined whether the first agency or the second agency question determines their consumption bundle. This ensured that both agency decisions in both games are fully incentivized.

5. Subjects were asked to guess the food and drink rankings of their spouse and their randomly assigned partner, but unlike in LAB1 guessing correctly is now incentivized: those who guess the preferred food and drink of the spouse or partner receive PKR100; those who guess only one of them receive PKR50. Others receive 0. Subject were then asked to select a consumption bundle for their partner - except in the Computer Match treatment for which this decision is too artificial. The computer, however, selects a bundle at random for each of its assigned partners.

6. As in the first experiment, some subjects were informed of the preference rankings of their partner before choosing a bundle for them. This did not apply to the Computer Match treatment.

7. The choice between a coin toss and half a glass was replaced by the following: Subjects were first told that they will receive the bundle selected for them by their partner, but they can forfeit a fraction of their show-up fee to get their own choice. Subjects were asked to make this decision for one of three possible forfeited amounts - 5PKR, 20PKR and 50PKR - equally randomized across subjects. Once subjects had made this choice, they were told what their partner has selected for them, and they were asked again if they wanted to pay (e.g., 5PKR, 20PKR or 50PKR) to get what they had themselves selected.

8. We used a dictator game to measure altruism towards each of the two partners - the Family Match and the Stranger Match. Participants matched with the computer only played the dictator game with respect to their Family Match.

With incentivization we have a stronger test of hypothesis H1: we can now investigate whether guesses improve when subjects are compensated for making a correct guess. By incentivizing subjects to guess correctly we aim to eliminate the incentive to purposely misreport what they believe to be their partner's preferences. Hence this yields a more accurate test of demand for power in the uninformed case.

Regarding demand for agency, the presence of a wider range of partners not only introduces more variation in the predicted risk of not getting one's choice $(\mathrm{H} 3 \mathrm{~b})$, it also permits to investigate whether the sex of the partner affects pent-up or repressed demand for agency. The new design also makes it possible to directly test demand for pure agency:

H3d Do subjects have a demand for pure agency and, if so, does this demand varies systematically with the subject's gender and that of their partner? This test is implemented by investigating what proportion of subjects are willing to pay to receive 
their selected bundle even when the food or drink that their partner selected for them is identical to what they selected for themselves. Demand for pure agency is a preference over the process by which a consumption bundle is selected, independently of the instrumental value of agency. Someone with a pent-up demand for agency may, under the protection of the experiment, pay to personally decide what they consume, without any interference from anyone.

\subsection{The field experiment}

In an effort to verify the external validity of our lab findings, we implemented a simplified version of our design as a field experiment. Subjects are clients of a rural microfinance institution participating to the randomized controlled trial of a microfinance product with credit and savings characteristics (see Afzal et al. 2016 and Afzal et al. 2018 for details). This means that the subject population is similar to that of lab experiments 1 and 2, i.e., primarily middle-aged women and their husband. The RCT spanned a period of one year, with a baseline survey at the beginning and an endline survey at the end. The experiment was conducted with 1991 respondents, 80\% of whom were married.

In the baseline survey we told participants that, as a token of our appreciation for their participation in the RCT, at endline we would offer them a small monetary reward plus one of three possible leather items engraved with initials of their choice. The three items to choose from were: a woman's purse; a man's wallet; and a child pencil case. The items were chosen to be relatively similar and of similar value, but to be desirable to induce potential competition between spouses. To further reinforce competition, the items were gendered - i.e., for an adult man or woman - except for the pencil case which can be regarded as a household public good from the point of view of the spouses. Initials were added to make the item individual-specific, so as to minimize resale and gifting the good to someone else.

A female enumerator asked each female participant to choose one of these three objects and to tell us which initials to inscribe on it - e.g., her initials on the purse, her husband's initials on the wallet, or her child's initials on the pencil case. The same question was separately asked to the husband by another enumerator. No further action was taken at baseline.

One year later at endline, we revisited both husband and wife and offered them the following choices. We reminded the husband of the item he had chosen at baseline, and we asked him to confirm or revise his choice. We told him that a coin toss would decide whether the household would receive his preferred item or his wife's preferred item. We then asked him whether he wished to delegate the final choice of item to his wife. To those who refused, we asked whether they were willing to delegate the choice to their wife in exchange for a monetary transfer. Two price levels (50 PKR and $200 \mathrm{PKR}$ ) were offered to those who refused.

We separately told each wife that a coin toss would determine whether we offer her 
household the item she had chosen at baseline, or the item her husband has just selected. ${ }^{10}$ We told the wife that she could secure her chosen item by forfeiting a fraction of the monetary compensation for participating in the study. Two separate price levels were offered, and responses are recorded for both. These choices were offered to each female participant even if her husband decided to delegate the choice to her. We then revealed whether her husband had delegated the choice to her, in which case the female participant received what she selected and forfeited nothing. If the husband had not delegated, we first selected one of the two price levels using a coin toss. If the coin toss yielded a decision not to pay for executive agency, we proceeded to a second coin toss to determine whether the offered item was her choice or her husband's. Otherwise the female participant forfeited the selected amount from her participation fee, and received the item of her choice.

This design allows us to test hypotheses H3a and H3b. For the latter we use the fact that, with a one year interval between the two surveys, there is ample time for spouses to share information about their baseline choices. We also observe altruism in the baseline choice: since the items are gender-specific, altruistic husbands can select the purse and altruistic wives can select the wallet. Each spouse can also select the pencil case for one of their children. The novelty of this design is that it allows investigating demand for power as follows:

H2b Are husband willing to pay for power over their wife's consumption? We investigate this question by examining the proportion of husbands who refuse to delegate the choice of item to their wife, and by testing whether this refusal can be reversed by the offer of a monetary transfer.

\section{Empirical results}

Before presenting our experimental results, we provide summary evidence on the study population. All our female subjects are adult women in the Pakistan Punjab. Most of them are married and have children. Descriptive statistics are presented in Table 1. The average female subject is 39 years old and about half are literate. Subjects belong to a household with an average monthly expenditure of little less than Rs. $19000(\$ 190)$. Except for the LAB1 sample, which consists of micro-enterprise loan borrowers, more than three-quarters of the LAB2 and field experiment samples are housewives. A little under $75 \%$ of all three samples consist of women who are married to the household head.

We now report on our analysis of LAB1 and LAB2. The field experiment is discussed in the next section. Empirical results are presented in the order in which the various hypotheses were introduced in the previous section.

\footnotetext{
${ }^{10}$ Efforts were made during data collection to prevent communication between husband and wife while these two separate interviews were ongoing. Given the logistical difficulty of preventing communication between spouses in a field setting, we cannot however rule out that communication took place between some of the participants.
} 
Table 1: Descriptive statistics on the RCT and LAB samples

\begin{tabular}{|c|c|c|c|c|c|c|}
\hline & \multicolumn{2}{|r|}{ LAB1 } & \multicolumn{2}{|c|}{ LAB2 } & \multicolumn{2}{|c|}{ FIELD } \\
\hline & $n$ & mean & $n$ & mean & $n$ & mean \\
\hline Age & 336 & 38.283 & 716 & 36.110 & 1991 & 39.358 \\
\hline Can read and write & 324 & 0.633 & 716 & 0.483 & 1991 & 0.494 \\
\hline $\begin{array}{l}\text { Average monthly household } \\
\text { expenses (PKR) }\end{array}$ & 336 & 14405.8 & 716 & 14291.15 & 1991 & 18474.04 \\
\hline Self employed (females) & 156 & 0.263 & 358 & 0.139 & 1991 & 0.114 \\
\hline Housewives (females) & 156 & 0.372 & 358 & 0.874 & 1991 & 0.740 \\
\hline $\begin{array}{l}\text { Head of the household (fe- } \\
\text { males) }\end{array}$ & 168 & 0.095 & 358 & 0.003 & 1991 & 11.904 \\
\hline $\begin{array}{l}\text { Spouse of the household } \\
\text { head (females) }\end{array}$ & 168 & 0.744 & 358 & 0.732 & 1991 & 0.743 \\
\hline
\end{tabular}

Note: Reporting values for female respondents in the field experiment (only).

\subsection{Knowledge of others' preferences}

We first examine hypothesis $\mathrm{H} 1$, that is, whether subjects can accurately guess the rankings of other subjects. We compare these guesses to three benchmarks: random guesses; optimal guesses; and perfect foresight. Random guesses ascribe a probability for each ranking equal to the frequency of that ranking among subjects. It represents a lower bound on guessing accuracy - subjects should be able to do better than that. Perfect foresight means the subject predicts perfectly the entire rankings of their assigned partner. Subjects may approach this benchmark when asked to guess the rankings of a spouse or family member. When subjects are uninformed about the specific preferences of their assigned partner, the optimal guess is to pick the single most common rankings in the study population, perhaps differentiated by gender (Eckel 2016). For instance, since $75 \%$ of subjects prefer soft drinks to other beverages, guessing 'soft drink' will be right $75 \%$ of the time when matched with an unknown subject. This assumes that subjects have some idea of what items are most popular among other participants - but it does not require knowledge of all probabilities, only of the mode of each distribution. Subjects may approach this benchmark when they guess the rankings of a stranger. Finally, for those subjects matched with a computer in LAB2, we expect them to do no better than the random guess benchmark.

In LAB1, subjects rank three items. Since guessing the top and bottom-ranked items automatically implies a guess about the third, guessing accuracy only takes three values: 0,1 , or 2 correct guesses. In LAB2, subjects rank three items twice - a food item and a beverage - and the maximum number of correct guesses is $4 .{ }^{11}$

Figures 1 and 2 displays guessing accuracy in LAB1 and LAB2, respectively. In Figure 1, we see that LAB1 subjects do better than random guesses, but not by much. This confirms that the consumption items selected for this experiment are not strongly

\footnotetext{
${ }^{11}$ Except for in the Computer Match where subjects only guess the computer's top ranked items. This mechanically limits the number of correct responses subjects can give to 2 instead of 4 .
} 
differentiated - which agrees with the observation that reported preferences are less differentiated than in the LAB2 experiment. We also note that when guessing the preferences of a stranger, subjects do less well than our optimal benchmark - possibly because subjects are unsure about the modal preference. Some subjects do better than optimal guessing when matched with a spouse of family member, suggesting that they have information about their specific preferences. But we are far from perfect foresight: more than $40 \%$ of LAB1 subjects are unable to guess the top or bottom ranked item of their family member.

In contrast, LAB2 guesses are much better than random (Figure 2). This is probably because guessing is incentivized and preferences are more contrasted than in LAB1: 74\% of subjects prefer the same dish and $76 \%$ prefer the same beverage. Subjects do not outperform optimal guessing, however: only 14 to $17 \%$ of subjects manage to correctly guess their partner's rankings, compared to $20 \%$ with optimal guessing.

To test whether differences between partner matchings are statistically significant, we regress guess quality on matching type. Since LAB1 subjects only play once while LAB2 subjects play twice, we have more observations for LAB2 subjects. To facilitate hypothesis testing, we include fictitious observations for random guess and optimal uninformed guess, and we use random guesses as the omitted treatment category. In this manner, coefficients on matching dummies can be interpreted as the percentage improvement over random matching.

Results are presented in Table 2. Estimates for LAB1, presented in column 1, confirm that subjects in both matching treatments do significantly better than random guessing: the coefficients are both statistically significant. Optimal matching does best on average, but its coefficient is not statistically different from that of either family or stranger matching. We also note that women are better able to predict the preferences of their partner.

Results for LAB2 are qualitatively similar: subjects do better than random matching when paired with a human subject - not with the computer. ${ }^{12}$ Subjects fail to achieve the optimal guessing benchmark on average, and the shortfall is statistically significant whenever subjects are matched with a partner of the opposite sex, whether family member of stranger. Only when matched with a same sex partner is guessing accuracy not statistically different from optimal guessing. In LAB2 female subjects are not better at predicting their partner's rankings.

Taken together, these results indicate that individuals in our sample population know relatively little about the specific preferences of their family members: they are about equally bad at guessing the preference rankings of a family member as they are guessing that of a stranger. This implies that agency over own consumption may have instrumental value, particularly for individuals who do not have the modal preference.

\footnotetext{
${ }^{12}$ See earlier footnote.
} 


\subsection{Respect for others' preferences}

We now turn to hypothesis H2a. To recall, the sequencing of the experiment is as follows: subjects are asked to guess the preference rankings of their partner; half of the subjects are then informed of the preference rankings reported by their partner; and finally subjects select a consumption bundle for their partner. From the choices made by uninformed subjects, we can investigate whether participants pick for their partner what they guess is their partner's preferred bundle. From the choices made by informed subjects, we can investigate whether participants pick for their partner what they have been told is their partner's preferred bundle. In both cases, we are testing whether participants choose for their partner a consumption bundle that they believe - or know - to be their partner's preferred bundle.

We take not respecting the partner's preferences as a sign of demand for power. What this demand for power means has to be understood within the context of the experiment. A dominant individual accustomed to imposing his or her will on others may seek to do the same within the experiment - for them it is 'business as usual'. It is also conceivable that individuals who normally have little ability to impose their will on others, take advantage of the experiment to do so - thereby revealing a 'pent-up' demand for power.

Results are presented in Table 3. In addition to female and stranger dummies interacted with each other, we also include the amount given by the subject to his/her partner in the dictator game, and the amount received by the subject from his/her partner in the same game. We regard the amount given as proxying for altruism towards the partner. We include the amount received from the partner as possible proxy for the altruism that the subject expects from the partner - since subjects only discover what they receive from their partner at the end of the experiment, our measure is likely to contain measurement error.

In column 1 we show estimates for uninformed participants in LAB1 and LAB2, respectively. The dependent variable is a dummy equal to 1 if the subject picks for the partner what they guessed the partner prefers. For LAB1, $73 \%$ of male subjects matched with their spouse pick for their partner what they guess their partner prefers. This proportion falls by 12 percentage points for males matched with a female stranger, but the difference is not statistically significant. In contrast, women are on average 17 percentage points less likely to select what they guess is their partner's preferred juice - a difference that is statistically significant at the $5 \%$ level. A similar - though less precisely estimated - coefficient is found for female subjects matched to a stranger. Take together this evidence suggests that most male participants respect what they believe to be their spouse's preferences. But among female participants, who were shown in Section 2 to have less executive agency than their husband, a few may take advantage of the experiment to impose their choice on a male partner - which would indicate pent-up demand for power. We cannot, however, rule out the possibility that women are accustomed to decide what people eat at home and thus regard selecting food for others as their privilege. Either way, the evidence suggests slightly more demand for power among female participants.

In the second panel of Table 3 we report corresponding estimates for LAB2 subjects, 
combining choices of food and drink. Among LAB2 uninformed male subjects, $82 \%$ pick the item that they guess their wife (or female family member) prefers. This proportion falls by $10 \%$ for their wife - a difference that is statistically significant at the $1 \%$ level. This finding is similar to what was found for LAB1. Women are also less likely to pick their best guess when matched with a stranger male, but this difference is not statistically significant. This confirms that demand for power by women is directed towards males, a finding that is in line with pent-up demand for power over men. Other coefficients are not significant.

In column 2 of Table 3 we report coefficient estimates for informed participants. Here the dependent variable equals 1 if the subject picks for the partner what the partner ranked highest. For LAB1 subjects, we find that $61 \%$ of male subjects accomodate the preference of a female family member, but only $35 \%$ of them accomodate the preference of a female stranger - a difference of 26 percentage points, significant at the $5 \%$ level. The corresponding frequency for female subjects matched with a family member is a lower $55 \%$, again suggesting that they are less likely to respect the preferences of their male partner - consistent with pent-up demand for power. But women are more likely respect the preferences of a male stranger. The differences between male and female subjects are not statistically significant, however.

A similar pattern is observed for LAB2 subjects: $77 \%$ of informed men pick their spouse's preferred food compared to $65 \%$ of women - a difference that is statistically significant at the $1 \%$ level. We also find that male subjects pay less respect to the preferences of strangers - significantly so for strangers of the opposite sex.

To refine our analysis, we examine the effect of information depending on whether the subject initially guessed the preferred item of the partner or not. We have seen that many uninformed participants pick for their partner a bundle different from what they believe their partner wants. From the previous subsection, we also know that many subject guess wrong. Given this, it is conceivable that subjects pick for their partner a good that they erroneously believe to be different from what the partner likes. Informing these subjects of their partner's true preferences could induce them to revise their selection away from what the partner likes, i.e., when informed they would be less likely to pick what their partner wants. For those subjects with pent-up demand for power, information could help reduce the frequency with which they respect their partner's preferences. We do not anticipate a similar effect among subjects who correctly guessed their partner's preferences, except perhaps for a positive confirmation effect: providing information confirms what the partner selected and comforts the subject in their choice.

To investigate these possibilities, we estimate the effect of the information treatment on the probability that the subject picks their partner's preferred bundle, conditional on whether the subject guess the partner's top choice or not. Results are presented in Table 4. We find that, among LAB1 subjects who guess wrong, information increases the probability of picking the partner's choice. But the increase is only significant among male subjects matched with a family member. ${ }^{13}$ Among female subjects, the effect of information on picking the correct bundle is never significant, suggesting that women

\footnotetext{
${ }^{13}$ For stranger matching, the effect is smaller in magnitude and only significant at the $10 \%$ level.
} 
who guess wrong do not adjust their choice once informed of their mistake.

Among subjects who guess right, information has a more contrasted effect. We again find that male subjects matched with a family member are significantly more likely to pick the correct bundle. But male subjects matched with a stranger and female subjects matched with a family member are, if anything, less likely to pick the right juice if they see their initial guess confirmed in the information treatment. The effect is large in magnitude although not statistically significant. The contrast between the response to information between male and female subjects in the family matching is again consistent with pent-up demand for power directed towards male family members.

Some of these findings are replicated in the LAB2 experiment. We see that, on average, information significantly improves selection quality. We again find that men who guessed wrong revise their choice to accomodate a female family member's top choice. The magnitude of the difference is large $-27.4 \%$ - and it is statistically significant. In contrast, women who guess wrong are no more likely to pick their male family member's preferred item when informed than when uninformed. This does not mean that female subjects never respond to information: when matched with a male stranger, they revise their choice relative to their initial guess. But it means that they disregard the information they have been given when matched with a male relative.

For subjects who correctly guess the preference of their partner, providing information should in principle have no effect on choice - except perhaps a positive confirmation effect. This is indeed what we find to male subjects in LAB1: they are 24 percentage points more likely to pick the correct juice when informed. In contrast, female subjects who guessed right are less likely to pick the correct juice when informed, suggesting that they revise their choice negatively. This pattern, although large in magnitude, is not statistically significant. It is also not replicated in LAB2, where we find no systematic effect of information on picking the correct item for the partner.

Taken together, these results indicate that male and female participants to the experiment behave in different ways: female participants are less likely to respect the top choice of a male partner, suggesting a demand for power, that is, the desire to override the food preference of a male family member. We do not observe a similar behavior among men, at least within the confines of our food-and-drink experiment. It remains to be seen whether this pattern would repeat for larger decisions outside the traditional domain of women.

\subsection{Demand for agency}

We now turn to the part of the experiment that investigates willingness to pay for agency. We start with hypotheses H3a and H3b. Demand for agency by gender and matching type is shown in Table 5 for the LAB1 and LAB2 experiments, pooling the informed and uninformed treatments. In LAB1, demand for agency equals 1 if the subject refuses the coin toss and prefers to receive half a glass of his/her preferred juice - and 0 otherwise. In LAB2, demand for agency equals 1 if the subject prefers to incur a monetary reduction of their showup fee than receiving the food and drink that the partner has selected for them - and 0 otherwise. 
We first note that a sizeable proportion of subjects in both experiments are willing to pay for agency: $23 \%$ in LAB1 and 26\% in LAB2. The answer to hypothesis H3a is thus yes. There are, however, differences in pattern by gender and matching type across the two experiments. In LAB1, women are slightly less likely to demand agency when matched with a family member, but much less likely to do so when matched with a male stranger. The latter difference is statistically significant. Other pairwise differences are not. Why women would be less willing to exert agency when matched with an anonymous stranger is unclear given that, by experimental design, the identity of the stranger, who sits in another room, is never revealed and the risk of retribution is negligible. We check the robustness of this finding below.

Results from the LAB2 subjects are more consistent with expectations. All subjects demand agency more often when matched with a stranger, who subjects may expect to be less familiar with their specific preferences. For men, the magnitude of the difference is fairly small, but it is statistically significant relative to family matching. The difference is larger for women, $40 \%$ of whom prefer to forfeit part of their showup fee to receive the food and drink of their choice rather than something selected by a stranger or a computer. We also note a large significant difference in willingness to pay for agency between male and female LAB2 subjects, across all matching types: female subjects are on average $56 \%$ more likely to pay for agency than men. Finally, subjects of both genders are less likely to pay for agency when matched with a stranger of the same sex instead of the opposite sex, but the difference remains largest for women.

LAB2 subjects are given the opportunity to reject the random choice made by a computer. The reason for including this treatment is the concern that subjects may be reluctant to challenge the choice made by another subject, e.g., out of courtesy or for fear of offending them. If this is an issue, we expect more rejection of computer choices since they do not involve human intervention and the computer cannot possibly be 'offended' by rejection. We find no evidence of such concerns: the subjects' propensity to reject the choice of the computer is not larger than that of a stranger of the opposite sex. This offers reassurance that observed willingness to pay for agency is not self-censored.

To throw more light on the LAB1 results on demand for agency among women, we take advantage of a feature specific to the LAB1 experiment, namely, that all subjects play an ultimatum game against their assigned partner. Since the game is played using a strategy method, we know each subject's response to all possible offers - and we do not have to worry about endogeneity of rejection with respect to the amount offered. Rejection in the ultimatum game results in a monetary loss equal to the offer made. We can thus use the propensity to reject a partner's offer as an alternative measure of demand for agency.

Results are shown in Table A1. To err on the side of caution, we only use the 318 subjects who demonstrate a clear understanding of the ultimatum game, but similar results are obtained if we use all subjects. ${ }^{14}$ We see that, as in Table 5, LAB1 subjects

\footnotetext{
${ }^{14}$ Participants were asked to answer three hypothetical questions where player 1 allocated a hypothetical amount and player 2 either accepted or rejected the allocation. Participants were given a score of 1 if they could correctly identify the amount Player 1 and Player 2 would go home with in each of the three test questions, 0 otherwise.
} 
are less likely to challenge an offer made by a stranger. But we also find a massively higher proportion of rejections among women than men, irrespective of matching type: while only $36 \%$ of men reject at least one hypothetical offer made by an accompanying family member, $86 \%$ of women do so. Similarly, $29 \%$ of men reject at least one offer made by a stranger while the corresponding frequency among women is $78 \%$. These findings mirror what we find for LAB2 subjects in Table 5, providing suggestive evidence that the LAB1 results in Table 5 may be a aberration.

To recap, we find that female subjects often display a higher willingness to pay for agency than men, providing some support for hypothesis H3b. Whether this captures pent-up demand is unclear: we cannot rule out the possibility that women in the study population feel entitled to reject any food selection imposed by men, as they are used to exert agency on food preparation at home. The evidence from the ultimatum game nonetheless suggest that female demand for agency goes beyond protecting a small reserved domain of autonomy from husband interference. The evidence for pent-up demand for agency is even more compelling when combined with earlier results on higher demand for power among female subjects.

Next we investigate hypothesis H3c, that is, whether demand for agency varies with its instrumental value. To this effect, we test whether subjects are more willing to pay for agency when the expected gain is larger. As we have seen, subjects are often unaware of their partner's preference rankings - and even when they are aware of them, they often choose to ignore them. Having executive agency over own consumption can thus increase the likelihood of receiving one's preferred bundle. The question is whether subjects are more willing to pay when the chance of getting their preferred bundle is lower.

To test this hypothesis, we construct a variable proxying for the expected instrumental value of ex ante agency $A_{i}^{b}$. How this proxy is constructed is described in detail in Appendix B. We then regress ex ante demand for agency on this proxy variable. Estimation results are presented in Table 6 . We see that in LAB2 subjects are significantly more likely to pay for ex ante agency when its instrumental value is high for the choice of food. In both LAB1 and LAB2 the instrumental value of the choice of drink is not statistically significant. The cost of agency, which is varied randomly across subjects in the LAB2 experiment, has the expected sign and is borderline significant. These findings are consistent with the idea that demand for agency is at least partly driven by instrumental considerations.

We nonetheless find that gender and matching type dummies remain strong predictors of $A_{i}^{b}$, suggesting the presence of systematic variation in demand for agency that is not driven by its instrumental value. In particular we observe that men matched with strangers are more likely to exert agency than men matched with their spouse or family member. The results also confirm our earlier finding in Table 5 that women are more likely to exert agency than men in all stranger matching types.

To investigate the fundamental nature of demand for agency, we investigate hypothesis H3d using data collected in LAB2 only. In that experiment, we first ask subjects whether they wish to pay to ensure they receive the food and drink they have selected rather than what their partner has selected for them. Answers from this question were used to produce 
Tables 5 and 6 . We then tell subjects what their partner has actually selected for them and we ask them again if they still wish to pay to have what they themselves selected. We refer to answers to the first and second question as ex ante and ex post demand for agency, respectively. If demand for agency is driven solely by instrumental considerations, we should observe no demand for agency when the partner's choice matches the subject's. On the other hand, when the partner's choice is revealed to be different, we should observe an increase in ex post demand for agency relative to Table 5. In contrast, if subjects demand agency for its own sake, they may be willing to pay to get what they selected, even if it is the same as what their partner selected for them.

Table 7 reports the proportion of subjects who demand ex post agency. What we observe does not suggest that demand for ex post agency is solely driven by instrumental considerations. Among subjects whose partner selected the correct food and drink, $11 \%$ nonetheless elicit to pay for agency. At the same time, $83 \%$ of subjects $(100 \%-17 \%$ - see column 1 row 1) refrain from exercising agency when they know that what the partner has selected is not what they prefer. In fact, only $53 \%$ of subjects who demanded agency ex ante still demand it ex post after discovering that their partner has not selected their preferred food and drink. This suggests reluctance in going against a specific decision made by someone else after having been informed of that decision. We also find that, among those subjects who did not demand agency ex ante, only $4 \%$ of those who discover their partner got them the wrong food and drink decide to pay a small fee to get their preferred bundle. Furthermore, about the same proportion of subjects insists on exerting agency even when the partner gets their food or drink right. On the other hand, among those subjects who exerted agency ex ante, we find that $36 \%$ of them continue to exert agency ex post even when they are getting the right food and drink from their partner. These findings are difficult to reconcile with a pure instrumental value of agency: there is too much demand for agency when the partner's selection is correct, and not enough when the partner is wrong.

We nonetheless note that, in Table 7, ex post demand for agency falls when the partner gets the correct food. To test this formally, we regress demand for ex post agency $A_{i}^{p}$ on the actual value of agency - which is known by construction. The results, shown in Table 8 , are not too dissimilar from those shown in Table 6: ex post demand $A_{i}^{p}$ increases with the gain from agency and falls with the price of agency. But estimated coefficients are smaller than what pure instrumental motivations would imply. We also find that female subjects are much less likely to exert agency ex post, suggests reluctance in going against someone else's decision among women - and men matched with their wife. Men matched with a stranger are less reluctant to exert ex post agency. This suggests that at least part of the ex ante agency exercised by women in our experiment reflects pent-up demand for agency, and that much of it is driven by non-instrumental considerations.

Before turning to the evidence from the field experiment, it is worth pointing out that a large proportion of subjects do not receive their preferred bundle. Part of this is due to the fact that their partners either do not know their preferences or choose to ignore them; part is due to the fact that subjects do not elicit to exercise agency primarily when the expected or realized gains from agency are the largest. Put differently, subjects are not particularly good at targeting agency to situations where they are least likely 
to receive their preferred choice. For instance, in LAB2, ex ante agency increases the proportion of subjects who receive their preferred food and drink only from $48 \%$ to $62 \%$. More surprising, ex post agency reduces this proportion to $56 \%$ - primarily because many women who choose to exert agency ex ante refrain from doing so ex post, even though their partner selected the wrong bundle. ${ }^{15}$ This is quite remarkable given that, in the context of the experiment, individual consumption choices are deeply shrouded from their partners. To observe this, it must be the case that attitudes towards agency are internalized by subjects and at least partly enforced through internalized roles and norms.

\section{Evidence from a field experiment}

In addition to the two lab experiments we have discussed, we ran a field experiment focusing on similar issues that allowed us to test hypotheses $3 \mathrm{~b}, 4 \mathrm{a}$ and $4 \mathrm{~b}$. The detailed experimental protocol is given in the Online Appendix A3. ${ }^{16}$

We first look at the gift selections made by husbands and wives. The purse is most popular, being selected by $81 \%$ of women and $64 \%$ of men. The wallet comes second, selected by $32 \%$ of men and $15 \%$ of women. Only $4 \%$ of men and women select the pencil case. There is considerable overlap between the choices made: $73 \%$ of couples select the same gift. Participants seem aware of this on average: $72 \%$ of women and $69 \%$ think their spouse has made the same selection as them. These beliefs, however, are only true $59 \%$ to $63 \%$ of the time, respectively. Morever, beliefs are not aligned across spouses: $57 \%$ of couples both believe their selections are identical, $17 \%$ both believe they each selected different things, and $27 \%$ have misaligned beliefs, i.e., one spouse thinks the other has selected the same thing, and the other thinks the opposite. This means that in $43 \%$ of the couples at least one spouse believes that they have selected different things. The creates space for instrumental value of agency, which we capture with a dummy $M_{i}$ equal to 1 if individual $i$ believes that his/her spouse has selected the same gift and 0 otherwise.

In Table 9 we regress the husband's refusal to delegate on $M_{i}$. We also include a dummy $T_{i}$ if $i$ 's household was assigned to the microfinance treatment and 0 otherwise. Only 16 husbands opt for the coin toss and refuse to fully delegate the choice of gift to their wife, providing little support for hypothesis H2b. Yet we find that a husband is significantly more likely to delegate when he believes his wife selects the same gift as him - a finding in line with the instrumental value of agency. It remains that $31 \%$ men believe their wife selected a different gift, and only a small fraction of them refuse to delegate the gift choice to their wife. In LAB1 and LAB2 we found that many subjects - including men - disregard the stated preferences of their spouse. Here we find overwhelming willingness to delegate.

\footnotetext{
${ }^{15}$ Without exercising agency, $52 \%$ of LAB2 female subjects would receive their preferred food and drink. This proportion rises to $68 \%$ when ex ante agency is taken into account; but it falls back to $59 \%$ with ex post agency instead. The corresponding proportions for men are $43 \%, 55 \%$ and $53 \%$ - confirming that reluctance towards ex post agency is virtually non-existent among male subjects.

${ }^{16} \mathrm{As}$ is apparent in the Online Appendix A3, we also attempted to measure willingness to pay for agency in a hypothetical, non-incentivized way. This attempt, however, yielded results that suggest the questions were not fully understood or not taken seriously. They are omitted here.
} 
A possible interpretation is that process matters: if male subjects are explicitly asked to defer to their wife, many agree to do so - especially in the context of a female-oriented microfinance intervention. But if they are not asked to defer, they happily impose their own preferences. We also find that, among the 16 men who refuse to delegate, only 2 agree to delegate in exchange for PKR50 and 3 for PKR200 - an amount equivalent to $40 \%$ of the value of the gift. This suggests of those men who refuse to delegate, many are also animated by motives other than instrumental and not amenable to financial compromise.

In Table 10 we estimate a similar regression for women's decision to forfeit money so as to receive their preferred gift. Since each woman makes this decision twice - once facing a price of PRK50 and once with PKR200 - the estimated regression combines both decisions. ${ }^{17}$ Most women pay for agency: $77 \%$ when the price of agency is PKR50, 61\% when it is PKR200 (i.e., 40\% of the full cost of the gift). These proportions are much higher than the $28 \%$ of women who believe that their husband chose something else. We nonetheless find support for the instrumental value of agency: a woman who believes her husband chose the same gift as her is 4 percentage points less likely to pay for agency. We also find responsiveness to the cost of agency.

Regarding the effect of being offered the microfinance treatment, we see that women invited to participate are 4 percentage points less likely to demand agency. Combined with the observation that average demand for agency is high, we conclude that pent-up demand for agency is high among participating women, but women empowered by the microfinance intervention feel slightly less need to pay for agency. This interpretation is consistent with the idea that empowerment reduces pent-up demand for pure agency. Finally, we find that women who selected the pencil case are significantly more likely to pay to make sure they get it. This latter finding is consistent with the empirical evidence suggesting that women with more agency or financial power tend to spend more on their children.

\section{Conclusion}

In this paper we have experimentally investigated demand for agency within households. Using two lab experiments and one field experiment, we have tested specific hypotheses regarding demand for agency and power without and across households. We have investigated whether individuals know and respect the preferences of others, and whether subjects have pent-up demand for agency.

Contrary to what is regularly assumed in much intrahousehold analysis, we find evidence that spouses are often ill-informed about each other's consumption preferences. Also, they are often no better at guessing their spouse's preferences than those of a random stranger. We also find a surprisingly high propensity for subjects to disregard what they believe or know about each others' preferences. Women in particular are more likely than men to disregard information about their male relative's preferences. This is true

\footnotetext{
${ }^{17}$ To allow for possible correlation between the two agency decisions, standard errors are clustered at the individual level.
} 
even though, given our setting, there is little reason to suspect subjects of wanting to impose consumption choices on others 'for their own good' or to follow moral precepts. We interpret this finding as suggestive of pent-up demand for power, that is, for imposing on others a consumption bundle that knowingly deviates from their preferences.

We find significant evidence of demand for agency in all three experiments. Some of the observed variation can be explained by differences in the instrumental value of agency or in the cost of exercising agency. But subjects often make choices that are incompatible with a pure instrumental motive. In particular, we find many subjects willing to pay for agency even when they are informed that the choice made by their partner is the same as theirs. We take this evidence as suggesting a pure demand for agency, i.e., a willingness to pay for having executive agency over consumption choices, irrespective of their material consequences. These findings add to the experimental evidence that people do not just have preferences over material outcomes (as captured by a utility function); they also have preferences over the process by which these material outcomes are achieved. Much of the existing evidence involves moral considerations - e.g., the willingness to punish (e.g., Charness and Rabin 2002) or the desire to redistribute (e.g., Zizzo and Oswald 2001). In this paper, we find evidence of demand for agency for its own sake, not simply to pursue a material goal.

We set out to study pent-up demand for agency among Pakistani women, who are often believed to be under the domination of a male member of their household - e.g., their father or their husband. The evidence we uncover suggests that relationship between gender and agency is more complex than initially recognized. First, the fact that household members often ignore - or choose to ignore - each other's consumption preferences is a surprising finding which, a priori, confers much instrumental value to individual executive agency over own consumption. While demand for agency responds to the benefits and costs of agency among both men and women, we also find female subjects in our study population to be equally or more willing to exert agency than their male counterparts. This is true in spite of the fact that, when asked about executive and consultative agency within the household, our study population appears strongly patriarchal.

What have we learned about demand for agency? Men and women seem to value making consumption choices for themselves and others, over and beyond what these choices imply for their own material consumption. The process by which consumption is decided seems to be an important consideration for intrahousehold welfare - and this includes women wanting to impose their choice on men nearly as much as men wanting to impose their choice on women. To an economist, these tendencies are disturbing because they imply that, even in relatively poor households such as those we study, people are willing to reduce allocative efficiency in consumption simply to assuage a desire for power and agency. More research is needed on preferences over process in intrahousehold decisions and on their effect on material and subjective welfare.

Results from the field experiment throw additional light on how 'pent-up demand' for agency should be interpreted, at least in the context of our experiments. Based on survey questions, the women in our study population have little executive agency within their own household. Our experiments give them an opportunity to manifest a repressed desire 
to make choices for themselves - and others. Pent-up demand for power and agency is thus a manifestation of lack of empowerment, a venting off steam, so to speak. It suggests that, given the opportunity, individuals who have little say over household decisions that affect them directly are willing to engage in inefficient actions - such as paying to receive items that someone else had already selected for you, or deliberately forcing others to consume things they do not prefer. Seen in this light, the patterns we document here are reminiscent of those documented by Jakiela and Ozier (2015): the authors showed that women prefer making a low return investment that is hidden from their spouse than a high return investment that is observable to others in the household. When the evidence is taken together with ours, it suggests that people who feel unempowered are willing to make inefficient - and potentially destructive - choices in order to achieve a degree of agency over their consumption. If this interpretation is correct, empowering women (and other household members) should reduce pent-up demand for agency and power, and as a result has the potential to reduce inefficiency in the intrahousehold allocation of resources.

\section{References}

Afzal, U., G. d'Adda, M. Fafchamps, S. Quinn, and F. Said (2017): "Two Sides of the Same Rupee? Comparing Demand for Microcredit and Microsaving in a Framed Field Experiment in Rural Pakistan", Economic Journal.

Afzal, U., G. d'Adda, M. Fafchamps, S. Quinn, and F. Said (2018). "When Nudge Turns to Shove: A Field Experiment Adding Commitment Features to a Commitment Savings Product", Oxford University (mimeo)

Alan, Sule and Seda Artac (2016). "Mitigating the Gender Gap in the Willingness to Compete: Evidence from a Randomized Field Experiment", Department of Economics, University of Essex (mimeo)

Ambler, K., (2015). "Don't tell on me: Experimental evidence of asymmetric information in transnational households". Journal of Development Economics, 113: 52-69.

Anderson, S., and J.-M. Baland (2002). "The Economics of ROSCAs and Intrahousehold Resource Allocation, â€ The Quarterly Journal of Economics, 117(3), 963â€"995.

Ashraf, N., (2009). "Spousal control and intra-household decision making: An experimental study in the Philippines". American Economic Review, 99(4): 1245-77.

Ashraf, N., Field, E., Lee, J., (2014). "Household Bargaining and Excess Fertility: An Experimental Study in Zambia". American Economic Review, 104: 2210-37.

Bartling, Bjorn, Ernst Fehr, \& Holger Herz, (2014). "The intrinsic value of decision rights". Econometrica, 82 (6): 2005-2039.

Bobonis, G.J., (2009). "Is the Allocation of Resources within the Household Efficient? New Evidence from a Randomized Experiment". Journal of Political Economy, 117(3): 453-503.

Bolton, Gary, Jordi Brandts, and Axel Ockenfels, (2005). "Fair procedure: evidence 
from games involving lotteries". The Economic Journal, 115: 1054-1076.

de Brauw, A., Gilligan, D.O., Hoddinott, J., Roy, S., (2014). "The Impact of Bolsa Família on Women's Decision-Making Power". World Development, 59: 487-504.

Browning, Martin, Francois Bourguignon, Pierre-Andre Chiappori, and Valerie Lechene (1994). "Income and Outcomes: A Structural Model of Intrahousehold Allocation", Journal of Political Economy, 102(6): 1067-96

Browning, M. \& P. A. Chiappori, (1998). "Efficient Intra-Household Allocations: A General Characterization and Empirical Tests," Econometrica, 66(6): 1241-78, November.

Browning, Martin, Pierre-André Chiappori \& Valérie Lechene, (2010). "Distributional Effects in Household Models: Separate Spheres and Income Pooling," Economic Journal, 120(545): 786-99, 06.

Browning, Martin, Pierre-André Chiappori \& Arthur Lewbel, (2013). "Estimating Consumption Economies of Scale, Adult Equivalence Scales, and Household Bargaining Power," Review of Economic Studies, 80(4): 1267-1303.

Browning, Martin \& Chiappori, Pierre-André \& Weiss, Yoram, (2014). Economics of the Family, Cambridge University Press, Cambridge

Carlsson, F., Martinsson, P., Qin, P., Sutter, M., (2009). "Household Decision Making and the Influence of Spouses' Income, Education, and Communist Party Membership: A Field Experiment in Rural China", SSRN Scholarly Paper No. ID 1395246

Castilla, C., (2014). "What's yours is mine, and what's mine is mine: Bargaining power and income concealing between spouses in India". Working paper.

Castilla, C., (2015). "Trust and Reciprocity between Spouses in India". American Economic Review, 105(5): 621-624.

Castilla, C., Walker, T., (2013). "Is Ignorance Bliss? The Effect of Asymmetric Information between Spouses on Intra-Household Allocations", American Economic Review, 103(): 263-68

Charness, Gary and Matthew Rabin (2002). "Understanding Social Preferences with Simple Tests", Quarterly Journal of Economics, 117(3): 817-69

Chen, J.J., (2013). "Identifying non-cooperative behavior among spouses: Child outcomes in migrant-sending households". Journal of Development Economics, 100(1): 1-18.

Chiappori, Pierre-Andre (1988). "Nash-Bargained Household Decisions: A Comment", International Economic Review, 29(4): 791-96, November

Chiappori, Pierre-Andre (1991). "Nash-Bargained Household Decisions: A Rejoinder", International Economic Review, 32(3): 761-62, August

Chiappori, Pierre-Andre (1997a). "Collective Models of Household Behavior: The Sharing Rule Approach", in Intrahousehold Resource Allocation in Developing Countries: Methods, Models and Policy, Lawrence Haddad, John Hoddinott and Harold Alderman (eds.), IFPRI, Washington D.C. 
Chiappori, Pierre-Andre, (1997b). "Introducing Household Production in Collective Models of Labor Supply," Journal of Political Economy, 105(1): 191-209, February.

Dasgupta, Utteeyo, \& Mani, Subha, (2015). "Only Mine or All Ours: Do Stronger Entitlements Affect Altruistic Choices in the Household". World Development, 67: 363 375 .

Deer, Carmen D. and Twyman, J. (2012). "Asset Ownership and Egalitarian Decision Making in Dual-headed Households in Ecuador", Review of Radical Political Economics, 44(3): 313-20, September

de Laat, J., (2014). "Household allocations and endogenous information: The case of split migrants in Kenya". Journal of Development Economics, 106: 108-17.

Dercon, Stefan \& Pramila Krishnan, (2000). "In Sickness and in Health: Risk Sharing within Households in Rural Ethiopia," Journal of Political Economy, 108(4): 688-727, August.

Duflo, Esther (2003). "Grandmothers and Granddaughters: Old-Age Pensions and Intrahousehold Allocation in South Africa," World Bank Economic Review, 17(1): 1-25, June.

Duflo, E., Udry, C., (2004). "Intrahousehold resource allocation in Cote d'Ivoire: Social norms, separate accounts and consumption choices". National Bureau of Economic Research Working Paper No. 10498, May.

Eckel, Catherine C. \& Grossman, Phillip J. (1998). "Are Women Less Selfish than Men?: Evidence from Dictator Experiments". The Economic Journal, 108(448), 726 735 .

Eckel, Catherine C. \& Grossman, Phillip J. (2001). "Chivalry and Solidarity in Ultimatum Games", Economic Inquiry, 39 (2), 171 - 188.

Eckel, Catherine (2016). "Making Decisions for Others: The Consequences of Gender Stereotypes", Texas A\&M (mimeo)

Fafchamps, Marcel, Bereket Kebede \& Agnes R. Quisumbing, (2009). "Intrahousehold Welfare in Rural Ethiopia," Oxford Bulletin of Economics and Statistics, 71(4): 567-99, 08 .

Fafchamps, Marcel \& Agnes R. Quisumbing (2008). "Household Formation and Marriage Markets", in Handbook of Development Economics Volume 4, T. Paul Schultz and John Strauss (eds.), Elsevier.

Fafchamps, Marcel \& Quisumbing, Agnes, (2005). "Assets at marriage in rural Ethiopia," Journal of Development Economics, 77(1): 1-25, June.

Falk, Armin \& Kosfeld, Michael, (2006). "The hidden cost of control", The American Economic Review, 96 (5): 1611-1630.

Fehr, Ernst, Holger Herz, \& Tom Wilkening, (2013). "The Lure of Authority: Motivation and Incentive Effects of Power". American Economic Review, 103 (4): 1325-1359.

Fiala, N. (2017). "Business is tough, but family is worse: The role of family constraints 
on microenterprise development in Uganda", The World Bank (mimeograph)

Glennerster, Rachel, Claire Walsh, and Lucia Diaz-Martina (2018). A Practical Guide to Measuring Women's and Girls' Empowerment in Impact Evaluations, J-PAL, Boston

Guth, Werner \& Hannelore Weck-Hannemann, (1997). "Do people care about democracy? An experiment exploring the value of voting rights". textitPublic Choice, 91: $27-47$.

Hoel, J.B., (2015). "Heterogeneous households: A within-subject test of asymmetric information between spouses in Kenya". Journal of Economic Behavior $\&$ Organization, 118: $123-35$.

Iversen, V., Jackson, C., Kebede, B., Munro, A. \& Verschoor, A. (2006). "What's Love Got To Do With It? An Experimental Test of Household Models in East Uganda." Discussion Papers in Economics 06/01, Royal Holloway University of London.

Iversen, V., Jackson, C., Kebede, B., Munro, A., Verschoor, A., (2011). "Do Spouses Realise Cooperative Gains? Experimental Evidence from Rural Uganda". World Development, 39(4): 569-78.

Jakiela, P., Ozier, O., (2015). "Does Africa Need a Rotten Kin Theorem? Experimental Evidence from Village Economies". Review of Economic Studies, 83(1): 231-68

Kebede, B.; Tarazona, M.; Munro, A. and Verschoor, A. (2014) "Intra-household Efficiency: An Experimental Study from Ethiopia", Journal of African Economies, 23(1): 105-50.

Krupka, Erin and Roberto A. Weber (2013). "Identifying Social Norms Using Coordination Games: Why Does Dictator Game Sharing Vary?", Journal of the European Economic Association, 11(3): 495-24, June

Mani, A. (2011). "Mine, yours or ours? The efficiency of household investment decisions: An experimental approach.: Working Paper.

McElroy, Marjorie B. (1990). "The Empirical Content of Narsh-Bargained Household Behavior", Journal of Human Resources, 25(4): 559-83

Memon, A. S., Naz, S., Abbas, H., Zahid, J., Tabbasum, R., and Zeshan, M. (2014). Alif Ailaan Pakistan District Education Rankings 2014. Alif Ailan.

Munro, A., Bateman, I.J., McNally, T., (2008). "The Family Under the Microscope: An Experiment Testing Economic Models of Household Choice". SSRN Scholarly Paper No. ID 1138969.

Owens, David, Zachary Grossman, and Ryan Fackler, (2014). "The Control Premium: A Preference for Payoff Autonomy". American Economic Journal: Microeconomics, 91: $138-161$.

de Palma, A., Picard, N., Ziegelmeyer, A., (2009). "Individual and couple decision behavior under risk: evidence on the dynamics of power balance". Theory and Decision, $70(2): 45-64$.

Qian, Nancy, (2006). "Missing Women and the Price of Tea in China: The Effect of 
Sex-Specific Earnings on Sex Imbalance," CEPR Discussion Papers 598

Robinson, J., (2012). "Limited Insurance within the Household: Evidence from a Field Experiment in Kenya". American Economic Journal: Applied Economics, 4(4): 140-64.

Schaner, S., (2015). "Do opposites detract? Intrahousehold preference heterogeneity and inefficient strategic savings". American Economic Journal: Applied Economics, 7(2): $135-74$

Zizzo DJ, and Oswald AJ (2001). "Are people willing to pay to reduce others' incomes?", Annales d'Economie et de Statistique, 63-64: 39-62. 


\section{Tables and Figures}
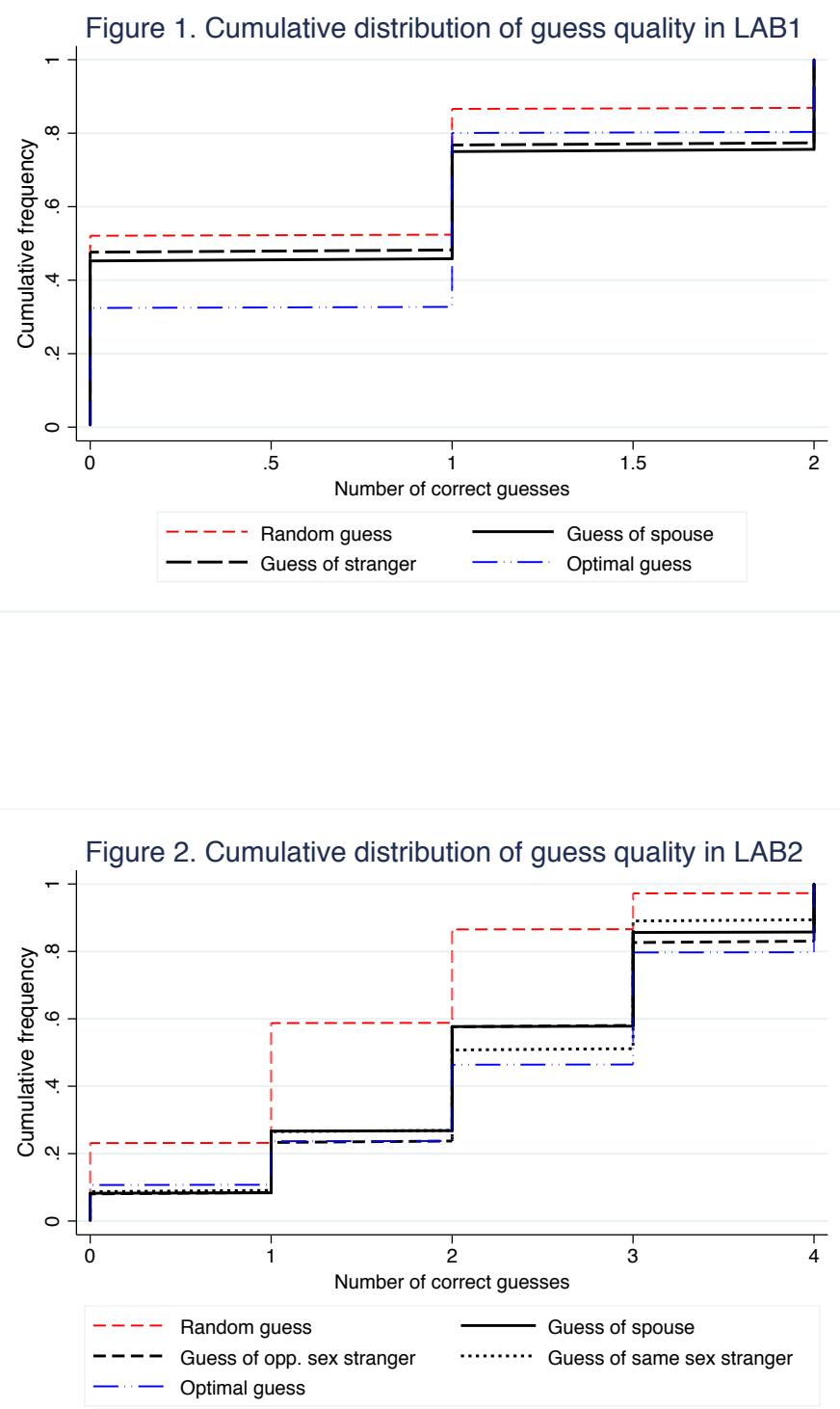
Table 2. Ability to guess partner's preferences by matching type

\begin{tabular}{lcrrr} 
& LAB1 & \multicolumn{3}{c}{ LAB2 } \\
Matching type & Coef. & t-stat. & Coef. & t-stat. \\
Family member & 0.185 & $\mathbf{2 . 6 1 * *}$ & 0.892 & $\mathbf{1 7 . 1 2} * * *$ \\
Stranger of opposite sex & 0.143 & $\mathbf{2 . 0 2} * *$ & 0.958 & $\mathbf{1 1 . 9 8} * * *$ \\
Stranger of same sex & n.a. & & 0.925 & $\mathbf{1 2 . 1 2} * * *$ \\
Computer & n.a. & & -0.381 & $\mathbf{- 4 . 5 8} * * *$ \\
Optimal uninformed benchmark & 0.262 & $\mathbf{4 . 5 4} * * *$ & 1.071 & $\mathbf{2 5 . 1 5} * * *$ \\
& & & & -1.63 \\
Female dummy & 0.054 & 1.14 & -0.057 & 38.95 \\
Intercept & 0.586 & 12.46 & 1.354 & \\
Number of observations & & & $4296(1432)$ &
\end{tabular}

Notes: The dependent variable is the quality of the guess. In LAB1 it equals 1 if i correctly guesses j's top and bottom ranked juice. In LAB2 it equals 4 if $i$ has 4 correct guesses (i.e., correctly guesses j's top ranked food and drink and bottom ranked food and drink), 3 if $\mathrm{i}$ has 3 correct guesses, etc. The omitted match category is an artificial set of observations in which each subject guesses the partner's preferences using population frequencies as probabilities. As a result, coefficients can be interpreted as improvement over random guessing, e.g., the intercept is the average quality of a random guess, and the coefficient of spouse/family member shows by the improvement of the guess relative to random guessing. We also include optimal guessing by an uninformed subject as benchmark to facilitate comparisons. Note that this regression corresponds to one specific vector of random guesses. The absolute value of coefficients changes with each draw, but relative values do not. Possible variation in the significance of coefficients (relative to random) is discussed in the text.

IN LAB1 there are 336 subjects. For each of these observations, one random guess and one optimal uninformed guess are then added, thereby adding $336 \times 2$ fictitious observations. In LAB2 subjects appear twice: once matched with their family member, and once with a stranger, threby making 1432 observations. For each of these observations, one random guess and one optimal uninformed guess are then added, thereby adding $1432 \times 2$ fictitious observations. The role of these fictituous observations is to allow an easy comparison of actual guesses to these two benchmarks.

Standard errors are clustered at the pair level. T-statistics significant at the $10 \%$ level are shown in bold. 
Table 3. Respect for partner's preferences

\begin{tabular}{|c|c|c|c|c|c|}
\hline \multicolumn{2}{|l|}{ LAB1 -- juice choice } & \multicolumn{2}{|c|}{$\begin{array}{l}\text { Uninformed treatment } \\
\text { Does subject pick their } \\
\text { best guess for partner? }\end{array}$} & \multicolumn{2}{|c|}{$\begin{array}{l}\text { Informed treatment } \\
\text { Does subject pick the } \\
\text { partner's top rank? }\end{array}$} \\
\hline \multicolumn{2}{|c|}{ Gender of subject Maching } & Coef. & t-stat. & Coef. & t-stat. \\
\hline Male & Stranger & -0.117 & -1.13 & -0.262 & $-2.41 * *$ \\
\hline Female & Family & -0.173 & $-2.19 * *$ & -0.059 & -0.75 \\
\hline Female & Stranger & -0.162 & -1.56 & -0.061 & -0.55 \\
\hline \multicolumn{2}{|c|}{ Amount given in DG game } & 0.076 & 0.05 & -0.049 & -0.29 \\
\hline \multicolumn{2}{|c|}{ Amount received in DG game } & -0.027 & -0.18 & 0.151 & 0.91 \\
\hline \multicolumn{2}{|l|}{ Intercept } & 0.710 & 4.83 & 0.560 & 3.48 \\
\hline \multicolumn{2}{|l|}{ N. observations } & 170 & & 166 & \\
\hline \multicolumn{6}{|c|}{ LAB2 -- food and drink choice } \\
\hline \multicolumn{2}{|c|}{ Gender of subject Maching } & Coef. & t-stat. & Coef. & t-stat. \\
\hline Male & Opposite sex & -0.036 & -0.70 & -0.102 & $-1.98 * *$ \\
\hline Male & Same sex & -0.061 & -1.23 & 0.060 & -1.21 \\
\hline Female & Family & -0.101 & $-3.40 * * *$ & -0.124 & $-4.08 * * *$ \\
\hline Female & Opposite sex & -0.663 & -1.51 & -0.061 & -1.20 \\
\hline Female & Same sex & -0.029 & -0.63 & -0.080 & -1.50 \\
\hline \multicolumn{2}{|c|}{ Amount given in DG game } & -0.021 & -0.44 & 0.055 & 1.05 \\
\hline \multicolumn{2}{|c|}{ Amount received in DG game } & 0.041 & 0.85 & -0.144 & $-2.40 * *$ \\
\hline \multicolumn{2}{|l|}{ Drink dummy } & 0.036 & 1.61 & 0.049 & $1.94 *$ \\
\hline \multicolumn{2}{|l|}{ Intercept } & 0.819 & 18.41 & 0.787 & 16.28 \\
\hline \multicolumn{2}{|l|}{ N. observations } & 1216 & & 1216 & \\
\hline
\end{tabular}

Standard errors clustered at the pair level. t-statistics significant at the $10 \%$ shown in bold. LAB2 observations include family matching observations plus stranger matchings; subjects matched with a computer are not included since computers have no preferences. Furthermore, observations for food and drinks are combined. This means in LAB2 there are four observations per subject: food and drink for family matching; and food and drink for stranger matching -except for subjects matched with a computer, in which case there are two observations per subjects: food and drink for family matching. For uninformed subjects, the dependent variable equals 1 if the subject picks their best guess of their partner's top ranked item, and 0 otherwise. For informed subjects, the dependent variable equals 1 if the subject picks what they know to be their partner's top ranked item, and 0 otherwise. In LAB1, the number of informed and uninformed subjects differs slightly due to variation in the number of subject pairs across sessions. 
Table 4. Marginal effect of information on choice, conditional on guessing the partner's top rank Initial guess (before receiving information):

LAB1 -- juice choice

Subject guessed wrong

Subject guessed right

Frequency of correct choice

When uninformed

When informed

Sample average

$27.1 \%$

$41.4 \%$

probability of correct choice

Overall

Male subject/family match

Male subject/stranger match

Female subject/family match

Female subject/stranger match

N. observations

LAB2 -- food and drink choice

Frequency of correct choice

When uninformed

When informed

probability of correct choice

Overall

Male subject/family match

Male subject/opposite sex match

Male subject/same sex match

Female subject/family match

Female subject/opposite sex match

Female subject/same sex match

N. observations

204

Sample average

$73.0 \%$

$69.9 \%$

$\begin{array}{rcrc}\text { dydx } & \text { t-stat. } & \text { dydx } & \text { t-stat. } \\ 14.2 \% & 2.05 * * & -5.4 \% & -0.64 \\ 55.6 \% & 5.37 * * * & 24.1 \% & 1.73 * \\ -1.7 \% & -0.14 & -19.4 \% & -1.10 \\ 4.2 \% & 0.28 & -21.1 \% & -1.47 \\ -0.4 \% & -0.28 & -1.4 \% & -0.09\end{array}$

132

Sample average

$24.3 \%$

$38.1 \%$

\section{dydx t-stat.}

$13.7 \%$

$27.4 \%$

$15.4 \%$

$4.3 \%$

$4.5 \%$

$25.0 \%$

$6.1 \%$

803
Sample average

$87.0 \%$

$85.9 \%$

dydx t-stat.

$-1.1 \% \quad-0.57$

$0.0 \% \quad-0.01$

$-1.2 \% \quad-0.19$

$1.8 \% \quad 0.41$

$-3.8 \% \quad-0.99$

$1.6 \% \quad 0.23$

$-2.4 \% \quad-0.47$

1629

Marginal effects are estimated using a regression of the dependent variable on a fully interacted set of an informed treatment dummy, a gender dummy, and dummies for each matching type. In the regression, standard errors are clustered by subject pair. The regression is estimated separately for subjects who incorrectly guessed the top rank of their partner, and subjects who guessed correctly. The marginal effects of the information treatment that are reported in the Table are obtained using the 'margins, dydx' command in Stata. t-statistics significant at the $10 \%$ level or better are reported in bold. In LAB2 observations for food and drinks are combined. This means that in LAB2 there areup to four observations per subject: food and drink for family matching; and food and drink for stranger matching -- except for subjects matched with a computer, in which case there are two observations per subjects: food and drink for family matching. 


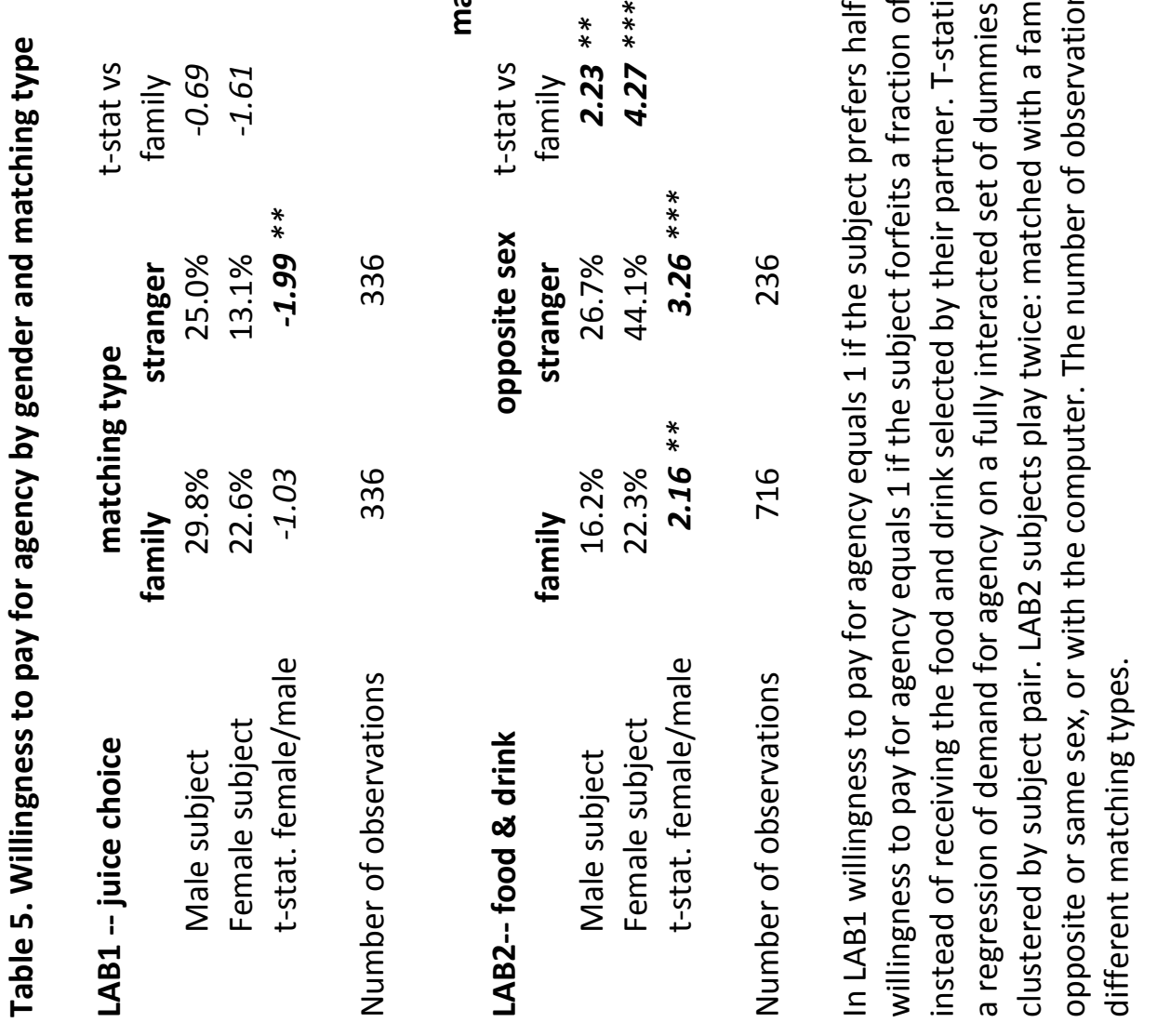


Table 6. Testing demand for ex ante instrumental agency

\begin{tabular}{|c|c|c|c|c|c|}
\hline \multirow{2}{*}{\multicolumn{2}{|c|}{ Gain from agency (instrumented): }} & \multicolumn{2}{|c|}{ LAB1 } & \multicolumn{2}{|c|}{ LAB2 } \\
\hline & & Coef. & t-stat. & Coef. & t-stat. \\
\hline Juice / food & & -0.069 & -0.27 & 0.136 & $2.32 * *$ \\
\hline Drink & & n.a. & & -0.940 & -0.35 \\
\hline Cost of agency & & n.a. & & -0.001 & -1.66 \\
\hline \multicolumn{6}{|c|}{ Matching and gender: } \\
\hline Gender & Maching & & & & \\
\hline Male & Opposite sex & -0.044 & -0.65 & 0.094 & $2.06 * *$ \\
\hline Male & Same sex & n.a. & & 0.087 & $2.05 * *$ \\
\hline Male & Computer & n.a. & & 0.034 & 0.73 \\
\hline Female & Family & -0.068 & -0.99 & 0.070 & $2.44 * *$ \\
\hline Female & Opposite sex & -0.160 & $-2.47 * *$ & 0.285 & $5.64 * * *$ \\
\hline Female & Same sex & n.a. & & 0.207 & $4.46 * * *$ \\
\hline Female & Computer & n.a. & & 0.241 & $4.58 * * *$ \\
\hline \multicolumn{2}{|l|}{ Intercept } & 0.312 & 4.01 & 0.153 & 4.87 \\
\hline \multicolumn{2}{|c|}{ Number of observations } & 336 & & 1432 & \\
\hline
\end{tabular}

The Table reports IV estimates of the effect of the expected gain from agency on willingness to pay for agency. The dependent variables is as in Table 5. At the time of making the decision, subjects do not know what the partner has selected for them. Instruments include a fully interacted set of dummies for gender, informed treatment, matching type, and own top rank. In LAB1 the predicted gain in the probability of getting preferred juice varies between $8 \%$ and $44 \%$, with a mean of $25 \%$ (s.d. 9\%). In LAB2 the predicted gain vary between $8 \%$ and $100 \%$ for both food and drink, with an average of $36 \%$ (s.d. $24 \%$ ) for food and $34 \%$ (s.d. $26 \%$ ) for drink. The cost of agency takes values 5, 20 and 50, equally randomized across subjects. Standard errors a clustered at the pair level. t-statistics significant at the $10 \%$ level or better are shown in bold. For all matching types, demand for agency in LAB2 tests as significantly higher for female than male subjects. 
Table 7. Proportion of LAB2 subjects who demand ex post agency

\begin{tabular}{|c|c|c|c|c|c|}
\hline $\begin{array}{l}\text { Food selected by partner is: } \\
\text { Drink selected by partner is: }\end{array}$ & $\begin{array}{l}\text { incorrect } \\
\text { incorrect }\end{array}$ & $\begin{array}{r}\text { incorrect } \\
\text { correct }\end{array}$ & $\begin{array}{r}\text { correct } \\
\text { incorrect }\end{array}$ & \begin{tabular}{l|} 
correct \\
correct
\end{tabular} & $\begin{array}{l}\text { overall } \\
\text { overall }\end{array}$ \\
\hline \multicolumn{6}{|c|}{ Proportion of subjects who demand agency after being informed of their partner's selection for them: } \\
\hline All subjects & $17.2 \%$ & $20.5 \%$ & $12.2 \%$ & $10.8 \%$ & $14.0 \%$ \\
\hline N. obs. & 250 & 269 & 230 & 683 & 1432 \\
\hline Male subjects & $17.7 \%$ & $22.2 \%$ & $12.7 \%$ & $13.9 \%$ & $16.1 \%$ \\
\hline N. obs. & 136 & 144 & 126 & 310 & 716 \\
\hline Female subjects & $16.7 \%$ & $18.4 \%$ & $11.5 \%$ & $8.3 \%$ & $11.9 \%$ \\
\hline N. obs. & 114 & 125 & 104 & 373 & 716 \\
\hline \multirow{2}{*}{\multicolumn{6}{|c|}{$\begin{array}{l}\text { Proportion of subjects who demand agency after being informed of their partner's selection for } \\
\text { Among subject who demanded agency before being informed of their partner's selection }\end{array}$}} \\
\hline & & & & & \\
\hline All subjects & $52.9 \%$ & $61.8 \%$ & $40.7 \%$ & $35.5 \%$ & $45.0 \%$ \\
\hline N. obs. & 68 & 76 & 59 & 166 & 369 \\
\hline \multicolumn{6}{|c|}{ Among subject who do not demand agency before being informed of their partner's selection } \\
\hline All subjects & $3.9 \%$ & $4.2 \%$ & $2.3 \%$ & $2.9 \%$ & $3.2 \%$ \\
\hline N. obs. & 182 & 193 & 171 & 517 & 1063 \\
\hline
\end{tabular}

Notes: Each percentage is the proportion of LAB2 subjects willing to pay for agency after having been informed of their partner's food and drink selection for them. Subjects only make one decision combining food and drink. The top panel reports these proportions for all subjects and by gende, depending on whether the partner selected the correct food and drink or not. The bottom panel breaks down these proportions between subjects who demanded agency ex ante -- i.e., before being informed of their partner's selection for them -- and those who did not. 
Table 8. Testing demand for ex post pure agency

\begin{tabular}{|c|c|c|c|}
\hline \multicolumn{2}{|c|}{ Goin from aranculactunl } & \multicolumn{2}{|c|}{ LAB2 } \\
\hline \multicolumn{2}{|c|}{ Gain from agency (actual) } & Coef. & t-stat. \\
\hline \multicolumn{2}{|l|}{ Food } & 0.077 & $3.56 * * *$ \\
\hline \multicolumn{2}{|l|}{ Drink } & -0.004 & -0.21 \\
\hline \multicolumn{2}{|c|}{ Cost of agency } & -0.002 & $-3.89 * * *$ \\
\hline \multicolumn{4}{|c|}{ Martching and gender: } \\
\hline Gender & \multicolumn{3}{|l|}{ Maching } \\
\hline Male & Opposite sex & 0.138 & $3.15 * * *$ \\
\hline Male & Same sex & 0.066 & $1.78 *$ \\
\hline Male & Computer & 0.025 & 0.64 \\
\hline Female & Family & -0.017 & -0.78 \\
\hline Female & Opposite sex & 0.039 & 1.04 \\
\hline Female & Same sex & -0.008 & -0.25 \\
\hline Female & Computer & 0.049 & 1.24 \\
\hline \multicolumn{2}{|l|}{ Intercept } & 0.139 & 6.23 \\
\hline \multicolumn{2}{|c|}{ Number of observations } & 1432 & \\
\hline \multicolumn{4}{|c|}{$\begin{array}{l}\text { The Table reports OLS estimates of the effect of the actual gain } \\
\text { from agency on willingness to pay for agency. The dependent } \\
\text { variables equals } 1 \text { if the subject forfeits a fraction of the show- } \\
\text { up fee to receive their top ranked food and drink, and } 0 \\
\text { otherwise. At the time of making the decision, subjects know } \\
\text { what the partner has selected for them. The cost of agency } \\
\text { takes values 5, } 20 \text { and 50, equally randomized across subjects. } \\
\text { Standard errors a clustered at the pair level. t-statistics } \\
\text { significant at the } 10 \% \text { level or better are shown in bold. }\end{array}$} \\
\hline
\end{tabular}


Table 9. Husband's willingness to delegate in the field experiment

$\begin{array}{lcr} & \text { Coef. } & \text { t-stat. } \\ \text { Husband's preference=choice he expects wife to make } & 0.010 & \mathbf{2 . 1 7} * * \\ \text { Treated dummy } & 0.000 & -0.01 \\ \text { Intercept } & 0.985 & 191.53\end{array}$

Number of observations

Notes: The Table reports OLS estimates of the effect of the actual loss from delegation on willingness to delegate. The dependent variables equals 1 if the subject is willing to delegate the choice of gift to his wife, and 0 otherwise. At the time of making the decision, subjects do not know what the partner has selected for them, but they have been asked to make a guess. The main regressor of interest equas 1 if the preference of the husband is equal to the choice he expects his wife to make. $t$ statistics significant at the $10 \%$ level or better are shown in bold. 
Table 10. Testing demand for ex ante instrumental agency in the field experiment

\begin{tabular}{lcc}
\hline & Coef. & t-stat. \\
Instrumental value of agency & -0.039 & $\mathbf{- 2 . 0 1} * *$ \\
High cost of agency dummy & -0.160 & $\mathbf{- 1 4 . 9 2} * * *$ \\
Treated dummy & -0.039 & $\mathbf{- 2 . 0 1} * *$ \\
Preferences (purse is omitted category) & & \\
Wallet & 0.010 & 0.40 \\
Pencil case & 0.178 & $\mathbf{5 . 2 8}$ \\
Intercept & 0.814 & 35.55 \\
& & \\
Number of observations & 3982 & \\
\hline
\end{tabular}

Note: The Table reports OLS estimates of the value and cost of agency on willingness to exert agency. The dependent variables equals 1 if the subject is willing to forfeit part of a monetary participation fee, and 0 otherwise. Subjects make two separate decisions, one for which the cost of agency is PKR50 (the default); and the other for PKR200 (High cost of agency dummy=1). At the time of making the decision, subjects do not know what the partner has selected for them, but they have been asked to make a guess. The instrumental value of agency equals 1 if the preference of the wife is equal to the choice she expects her husband to make. Standard errors a clustered at the subject level. t-statistics significant at the $10 \%$ level or better are shown in bold. 


\section{Appendix A Executive and Consultative Agency}

Figure A1: Share of respondents who need permission, by decision importance
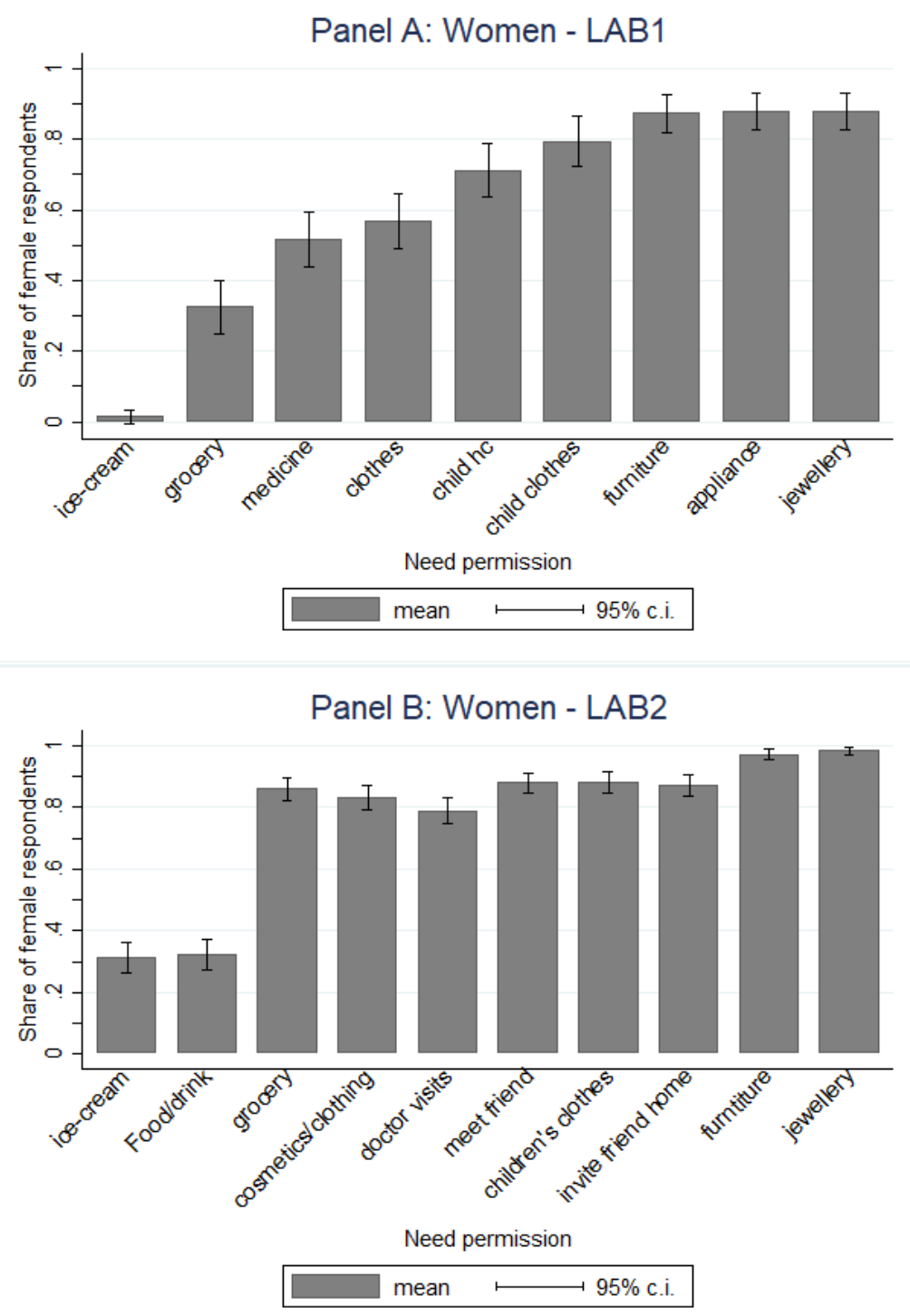


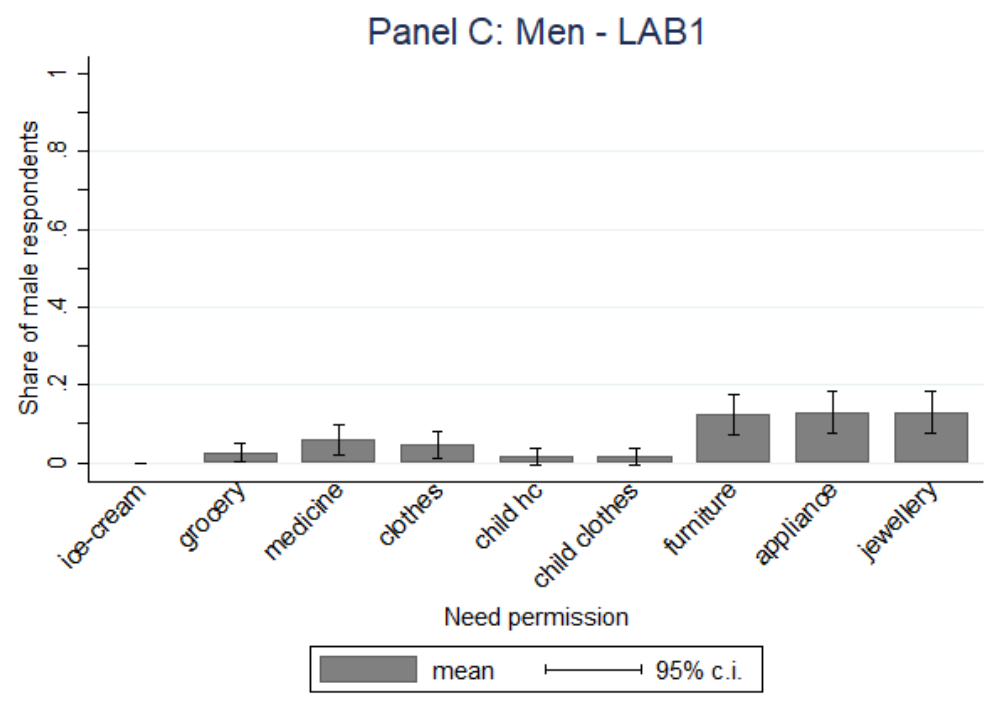

Panel D: Male - LAB2

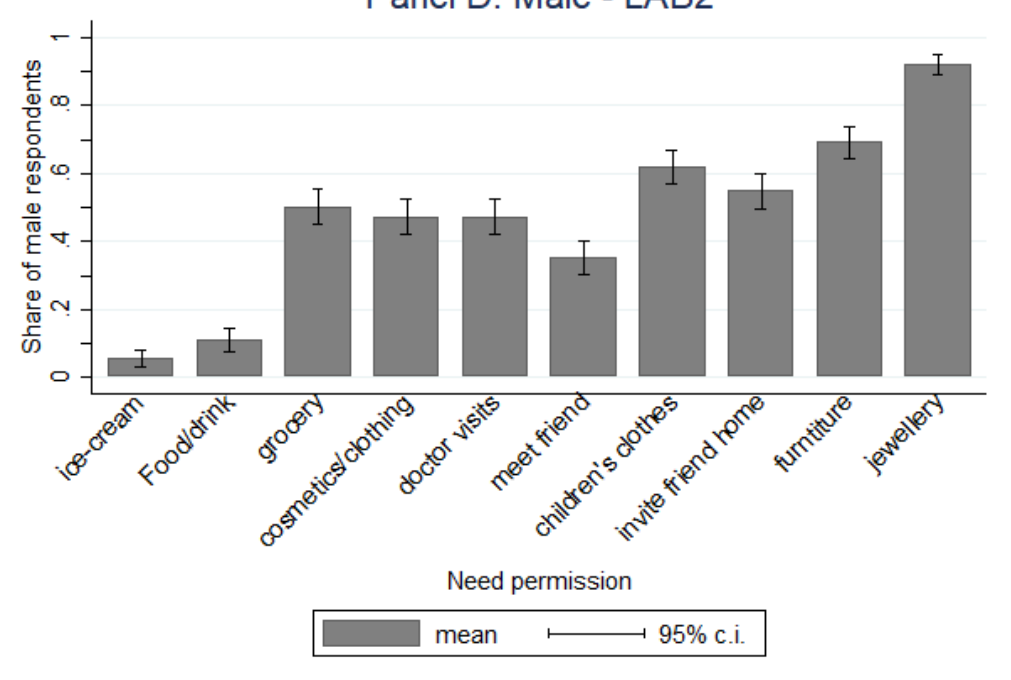




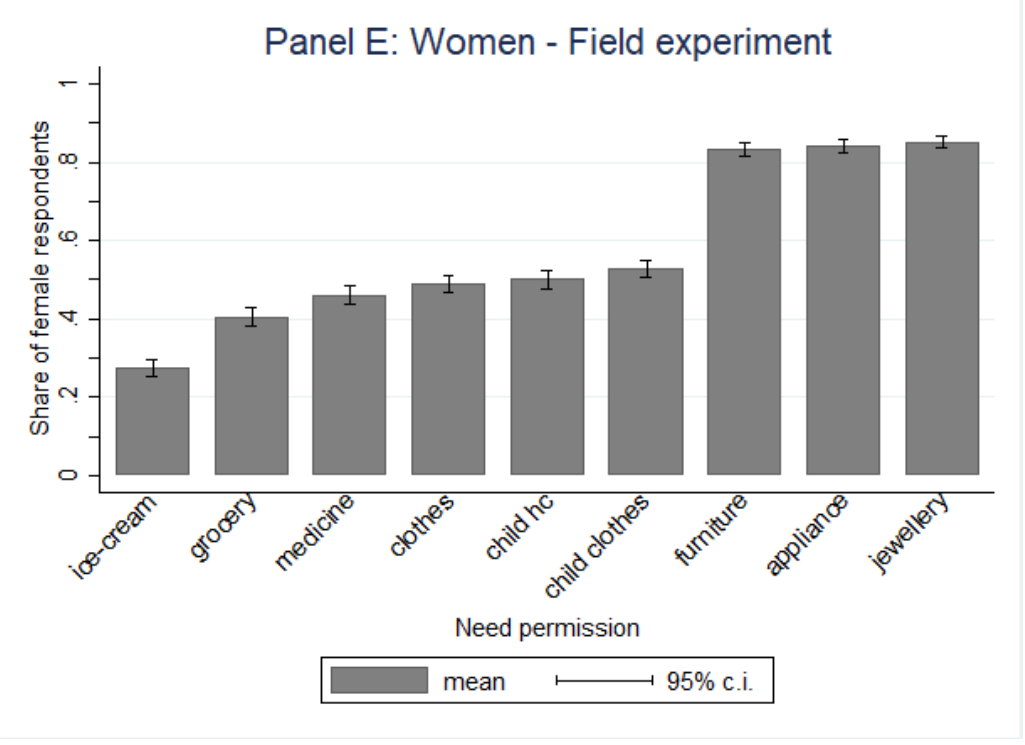

Notes: Apart from the sale of jewellery represented by the bar labelled 'jewellery', all other questions refer to requiring permission for purchase of the mentioned item. In LAB2, we also ask about permission to visit friends in town or invite them home, The graph also shows $95 \%$ confidence intervals for each bar. 
Figure A2: Share of female respondents reporting opinion taken into account: Field experiment only

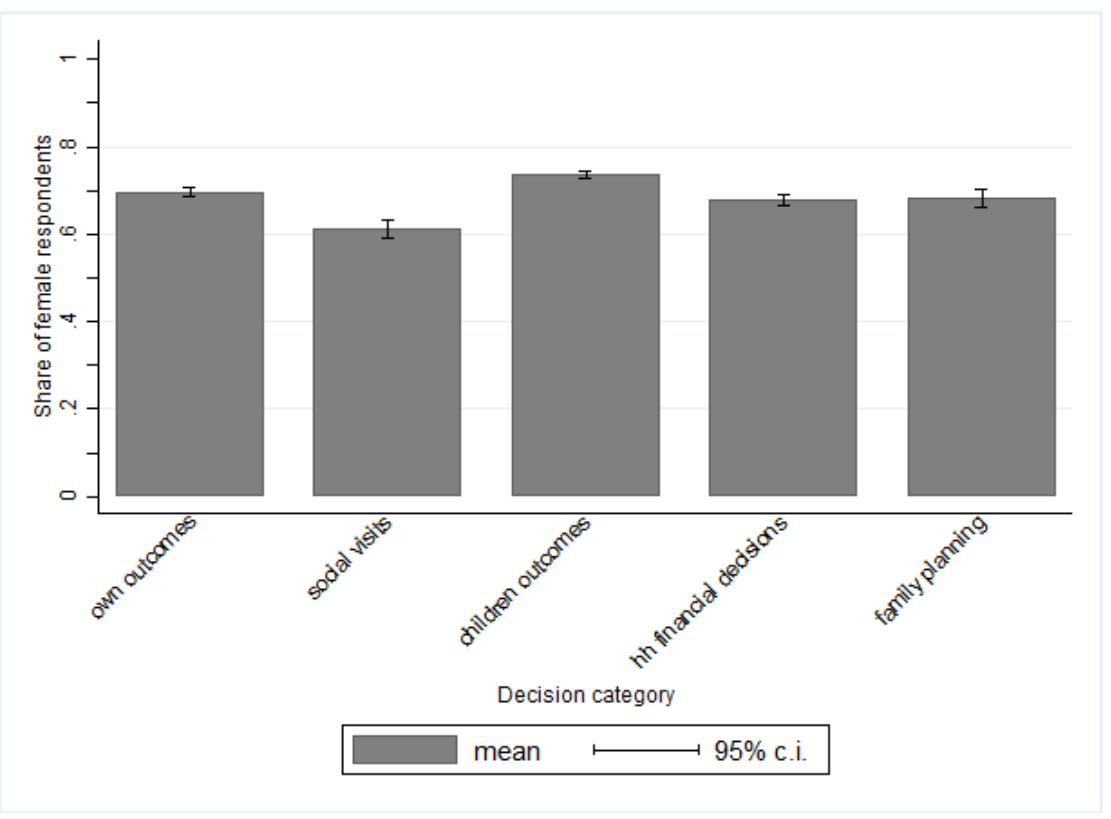

Notes: Decision categories are as follows: 'own outcomes' includes decisions regarding respondents' medical care, decision to work for earned income, and decision to borrow money from a MFI; 'social visits' include decisions to visit family members, 'children outcomes' refers to decisions regarding boys' schooling, decisions regarding girls' schooling, decision regarding children's marriage and decisions regarding children's medical care; 'financial decisions' include purchase of electronic appliances for the household, decisions about repairs of the house and decisions regarding the sale or purchase of the house; and 'family planning' includes decisions about family planning. 


\section{Appendix B: Proxying the instrumental value of agency}

By experimental design subject $i$ receives their preferred bundle with probability 1 when exerting agency. In LAB1, a coin toss determines whether a subject receives their selected juice or the juice selected for them by their partner. Let $d_{i}^{k}$ equal 1 if the partner selects $i$ 's preferred good $k$ and 0 otherwise. The realized value of agency $R_{i}$ for good $k$ is thus:

$$
R_{i}^{k}=\frac{1}{2}\left(1-d_{i}^{k}\right)
$$

where $k$ only takes one value - juice. In LAB2, the subject receives the food and drink their partner chooses for them, unless they pay for agency. The value of agency is then:

$$
R_{i}^{k}=1-d_{i}^{k}
$$

for $k=\{$ food,drink $\}$. When deciding whether to exert agency or not, subject $i$ does not know $d_{i}^{k}$, but they can form an expectation of the probability that $d_{i}^{k}=1$. Let this probability be written $E\left[d_{i}^{k}\right]=p_{i}^{k}$. The instrumental value of agency is thus the ex ante predicted value of $R_{i}^{k}$ :

$$
\begin{aligned}
V_{i}^{k} & =E\left[R_{i}^{k}\right] \\
& =\frac{1}{2}\left(1-p_{i}^{k}\right) \text { in LAB1 } \\
& =1-p_{i}^{k} \text { in LAB2 }
\end{aligned}
$$

As demonstrated earlier, $p_{i}^{k}$ varies systematically with experimental treatments (e.g., matching type and information treatment) and characteristics of subject $i$ (e.g., gender, preference ranking) - e.g., because they affect the partner's knowledge of $i$ 's preference ranking and their willingness to accomodate them. To capture this we estimate a regression model of the form:

$$
d_{i}^{k}=\sum_{m} \sum_{n} \sum_{r} \sum_{g} D_{m} D_{n} D_{r_{i}^{k}} D_{g_{i}}+e_{i}^{k}
$$

where the $D_{s}$ 's are categorical variables for matching type $m$, information dummy $n$, preference ranking of $i$ for good $k$ denoted $r_{i}^{k}$, and gender of $i$ denoted $g_{i}$. Let $\widehat{p}_{i}^{k}$ denote the expected value of $d_{i}^{k}$ predicted from the above estimated regression, estimated separately for LAB1 and LAB2 and for each good $k$. This value can then be used to obtain an estimate $\widehat{V}_{i}^{k}$ of $V_{i}^{k}$ for each experiment and consumption good. Equivalently, we can regress model (1) directly on $R_{i}^{k}$ to obtain an estimate of $E\left[R_{i}^{k}\right]$. In LAB1 $\widehat{V}_{i}^{k}$ varies between $8 \%$ and $44 \%$ (50\% is the maximum feasible), with a mean of $25 \%$ (s.d. $9 \%$ ). In LAB2 it varies between $8 \%$ and $100 \%$ for both food and drink, with an average of $36 \%$ (s.d. $24 \%$ ) for food and $34 \%$ (s.d. $26 \%$ ) for drink.

Ex ante demand for agency $A_{i}^{b}$ can then be written as:

$$
A_{i}^{b}=\alpha+\sum_{k} \beta_{k} R_{i}^{k}+\gamma C_{i}+\sum_{m} \sum_{g} D_{m} D_{g_{i}}+u_{i}
$$


where $C_{i}$ denotes experimental variation in the price of agency (only in LAB2) and where the realized value of agency $R_{i}^{k}$ is instrumented using $\widehat{V}_{i}^{k}$. This is equivalent to using $\sum_{m} \sum_{n} \sum_{r} \sum_{g} D_{m} D_{n} D_{r_{i}} D_{g_{i}}$ as instruments in equation (2). Gender and matching type dummies are included as controls because they may affect agency directly - for instance because women are reluctant to impose their own choice when matched with a male family member.

We also estimate a version of model (2) for ex post agency $A_{i}^{p}$ :

$$
A_{i}^{p}=\alpha+\sum_{k} \beta_{k} R_{i}^{k}+\gamma C_{i}+\sum_{m} \sum_{g} D_{m} D_{g_{i}}+u_{i}
$$

Here no instrumentation/prediction is required since, by construction, $i$ knows $R_{i}^{k}$ when deciding $A_{i}^{p}$. 


\section{Online Appendix A: Experimental protocols}

\section{A1. First laboratory experiment}

At the time of invitation, all couples were given basic information on the experiment and details on the time, date, and expected duration of the session (2-3 hours). ${ }^{18}$ Each couple was also informed of the compensation and expected earnings from participation: a participation fee of Rs. 1000 (\$10) (i.e., Rs. 2000 per couple), provided that they stayed for the entire duration of the session; and additional earnings of at most Rs. $1000(\$ 10)$. Informed consent was collected from all participants before the start of each session, and payments were made individually and privately at the end. Male questionnaires were not administered at the time of the RCT survey, thus data on males was collected at the time of the experiment.

\section{Recruitment}

Half of the LAB1 female subjects (98) are drawn in 2014 from among clients of a microfinance organization (the National Rural Support Programme, henceforth NRSP) participating in a randomized controlled trial (RCT). NRSP offers microenterprise loan products in urban and peri-urban areas of Bhakkar and Chakwal in the Pakistan Punjab and targets its financial products towards middle-aged married couples. Our initial intent was to recruit all of the LAB1 sample from the RCT sample in the Chakwal district. This proved impossible, however, because many invited households declined to participate due to time constraints. To make up for the shortfall, the LAB1 sample include randomly selected couples from the same muhallas - or geographical clusters - where the RCT households reside. $^{19}$

Women are invited to participate with their husband. In case the woman is unmarried or the husband is absent, the subject is invited to come accompanied by the adult male with the greatest power over household's finances.

\footnotetext{
${ }^{18}$ Each experimental session was held in a central location, at less than 20 minutes drive via public transport from any of the sampled muhallas. To facilitate participation by employed subjects, in particular men, we held sessions over the weekend.

${ }^{19}$ More precisely, we first randomly selected from the list of female RCT participants within each muhalla one subject to be invited to the experiment. Muhallas were used as sampling units to limt the flow of information between participants of different sessions. We then invited to the same session one couple from every 3rd household living on the same street as the RCT invitee. These two steps were repeated until we found enough couples to participate in the session. $58 \%$ of the LAB1 sample is from the original RCT sample, and the remaining $42 \%$ are randomly selected pairs from the same muhallas.
} 


\section{Sequence of events during experiment sessions}

1. Upon arrival, subject pairs are assigned to their respective gender-specific room. $74.4 \%$ of the participants came with their spouse; $14.88 \%$ with their son and $10.72 \%$ with male household members (for instance, brother, brother-in-law).

2. Each subject pair is randomly assigned to a matching treatment: either with spouse/household member they came with; or with stranger of opposite gender. $50.6 \%$ of the participants were paired with family member and $49.4 \%$ are paired with a stranger.

3. Each subject in the stranger matching treatment is assigned a partner; this is done without replacement, which means that all subjects in the stranger treatment have one partner and one partner only; by construction, the partner is not the household member they came with

4. Half of the subjects are randomly assigned to the information treatment. The randomization is done by pair ID codes assigned at the start of the treatment.

5. No contact is allowed between subjects of opposite genders during the entire experiment. Men and women are seated in separate rooms

6. Subjects of the same gender are seated in compartments separated by cardboard sheets. Contact between subjects in the same room is strongly discouraged but not impossible.

7. Preference game is always played first in each session.

- Subjects taste small samples of the three juice flavors.

- Subjects rank the three flavors by order of preference.

- Subjects pick the flavor they want to receive a full glass of.

- Subjects guess the preference ordering of their partner.

- Subjects in the information treatment are informed of the preference order of their partner.

- Subjects pick the flavor they want their partner to receive a full glass of.

- Subjects choose whether to take half-a-glass of their selected flavor, or 50\% chance of a full glass of their selected flavor and $50 \%$ chance of a full glass of the flavor selected for them by their partner.

- A coin toss determines which flavor the subject receives.

- Subjects consume the juice. 
8. Subjects play the Dictator (D), Taking (T) and Ultimatum (U) activities. The order of play is randomized across sessions as follows:

\begin{tabular}{cc} 
Game Order & Session No. \\
\hline D-T-U & $7,11,15$, \\
D-U-T & $3,5,9$ \\
T-U-D & 1 \\
T-D-U & 4 \\
U-D-T & $2,6,8$ \\
U-T-D & 10,13
\end{tabular}

9. The last activity is played. This is always the norms elicitation activity. Subjects answer two incentivized questions about financial autonomy of women. The two questions are answered twice; once the answers are matched to the spouse and once the answers are matched to a random stranger sitting in the next room. Subjects receive a fixed payoff of Rs. 250 for every question matched to a person sitting in the next room. Question about an ordinary purchase (scarf) is always asked before the question on investment decision. The order in the which answer is matched to either the household member or stranger is randomised. This order of matching is as follows:

\begin{tabular}{cc} 
Answers Matched to: & Session No. \\
\hline Household member, Stranger & $1,3,5,7,9,11,13,15$ \\
Stranger, Household member & $2,4,6,8,10,12,14$
\end{tabular}

10. Show-up fee + pay off from randomly selected activity (DG/TG/UG/norms) is paid to each participant in cash. The participants are provided this case in white envelopes and in privacy. 
We reproduce below the full protocol used in the experiment. The text below was read in Urdu to all participating subjects during the experiment. Square brackets [] contain instructions for enumerators.

\section{Introduction to the community}

Thank you [Community Head name or NRSP representative?], for organizing this meeting and allowing us to be here.

Also, thank you all for taking the time to be here today. My name is [experimenter's name], and I will be facilitating this meeting. Helping me today, we also have here [introduce everyone]. Before we start, we would like to give you Rs _--- as a compensation for your time. These Rs _--- are not a part of the activity and are yours to keep.

Purpose

- Today, we will conduct several activities in your community.

- The purpose of these activities is to better understand how people in this community make decisions.

- The results of the study may eventually be published in a scientific article or part of a book.

- It is not part of a development project of any sort.

- Your community and other communities around [Province name] were selected to participate from a large group of potential communities.

\section{Activities}

We will perform several tasks here today. At the end of all the tasks, we will draw a number from this hat [show numbers and hat]. Each number represents one of the tasks that you will have performed, number 1 for task 1 , number 2 for task 2 , and so on. The number that is drawn will determine which task is paid to you. This means that every task that you play today has the same chance of being paid to you. So you have to be careful to choose exactly what you want for each task, because that decision can be the one that determines your payment at the end. Is this clear to everyone? Do you have questions on this?

For our activities, we will select 20 participants. In a moment, I will explain how we select the participants. Before that, I want to make some general comments. Participants will be performing some tasks in exchange for real money that they will be able to take home. You should understand that this is not my money. It is money given to me by Oxford University, to use to conduct a research study. 
- We only need 20 individuals to participate in these tasks. Thus, unfortunately, not all of you will be able to participate.

- We will have a lottery to determine who will participate.

- To complete the lottery, we will write down your name and the name of your spouse on a piece of paper and then, fold the paper in half.

- Next, you will place your folded piece of paper in a bag.

- This means that we need one piece of paper for each couple present here today.

- We will then ask one of you to draw 10 pieces of paper from the bag containing the names.

- Those whose names are drawn will stay here and participate in the tasks, while the others will go home.

Is this clear to everyone? Does anyone have any questions on how we will select the 20 participants?

Please note that the meeting may take 3-4 hours, so if you think you will not be able to stay that long please let us know now.

\section{Consent}

- Before we begin, I will explain the basic activities we will do together, and the rules that we will follow.

- [Read Consent Statement]

If you wish to participate, please say, "I do." If you do not wish to participate, please advise us. You will be free to leave then. You will not be able to stay in the activity $\operatorname{room}(\mathrm{s})$ if you do not wish to participate.

[Random draw of names]

Those of you, whose names have not been called, can leave now. Thank you all for taking the time to come today.

[After people have left]

You will be matched with a partner for some of the tasks that you will perform today. Who your partner is depends on a random draw.

- We will now ask one member of each couple to draw a card from this bag [Hold bag up and show its content].

- The bag contains 5 yellow cards and 5 green cards. 
- If you draw a yellow card, we will give you and your spouse a yellow name tag to wear. If you draw a green card, we will give you and your spouse a green name tag to wear.

- The color of the card you draw will determine who your partner is for some of the tasks today.

We will explain more about your partner later, but for now we will go around the room for the random draw and to distribute the name tags.

[After people have been assigned to the spouse or stranger matching]

We will now take all women to one room, and all men to another room. Please follow [Assistant's name] if you are a woman, or [Assistant's name] if you are a man.

[Take the selected participants into the rooms and have them sit.]

[To the participants]

\section{Introduction to participants}

Welcome, and thank you again.

- Before we proceed any further, let me stress something that is very important. Many of you were invited here without understanding very much about what we are planning to do today. If at any time you find that this is something that you do not wish to participate in for any reason, you are of course free to leave at anytime. If you do choose to leave, you won't be able to come back into the activity room(s) until everyone if finished performing all the activities.

- Before we start, please make sure your mobile phones are switched off, to avoid interruptions during the meeting.

- If you have heard about activities that have been conducted here in the past you should try to forget everything that you have been told. These are completely different tasks.

- Please also be advised, there are no right or wrong choices, so you should choose whatever you think is best for yourself and not look at your neighbor's choices. It is important to remember that not everyone will win the same amount in the task. Everyone will still receive the _--- payment for participation, regardless of how much you win in the task

- We are about to begin. It is important that you listen as carefully as possible to the instructions, because only people who understand the tasks will actually be able to perform them. I will run through some examples to make sure you understand.

- You cannot ask questions out loud or talk about the tasks with anyone else while we are here together. 
- If you have questions at any time during the meeting, please raise your hand and ask, and we will come to you and answer them in private.

- I will read through a script to explain all the activities that we will perform here today. As you may know, these activities are conducted in other localities beside this one, so it is very important that people in every locality receive exactly the same information, and this is the reason why I must read from this script.

\section{NO TALKING}

- I will now say something very important. You cannot ask questions out loud or talk about the tasks with anyone else while we are here together.

- If you need to ask a question at any time, please raise your hand and I will come to you so I can answer your question privately.

- I will explain the tasks, do demonstrations, and let you practice the tasks before we perform them for real. These demonstrations and practices are to help you understand the rules and clarify any questions.

- Please be sure that you obey these rules because it is possible for one person to spoil the tasks for everyone by talking in front of the group. If this happens, we will not be able to continue forward with the tasks today and you will not be paid for the tasks.

- Is this clear to everyone? Does anyone have any questions so far about what will go on today?

[If anyone asks a question out loud, explain again that all questions must be asked in private]

\section{REAL PAYMENT}

- In today's activities, you will have the opportunity to receive a cash payment. The amount that you will receive depends on your decisions and on the decisions of others. It also depends on what task is selected to be paid.

- Remember that at the end of all the activities, we will draw a number from a hat. That number will determine for which task you will be paid. This means that each task that you perform has the same chance of being selected to be paid.

- Remember also, that in addition to what you will earn from the activities, each of you will receive _-_- for participating in today's meeting. This money is yours, regardless of what happens during the activities. It will be paid to you in cash together with your earnings from the activities.

- It is real money, which you will be allowed to keep for yourself or do what you wish. This money will paid to you in cash at the end of the meeting. 
- During the activities you will make your decisions using paper slips [show slips], each representing 100 Rs. These paper slips will be converted into cash when you get paid at the end of the meeting.

\section{CONFIDENTIALITY}

- Your decisions and your payment are private and confidential. Nobody, apart from a member of our team will know what you earned, and he/she will not tell anyone.

- You all have a dark bag. You will have to make your decisions inside the bags, so that nobody else can see what you decide.

\section{Instructions for preferences game (Task 1)}

We are now ready to begin a task. Let me remind you that you may not ask questions or talk while you are here in the group. If you have any questions, you may raise your hand and I (the enumerator) or my assistant(s) will come answer your question privately. This is NOT the same task that you just performed, so be sure to listen to the instructions carefully.

Who will be your partner in this task? You remember that earlier we asked you to draw a card. Half of you drew yellow cards, the other half drew green cards. Your partner for this task is determined by the color of the card you drew.

- Those of you who drew a green card will be paired with a stranger in the other room. None of you will know exactly with whom you are paired. Only [researcher's name] knows who is matched with whom, and she/he will never tell anyone. [If this is not the first task: Your partner in this task is the same as the one in the previous task.]

- Those of you who drew a yellow card will be paired with their spouse in the other room.

Do you have questions on who your partner will be in this task? If you have questions, please raise your hand and I will come to you to answer your question privately.

[If this is not the first task: Your partner for this task is the same as the one for the previous task(s). That is, for those of you who drew a green card, your partner will be the same stranger in the other room that was paired with you in the previous task(s), while for those of you who drew a yellow card, your partner will be your spouse in the other room.]

\section{Part 1:}

I have here three different flavors of juice - apple, pineapple and orange. Before we begin this task, I would like you to taste each of these flavors and rank them on the basis of 
how much you like them. You should rank your favored flavor as number 1, your secondfavored flavor as number 2, and your least favored flavor as number 3. You cannot rank two flavors equally. My assistant(s) will offer you a sample of the three flavors of juice, and then you should write down your ranking on the sheet we will provide you. [Distribute a sheet with pictures of the 3 fruits, subjects should write a number next to each fruit representing the ranking.]

Does anyone have any questions? Please raise your hand and my assistant or I will come and address your query.

\section{Part 2:}

Your partner in the other room has also been asked to rank the three flavors of juice. We would like you to guess your partner's ranking. We will now distribute a sheet, where you can write your guess. We will give you Rs. _-- for guessing correctly! This money will be paid to you at the end of all activities, on top of your earnings from the task that is randomly selected to be paid.

\section{Part 3:}

Now, we will distribute to half of you a sheet, containing the ranking given by your partner. The others will not know how your partner ranked the juice flavors.

[The experimenter and assistants distribute to a randomly selected half of participants (half from each group) the partner's ranking sheet.]

Now I would like for you to make two decisions:

- Choose what flavor you would like to consume.

- Choose a flavor for your partner to consume. It does not have to be the same flavor that you choose for yourself, nor it must necessarily be your partner's preferred flavor, if you know it.

- In the other room, your partner is being asked to do the same.

- There is a fifty percent chance that you will be given the flavor that you chose for yourself, and a fifty percent chance that you will be given the flavor that your partner chose for you. Similarly, your partner has a fifty percent chance to be given the flavor that he or she chose for him or herself, and a fifty percent chance to be given the flavor that you chose for him or her.

- Neither you nor your partner will be able to exchange the juice you are given with anyone else.

Shall we begin? Does anyone have any questions? Please raise your hand and my assistant or I will come and address your query. 
We will now distribute a decision sheet, where you can mark your choices [Distribute a decision sheet, with space to record one choice for the subject and one for the partner]

Please fill in your choice in the sheet of paper in front of you and fold it to let us know you are done. My assistants and I will come and collect your decision sheet.

\section{Part 4:}

We will now call you one by one to the back of the room and give you your juice. We will fill a large glass of juice for you [Show glass: the glass should be opaque, so that others cannot see how much juice is in it]. Remember, there is a fifty percent chance that you will get your favorite flavor, and a fifty percent chance that you will get the flavor that your partner picked for you. How will we decide if you'll get your favorite flavor or your partner's pick? We will toss a coin when we come to you. If the coin toss yields heads, then you will be given your favorite flavor; if tails, your partner's pick.

When we call you to give you your juice, before knowing whether you'll get your favorite flavor or your partner's pick for you (i.e. before tossing the coin), we will give you the opportunity to make sure you get your favorite flavor.

How? If you are willing to give up some of the juice, we will give you your favorite flavor of juice for sure. So, if you choose to have your favorite juice for sure, you will be given only half a glass of it. If instead you choose to have your favorite juice with a fifty percent chance, or your partner's pick with a fifty percent chance, then you'll be given a full glass of it.

We will now call you one by one.

[At individual meetings] Here I have the piece of paper with your ranking of the juice flavors, another piece of paper with your partner's pick for you, and a coin that I will toss to determine if you will get one full glass of your favorite flavor or of your partner's pick.

Would you like me to toss the coin and get a full glass of juice, or would you like to get your half a glass of your favorite flavor for sure? [record decision and implement it].

\section{Instructions for dictator game (Task 2)}

[Note: before each session, the order of tasks 1-3 is randomized]

We are now ready to begin another/the first task. Let me remind you that you may not ask questions or talk while you are here in the group. If you have any questions, you may raise your hand and I (the enumerator) or my assistant(s) will come answer your question privately. [If this is not the first task] This is NOT the same task that you just performed, so be sure to listen to the instructions carefully.

- This task is performed by pairs of individuals. Each pair is made up of a Player 1 and a Player 2. We will play two rounds of this task. 
- Each of you will perform this task with someone from the other room.

- Who your partner is depends on the color of the card you drew earlier, as I will explain to you shortly.

- [researcher's name] will provide $\$ 10$ to Player 1 in each pair of players..

- Player 1 must decide how to divide this money between himself or herself and Player 2. Player 1 may allocate between $\$ 0$ and $\$ 10$ to Player 2 .

- Player 2 takes home whatever Player 1 allocates to them, and Player 1 takes home whatever he or she does not allocate to Player 2.

Who will be your partner in this task? You remember that earlier we asked you to draw a card. Half of you drew yellow cards, the other half drew green cards. Your partner for this task is determined by the color of the card you drew.

- Those of you who drew a green card are paired with a stranger in the other room. None of you will know exactly with whom you are paired. Only [researcher's name] knows who is matched with whom, and she/he will never tell anyone.

- Those of you who drew a yellow card are paired with your spouse in the other room.

Do you have questions on who your partner is for this task? If you have questions, please raise your hand and I will come to you to answer your question privately.

[If this is not the first task: Your partner for this task is the same as the one for the previous task(s). That is, for those of you who drew a green card, your partner is the same stranger in the other room that was paired with you in the previous task(s), while for those of you who drew a yellow card, your partner is your spouse in the other room.]

We now run through 5 examples to show how the task might be performed.

[Notes: the researchers and assistants work through the examples and test questions with paper slips, each representing a 100 Rs note, on a flat surface with a line drawn on it demarcating the areas assigned to Players 1 and 2. Each of the examples presented below is presented either as an example or used as a test question as required. If more test questions are needed the researcher or assistant begin again with the first example above. The script below is written assuming that 6 more examples were given, 3 presented as test scenarios/practice rounds, i.e., the subjects are asked questions about the amounts the subjects would take home. The 11 examples/tests -5 above, 6 below - cover the full set of possible choices for Player 1.]

1. Here is the $\$ 10$. Imagine that Player 1 chooses to allocate $\$ 9$ to Player 2 . Then, Player 2 will go home with $\$ 9$ and Player 1 will go home with $\$ 1$ ( $\$ 10$ minus $\$ 9$ equals $\$ 1$ ). 
2. Here is another example. Imagine that Player 1 chooses to allocate $\$ 2$ to Player 2. Then, Player 2 will go home with $\$ 2$ and Player 1 will go home with $\$ 8$ (\$10 minus $\$ 2$ equals $\$ 8$ ).

3. Here is another example. Imagine that Player 1 chooses to allocate $\$ 5$ to Player 2. Then, Player 2 will go home with $\$ 5$ and Player 1 will go home with $\$ 5$ (\$10 minus $\$ 5$ equals $\$ 5)$.

4. Here is another example. Imagine that Player 1 chooses to allocate $\$ 7$ to Player 2. Then, Player 2 will go home with $\$ 7$ and Player 1 will go home with $\$ 3$ (\$10 minus $\$ 7$ equals $\$ 3$ ).

5. Here is another example. Imagine that Player 1 chooses to allocate zero to Player 2. Then, Player 2 will go home with zero and Player 1 will go home with $\$ 10$ ( $\$ 10$ minus zero equals $\$ 10)$.

[The experimenter and assistants hand out two envelopes for each subject. Each envelope features the subject's ID. The two envelopes are of different color. Moreover, Player 1's [2's] envelope has a 1 [2] written on it.]

We will now practice the task together. You will first practice the task as Player 1. You have been handed two envelopes. The yellow [or other color] one with 10 paper slips in it is the one that determines Player 1's payment. The other envelope, the blue [or other color] one, is empty and the paper slips you put in it will determine the payment to Player 2. As we work through the following examples, please put the paper slips into the empty envelope as indicated by the examples. We will walk around the room to check if your allocation matches the one from the example. This is important, because it allows us to make sure that everyone understands the task and how to make the decision.

Here are some more examples [The experiment assistants go around the room to check that subjects correctly place the paper slips into the envelopes. The experimenter explains the task again if mistakes are discovered]:

1. Imagine that Player 1 chooses to allocate $\$ 10$ to Player 2. Please place the paper slips into the blue envelope corresponding to this decision. How much will Player 2 go home with? And how much will Player 1 go home with? [Player 2 will go home with $\$ 10$ and Player 1 will go home with zero (\$10 minus $\$ 10$ equals zero).]

2. Here is another example. Imagine that Player 1 chooses to allocate $\$ 4$ to Player 2. Please place the paper slips into the blue envelope corresponding to this decision. How much will Player 2 go home with? And how much will Player 1 go home with? [Player 2 will go home with $\$ 4$ and Player 1 will go home with $\$ 6$ ( $\$ 10$ minus $\$ 4$ equals $\$ 6)$.]

3. Here is another example. Imagine that Player 1 chooses to allocate $\$ 6$ to Player 2. Please place the paper slips into the blue envelope corresponding to this decision. How much will Player 2 go home with? And how much will Player 1 go home with? 
[ Player 2 will go home with $\$ 6$ and Player 1 will go home with $\$ 4$ ( $\$ 10$ minus $\$ 6$ equals \$4).]

4. Suppose that Player 1 chooses to allocate $\$ 1$ to Player 2 . Please place the paper slips into the blue envelope corresponding to this decision. In this case, how much will Player 1 go home with? [\$9] And how much will Player 2 go home with? [\$1]

5. Now try this one. Suppose that Player 1 chooses to allocate $\$ 8$ to Player 2. Please place the paper slips into the blue envelope corresponding to this decision. In this case, how much will Player 1 go home with? [\$2] And how much will Player 2 go home with? [\$8].

6. Now try this one. Suppose that Player 1 chooses to allocate $\$ 3$ to Player 2. Please place the paper slips into the blue envelope corresponding to this decision. In this case, how much will Player 1 go home with? [\$7]. And how much will Player 2 go home with? [\$3].

- [Before each session, the order of rounds is randomly determined] You will all perform one round as player 1 and one round as player 2. You will first perform the task as Player 1 [or 2, depending on randomization], and then perform the task as Player 2 [or 1].

- We don't know yet whether you will be paid for this task, nor whether you will be paid for your decisions as Player 1 or as Player 2. How will we choose whether to pay you for this task, and whether to pay you as Player 1 or Player 2? After we have finished performing all the tasks, we will first draw a number from the hat [show again numbers and hat] to determine which task will be paid. If we draw the number 1 from the hat, then it means that this task is the one selected to be paid. If so, we will toss a coin: if heads come up then you will be paid as Player 1; if tails come up, we will pay you as Player 2.

[For Player 1s] You will now perform the task as Player 1. You have been handed two envelopes. The yellow [or other color] one with 10 paper slips in it is the one that determines your payment. The other envelope, the blue [or other color] one, is empty and the paper slips you put in it will determine the payment to Player 2. Please put the paper slips you want to give to player to the empty envelope. Please make sure your choice is not observed by others in the room. You must now wait while the rest of the players, finish performing the task. [If Player 1 is selected to be the first role to be played] Then we will play the second round of this task, where you are Player 2.

[The experimenter and assistants collect the envelopes.]

[For Player 2s] You will now perform the task as Player 2. Player 1 in the other room who has been matched with you has allocated a sum of money to you. After we finish performing all the activities, if this task and the role of Player 2 is the one selected to be paid I will pay you what Player 1 has allocated to you. 
We will now perform another task/We will now take a break. [Researcher's name] will pay you for this task [point to the pile of envelopes to demonstrate the amount] after we finish all the tasks, if this task is the one selected to be paid.

\section{Instructions for taking game (Task 3)}

We are now ready to begin another/the first task. Let me remind you that you may not ask questions or talk while you are here in the group. If you have any questions, you may raise your hand and I (the enumerator) or my assistant(s) will come answer your question privately. [If this is not the first task: This is NOT the same task that you just performed, so be sure to listen to the instructions carefully.]

- This task is performed by pairs of individuals. Each pair is made up of a Player 1 and a Player 2. We will play two rounds of this task.

- Each of you will perform this task with someone from the other room.

- Who your partner will be depends on the color of the card you drew earlier, as I will explain to you shortly.

- [researcher's name] will provide $\$ 10$ to Player 2 in each pair of players..

- Player 1 (not Player 2) decides how to divide this money between himself or herself and Player 2. Player 1 must allocate between $\$ 0$ and $\$ 10$ to himself, leaving the rest for player 2 .

- Player 2 takes home whatever Player 1 leaves them with, and Player 1 takes home whatever he or she does not leave to Player 2.

Who will be your partner in this task? You remember that earlier we asked you to draw a card. Half of you drew yellow cards, the other half drew green cards. Your partner for this task is determined by the color of the card you drew.

- Those of you who drew a green card will be paired with a stranger in the other room. None of you will know exactly with whom you are paired. Only [researcher's name] knows who is matched with whom, and she/he will never tell anyone. [If this is not the first task: Your partner in this task is the same as the one in the previous task.]

- Those of you who drew a yellow card will be paired with their spouse in the other room.

Do you have questions on who your partner will be in this task? If you have questions, please raise your hand and I will come to you to answer your question privately. 
[If this is not the first task: Your partner for this task is the same as the one for the previous task(s). That is, for those of you who drew a green card, your partner will be the same stranger in the other room that was paired with you in the previous task(s), while for those of you who drew a yellow card, your partner will be your spouse in the other room.]

We will now run through 5 examples to show you how the task might be performed:

[Notes: the researchers and assistants work through the examples and test questions with paper slips, each representing a 100 Rs note, on a flat surface with a line drawn on it demarcating the areas assigned to Players 1 and 2. Each of the examples presented below is presented either as an example or used as a test question as required. If more test questions are needed the researcher or assistant begin again with the first example above. The script below is written assuming that 6 more examples were given, 3 presented as test scenarios/practice rounds, i.e., the subjects are asked questions about the amounts the subjects would take home. The 11 examples/tests -5 above, 6 below - cover the full set of possible choices for Player 1.]

1. Here is the $\$ 10$ given to Player 2. Imagine that Player 1 chooses to leave $\$ 9$ to Player 2. Then, Player 2 will go home with $\$ 9$ and Player 1 will go home with $\$ 1$ $(\$ 10$ minus $\$ 9$ equals $\$ 1$ ).

2. Here is another example. Imagine that Player 1 chooses to leave $\$ 2$ to Player 2 . Then, Player 2 will go home with $\$ 2$ and Player 1 will go home with $\$ 8$ (\$10 minus $\$ 2$ equals $\$ 8)$.

3. Here is another example. Imagine that Player 1 chooses to leave $\$ 5$ to Player 2. Then, Player 2 will go home with $\$ 5$ and Player 1 will go home with $\$ 5$ ( $\$ 10$ minus $\$ 5$ equals $\$ 5)$.

4. Here is another example. Imagine that Player 1 chooses to leave $\$ 7$ to Player 2. Then, Player 2 will go home with $\$ 7$ and Player 1 will go home with $\$ 3$ (\$10 minus $\$ 7$ equals $\$ 3)$.

5. Here is another example. Imagine that Player 1 chooses to leave zero to Player 2. Then, Player 2 will go home with zero and Player 1 will go home with $\$ 10(\$ 10$ minus zero equals $\$ 10)$.

[The experimenter and assistants hand out two envelopes for each subject. Each envelope features the subject's ID. The two envelopes are of different color. Moreover, Player 1's [2's] envelope has a 1 [2] written on it.]

We will now practice the task together. You will first practice the task as Player 2. You have been handed two envelopes. The blue [or other color] one with 10 paper slips in it is the one that determines Player 2's payment. The other envelope, the yellow [or other color] one, is empty and the paper slips you put in it will determine the payment to Player 1. As we work through the following examples, please put the paper slips into the empty envelope as indicated by the examples. We will walk around the room to check if 
your allocation matches the one from the example. This is important, because it allows us to make sure that everyone understands the task and how to make the decision.

Here are some more examples [The experiment assistants go around the room to check that subjects correctly place the paper slips into the envelopes. The experimenter explains the task again if mistakes are discovered]:

1. Imagine that Player 1 chooses to leave $\$ 10$ to Player 2. Please place the paper slips into the blue envelope corresponding to this decision. How much will Player 2 go home with? And how much will Player 1 go home with? [Player 2 will go home with $\$ 10$ and Player 1 will go home with zero (\$10 minus $\$ 10$ equals zero).]

2. Here is another example. Imagine that Player 1 chooses to leave $\$ 4$ to Player 2 . Please place the paper slips into the blue envelope corresponding to this decision. How much will Player 2 go home with? And how much will Player 1 go home with? [Player 2 will go home with $\$ 4$ and Player 1 will go home with $\$ 6$ (\$10 minus $\$ 4$ equals \$6).]

3. Here is another example. Imagine that Player 1 chooses to leave $\$ 6$ to Player 2. Please place the paper slips into the blue envelope corresponding to this decision. How much will Player 2 go home with? And how much will Player 1 go home with? [Player 2 will go home with $\$ 6$ and Player 1 will go home with $\$ 4$ ( $\$ 10$ minus $\$ 6$ equals \$4).]

4. Suppose that Player 1 chooses to leave $\$ 1$ to Player 2 . In this case, how much will Player 1 go home with? [\$9] And how much will Player 2 go home with? [\$1]

5. Now try this one. Suppose that Player 1 chooses to leave $\$ 8$ to Player 2. Please place the paper slips into the blue envelope corresponding to this decision. In this case, how much will Player 1 go home with? [\$2] And how much will Player 2 go home with? [\$8].

6. Now try this one. Suppose that Player 1 chooses to leave $\$ 3$ to Player 2. Please place the paper slips into the blue envelope corresponding to this decision. In this case, how much will Player 1 go home with? [\$7]. And how much will Player 2 go home with? [\$3].

- [Before each session, the order of rounds is randomly determined] You will all perform one round as Player 1 and one round as Player 2. You will first perform the task as Player 1 [or 2, depending on randomization], and then perform the task as Player 2 [or 1].

- We don't know yet whether you will be paid for this task, nor whether you will be paid for your decisions as Player 1 or as Player 2. How will we choose whether to pay you for this task, and whether to pay you as Player 1 or Player 2? After we have finished performing all the tasks, we will first draw a number from the hat [show again numbers and hat] to determine which task will be paid. If we draw the 
number 1 from the hat, then it means that this task is the one selected to be paid. If so, we will toss a coin: if heads come up then you will be paid as Player 1; if tails come up, we will pay you as Player 2.

[For Player 1s] You will now perform the task as Player 1. You have been handed two envelopes. The blue [or other color] one with 10 paper slips in it is the one that determines Player 2's payment. The other envelope, the yellow [or other color] one, is empty and the paper slips you put in it will determine your payment. Please put the paper slips you want to allocate to yourself in the empty envelope. Please make sure your choice is not observed by others in the room. You must now wait while the rest of the players, finish performing the task. [If Player 1 is selected to be the first role to be played] Then we will play the second round of this task, where you are Player 2.

[The experimenter and assistants collect the envelopes.]

[For Player 2s] You will now perform the task as Player 2. Player 1 in the other room who has been matched with you has left you with a sum of money. After we finish performing all the activities, if this task and the role of Player 2 is the one selected to be paid I will pay you what Player 1 has left you with.

We will now perform another task/We will now take a break. [Researcher's name] will pay you for this task [point to the pile of envelopes to demonstrate the amount] after we finish all the tasks, if this task is the one selected to be paid.

\section{Instructions for ultimatum game (Task 4)}

We are now ready to begin another/the first task. Let me remind you that you may not ask questions or talk while you are here in the group. If you have any questions, you may raise your hand and I (the enumerator) or my assistant(s) will come answer your question privately. [If this is not the first task: This is NOT the same task that you just played, so be sure to listen to the instructions carefully.]

- This task is performed by pairs of individuals. Each pair is made up of a Player 1 and a Player 2. We will play two rounds of this task.

- Each of you will perform this task with someone from the other room.

- Who your partner will be depends on the color of the card you drew earlier, as I will explain to you shortly.

- [researcher's name] will provide $\$ 10$ to Player 1 in each pair of players..

- Player 1 decides how to divide this money between him or herself and Player 2. Player 1 must allocate between $\$ 0$ and $\$ 10$ to himself, leaving the rest for Player 2 .

- Before hearing the offer made to them by Player 1, Player 2 has to state whether he or she would accept or reject each of the possible offers between $\$ 0$ and $\$ 10$ that Player 1 could have made. 
- If Player 2 has stated that he or she would accept Player 1's offer, then Player 2 gets the amount of the offer and Player 1 gets the remainder. If Player 2 has stated that he or she would reject Player 1's offer, then Player 1 and Player 2 receive no money for this task.

Who will be your partner in this task? You remember that earlier we asked you to draw a card. Half of you drew yellow cards, the other half drew green cards. Your partner for this task is determined by the color of the card you drew.

- Those of you who drew a green card will be paired with a stranger in the other room. None of you will know exactly with whom you are paired. Only [researcher's name] knows who is matched with whom, and she/he will never tell anyone. [If this is not the first task: Your partner in this task is the same as the one in the previous task.]

- Those of you who drew a yellow card will be paired with their spouse in the other room.

Do you have questions on who your partner will be in this task? If you have questions, please raise your hand and I will come to you to answer your question privately.

[If this is not the first task: Your partner for this task is the same as the one for the previous task(s). That is, for those of you who drew a green card, your partner will be the same stranger in the other room that was paired with you in the previous task(s), while for those of you who drew a yellow card, your partner will be your spouse in the other room.]

We will now run through 5 examples to show you how the task might be performed:

[Notes: the researchers and assistants work through the examples and test questions with paper slips, each representing a 100 Rs note, on a flat surface with a line drawn on it demarcating the areas assigned to Players 1 and 2. Each of the examples presented below is presented either as an example or used as a test question as required. If more test questions are needed the researcher or assistant begin again with the first example above. The script below is written assuming that 6 more examples were given, 3 presented as test scenarios/practice rounds, i.e., the subjects are asked questions about the amounts the subjects would take home. The 11 examples/tests -5 above, 6 below - cover the full set of possible choices for Player 1.]

1. Here is the first example. Imagine that Player 1 offers $\$ 9$ to Player 2. Now, before hearing about this, Player 2 has stated that he would reject an offer of $\$ 9$ from Player 1. (Player 2 has also stated whether he would accept or reject all the other possible offers that Player 1 might have made, but we will not worry about that now.) Because Player 2 said he would reject $\$ 9$, Player 1 goes home with nothing and Player 2 goes home with nothing. 
2. Here is another example. Imagine that Player 1 offers $\$ 9$ to Player 2. Now, before hearing about this, Player 2 has stated that he would accept an offer of $\$ 9$ from Player 1. (Player 2 has also stated whether he would accept or reject all the other possible offers that Player 1 might have made, but we will not worry about that now.) In this case, Player 1 goes home with $\$ 1$ ( $\$ 10$ minus $\$ 9$ equals $\$ 1)$ and Player 2 goes home $\$ 9$.

3. Here is another example. Imagine that Player 1 offers $\$ 2$ to Player 2 . Now, before hearing about this, Player 2 has stated that he would accept an offer of $\$ 2$ from Player 1. (Player 2 has also stated whether he would accept or reject all the other possible offers that Player 1 might have made, but we will not worry about that now.) Because Player 2 said he would accept this offer, Player 1 goes home with $\$ 8$ $(\$ 10$ minus $\$ 2$ equals $\$ 8)$, and Player 2 goes home with $\$ 2$.

4. Here is another example. Imagine that Player 1 offers $\$ 2$ to Player 2. But now, before hearing about this, Player 2 has stated that he would reject an offer of $\$ 2$ from Player 1. (Player 2 also stated whether he would accept or reject each of the other possible offers that Player 1 could have made, but we will not worry about that now.) In this case, Player 1 goes home with nothing, and Player 2 also goes home with nothing.

5. Here is another example. Imagine that Player 1 offers $\$ 5$ to Player 2. Now, before hearing about this, Player 2 has stated that he would reject an offer of $\$ 5$ from Player 1. (Player 2 has also stated whether he would accept or reject all the other possible offers that Player 1 could have made, but we will not worry about that now.) Because Player 2 said he would reject an offer of $\$ 5$ from Player, Player 1 goes home with nothing and Player 2 goes home with nothing.

6. Here is another example. Imagine that Player 1 offers $\$ 5$ to Player 2. Now, before hearing about this, Player 2 has stated that he would accept an offer of $\$ 5$ from Player 1. (Player 2 has also stated whether they would accept or reject all the other possible offers that Player 1 could have made, but we will not worry about that now.) In this case, Player 1 goes home with $\$ 5$ (\$10 minus $\$ 5$ is $\$ 5)$ and Player 2 goes home with $\$ 5$.

7. Here is another example. Imagine that Player 1 offers $\$ 7$ to Player 2 . Now, before hearing about this, Player 2 has stated that he would accept an offer of $\$ 7$ from Player 1. (Player 2 has also stated whether he would accept or reject all the other possible offers that Player 1 could have made, but we will not worry about that now.) Because Player 2 said he would accept an offer of $\$ 7$, Player 1 goes home with $\$ 3$ ( $\$ 10$ minus $\$ 7$ equals $\$ 3$ ). And Player 2 goes home with $\$ 7$.

8. Here is another example. Imagine that Player 1 offers $\$ 7$ to Player 2. But now, before hearing about this, Player 2 has stated that he would reject an offer of $\$ 7$ from Player 1. (Player 2 has also stated whether he would accept or reject all the other possible offers that Player 1 might have made, but we will not worry about 
that now.) In this case, Player 1 goes home with nothing, and Player 2 goes home with nothing.

9. Here is another example. Imagine that Player 1 offers $\$ 0$ to Player 2. Now, before hearing about this, Player 2 has stated that he would accept an offer of $\$ 0$ from Player 1. (Player 2 has also stated whether he would accept or reject all the other possible offers that Player 1 could have made, but we will not worry about that now.) Because Player 2 said he would accept $\$ 0$ from Player 1, Player 1 goes home with $\$ 10$ ( $\$ 10$ minus zero is $\$ 10$ ) and Player 2 goes home with nothing.

10. Here is another example. Imagine that Player 1 offers $\$ 0$ to Player 2. But this time, before hearing about this offer, Player 2 has stated that he would reject an offer of $\$ 0$ from Player 1. (Player 2 has also stated whether he would accept or reject all the other possible offers that Player 1 could have made, but we will not worry about that now.) In this case, Player 1 goes home with nothing and Player 2 goes home with nothing.

[The experimenter and assistants hand out two envelopes for each subject. Each envelope features the subject's ID. The two envelopes are of different color. Moreover, Player 1's [2's] envelope has a 1 [2] written on it.]

We will now practice the task together.

To practice the round of the task in which you have the role of Player 1, you have been handed two envelopes. The yellow [or other color] one with 10 paper slips in it is the one that determines what Player 1's proposes to keep for him or herself. The other envelope, the blue [or other color] one, is empty and the paper slips you put in it will determine the offer you make to Player 2. As we work through the following examples, please put the paper slips into the empty envelope as indicated by the examples. We will walk around the room to check if your allocation matches the one from the example. This is important, because it allows us to make sure that everyone understands the task and how to make the decision.

Here are some more examples [The experiment assistants go around the room to check that subjects correctly place the paper slips into the envelopes. The experimenter explains the task again if mistakes are discovered]:

1. Imagine that Player 1 offers $\$ 10$ to Player 2. Now, before hearing about this, Player 2 has stated that he would reject an offer of $\$ 10$ from Player 1 . Player 2 has also stated whether he would accept or reject all the other possible offers that Player 1 could have made, but we will not worry about that now. Then Player 1 goes home with nothing and Player 2 goes home with nothing.

2. Imagine now that Player 1 offers $\$ 10$ to Player 2. But this time, before hearing about this, Player 2 has stated that he would accept an offer of $\$ 10$ from Player 1. Player 2 has also stated whether he would accept or reject all the other possible offers that Player 1 could have made, but we will not worry about that now. Then 
Player 1 goes home with nothing ( $\$ 10$ minus $\$ 10$ equals zero (nothing)) and Player 2 goes home with $\$ 10$.

3. Imagine that Player 1 offers $\$ 4$ to Player 2. Now, before hearing about this, Player 2 has stated that he would accept an offer of $\$ 4$ from Player 1 . Player 2 has also stated whether he would accept or reject all the other possible offers that Player 1 could have made, but we will not worry about that now. Then, Player 1 goes home with $\$ 6$ ( $\$ 10$ minus $\$ 4$ equals $\$ 6)$. And Player 2 goes home with $\$ 4$.

4. Imagine again that Player 1 offers $\$ 4$ to Player 2. Now, before hearing about this, Player 2 has stated that he would reject an offer of $\$ 4$ from Player 1 . Player 2 has also stated whether he would accept or reject all the other possible offers that Player 1 could have made, but we will not worry about that now. Then, Player 1 goes home with nothing. And, Player 2 goes home with nothing.

5. Imagine that Player 1 offers $\$ 6$ to Player 2. Now, before hearing about this, Player 2 has stated that he would reject an offer of $\$ 6$ from Player 1 . Player 2 has also stated whether he would accept or reject all the other possible offers that Player 1 could have made, but we will not worry about that now. Then Player 1 goes home with nothing and Player 2 goes home with nothing.

6. Imagine that Player 1 offers $\$ 6$ to Player 2. Now, before hearing about this, Player 2 has stated that he would accept an offer of $\$ 6$ from Player 1 . Player 2 has also stated whether he would accept or reject all the other possible offers that Player 1 could have made, but we will not worry about that now. Then Player 1 goes home with $\$ 4$ ( $\$ 10$ minus $\$ 6$ equals $\$ 4$ ). And Player 2 goes home with $\$ 6$.

Test question formats:

7. Suppose that Player 1 offers $\$ 1$ to Player 2 and that, before hearing about this, Player 2 has stated that he would accept an offer of $\$ 1$. In this case, how much will Player 1 go home with? [\$9] And how much will Player 2 go home with? [\$1].

8. And what if, before hearing about this, Player 2 has stated that he would reject an offer of $\$ 1$. In this case, how much will Player 1 go home with? [nothing] And how much will Player 2 go home with? [nothing]

9. Now try this one. Suppose that Player 1 offers $\$ 8$ to Player 2 and that, before hearing about this, Player 2 has stated that he would accept an offer of $\$ 8$. In this case, how much will Player 1 go home with? [\$2] And how much will Player 2 go home with? [\$8].

10. And what if, before hearing about this, Player 2 has stated that he would reject an offer of $\$ 8$. In this case, how much will Player 1 go home with? [nothing] And how much will Player 2 go home with? [nothing]

11. Now try this one. Suppose that Player 1 offers $\$ 3$ to Player 2 and that, before hearing about this, Player 2 has stated that he would reject an offer of $\$ 3$. In this 
case, how much will Player 1 go home with? [\$0] And how much will Player 2 go home with? [\$0]

12. And what if, before hearing about this, Player 2 has stated that he would accept an offer of $\$ 3$. In this case, how much will Player 1 go home with? [\$7] And how much will Player 2 go home with? [\$3]

To practice the round of the task in which you have the role of Player 2, you have been handed a decision sheet. The decision sheet shows you the 11 possible allocations that Player 1 can offer to Player 2. For each possible allocation, Player 2 has to decide whether he would accept that offer or not. If an offer is accepted, Player 1 and Player 2 are paid according to the corresponding allocation. If an offer is not accepted, then both players are paid 0 for this task. Player 2 decides whether to accept or reject an offer by ticking the yes or no box next to the offer.

Now please practice the round of the task in which you have the role of Player 2 by filling out the decision sheet, accepting or rejecting each possible offer made by Player 1 . We will walk around the room to check if you have any problems filling out the decision sheet. This is important, because it allows us to make sure that everyone understands the task and how to make the decision.

- [Before each session, the order of rounds is randomly determined] You will all perform one round as player 1 and one round as player 2. You will first perform the task as Player 1 [or 2, depending on randomization], and then perform the task as Player 2 [or 1].

- We don't know yet whether you will be paid for this task, nor whether you will be paid for your decisions as Player 1 or as Player 2. How will we choose whether to pay you for this task, and whether to pay you as Player 1 or Player 2? After we have finished performing all the tasks, we will first draw a number from the hat [show again numbers and hat] to determine which task will be paid. If we draw the number 1 from the hat, then it means that this task is the one selected to be paid. If so, we will toss a coin: if heads come up then you will be paid as Player 1; if tails come up, we will pay you as Player 2.

[For Player 1s] You will now perform the task as Player 1. You have been handed two envelopes. The yellow [or other color] one with 10 paper slips in it is the one that determines what you propose to keep for yourself. The other envelope, the blue [or other color] one, is empty and the paper slips you put in it will determine the offer you make to Player 2. Please put the paper slips you want to give to player to the empty envelope. Please make sure your choice is not observed by others in the room. You must now wait while the rest of the players finish performing the task. [If Player 1 is selected to be the first role to be played] Then we will play the second round of this task, where you are Player 2.

[The experimenter and assistants collect the envelopes.] 
[For Player 2s] You are a Player 2. Player 1 has allocated a sum of money to you. This money is in an envelope filled by someone in the other room. Before you know Player 1's offer to you, tell me for each possible offer Player 1 could make whether you would accept or reject it [ Hand subjects a sheet with different possible offer and have them select the ones they will accept and those they will reject. Each decision sheet is marked with the subject ID]. These decisions will determine what you actually receive once we see what Player 1 has offered you. Please note that you will not get a chance to change your mind after the envelope has been handed over. [Occasionally, when it seemed necessary, the players were given the following reminder...] Remember that Player 1's offer is already in an envelope. Nothing you decide now can change what is in it.

Now please make your decisions by filling out the decision sheet, accepting or rejecting each possible offer made by Player 1. Then fold the decision sheet in half, so that nobody can see your choices, and we will come to collect them.

[The experimenter and assistants collect the decision sheets, which depict graphically the following allocations and questions:

1. If Player 1 offered you $\$ 10$ and kept $\$ 0$ for him or herself would you accept or reject?

2. If Player 1 offered you $\$ 9$ and kept $\$ 1$ for him or herself would you accept or reject?

3. If Player 1 offered you $\$ 8$ and kept $\$ 2$ for him or herself would you accept or reject?

4. If Player 1 offered you $\$ 7$ and kept $\$ 3$ for him or herself would you accept or reject?

5. If Player 1 offered you $\$ 6$ and kept $\$ 4$ for him or herself would you accept or reject?

6. If Player 1 offered you $\$ 5$ and kept $\$ 5$ for him or herself would you accept or reject?

7. If Player 1 offered you $\$ 4$ and kept $\$ 6$ for him or herself would you accept or reject?

8. If Player 1 offered you $\$ 3$ and kept $\$ 7$ for him or herself would you accept or reject?

9. If Player 1 offered you $\$ 2$ and kept $\$ 8$ for him or herself would you accept or reject?

10. If Player 1 offered you $\$ 1$ and kept $\$ 9$ for him or herself would you accept or reject?

11. If Player 1 offered you $\$ 0$ and kept $\$ 10$ for him or herself would you accept or reject?]

We will now perform another tasks/We will now take a break. [Researcher's name] will pay you for this task [point to the pile of envelopes to demonstrate the amount] after we finish all the tasks, if this task is the one selected to be paid. 


\section{Instructions for Norm Elicitation game (Task 5)}

For this task, I will read to you descriptions of a series of situations. These descriptions correspond to situations in which one person, a woman, must make a decision. For each situation, you will be given a description of the decision faced by the woman. After I read to you the description of the decision, I will describe a choice that the woman might have made, and you should decide whether making that choice would be "socially appropriate" or "socially inappropriate" . or By socially appropriate, we mean behavior that is consistent with moral or proper behavior, that is, behavior that most people agree is the "correct" or "moral" thing to do. Another way to think about what we mean is that, if someone were to make a socially inappropriate choice, then someone observing the person's behavior might think poorly of that person or even get angry at that person.

In each of your responses, we would like you to answer as truthfully as possible, based on your opinions of what constitutes socially appropriate or socially inappropriate behavior.

To give you an idea of how the experiment will proceed, we will go through an example and show you how you will indicate your responses. I will now read to you an example of a situation. These cards that I am holding illustrate the situation and the decision sheet. [Experimenter illustrates the situation using a vignette, to make it easier for subjects to understand the situation].

Someone is at a local grocery store. While there, the person notices that someone has left a wallet/bag on the counter. How appropriate would it be to take the wallet for yourself?

If this were the situation we asked you about in the study, you would indicate the extent to which you believe taking the wallet would be "socially appropriate" or "socially inappropriate" . Recall that by socially appropriate we mean behavior that most people agree is the "correct" or "moral" thing to do.

You should indicate your choice by filling the decision sheet [Hold up a reproduction of the decision sheet, where the answers are pictured using smiley faces/thumbs up or down]. As you can see, the decision sheet has four symbols on it:

- 2 thumbs down, corresponding to "very socially inappropriate"

- 1 thumb down, corresponding to "somewhat socially inappropriate"

- 1 thumb up, corresponding to "somewhat socially appropriate"

- and 2 thumbs up, corresponding to "very socially appropriate".

This is to help you recognize and remember what each of these options mean.

For example, suppose you thought that taking the wallet was very socially inappropriate. Then, you would indicate your response by selecting the last symbol, the one with the two thumbs down on the decision sheet. 
Are there any questions about this example situation or about how to indicate your responses? I will now read to you several situations, all dealing with decisions that a woman might have to make. I will illustrate these situations using vignettes. For each of the choices, I would like you to think whether making that choice is very socially inappropriate, somewhat socially inappropriate, somewhat socially appropriate, or very socially appropriate for a woman to make. To indicate your response, you would place a check mark on the corresponding symbol on the decision sheet [Hold up reproduction of decision sheet again].

How will you get paid for this task? If this task is the one selected to be paid, we will pay you Rs 250 for each of your answers that matches the answer of someone in the other room, in addition to your participation fee. For instance, suppose the example situation above is part of this task, and this task is selected to be paid.

- Suppose your response was "somewhat socially appropriate,". Then you will receive Rs 250 for this question if the answer given by the person in the other room is also "somewhat socially appropriate".

- Suppose your response was "socially inappropriate". Then you will receive Rs 250 for this question if the answer given by the person in the other room is also "socially inappropriate".

Otherwise you would receive only the Rs 1000 participation fee.

Who is the person in the other room, whose answers is compared to your to determine your earnings from this task? It is a different person for each different question. We will explain exactly who this person is when we present each situation.

Do you have any questions? If you have any questions, please raise your hand and wait for the experimenter to come to you.

\section{Question 1}

We will now describe the first situation.

Imagine that a woman can buy a scarf for herself using money she has been given by her parents as a gift. She wants to buy a scarf. Her husband offers to go and buy the scarf for her. She can let the husband go shopping for her, or she can go herself. She decides to go shopping by herself.

How appropriate do you think it is for the woman to buy the scarf by herself? Do you think her decision is very socially appropriate, somewhat socially appropriate, somewhat socially inappropriate or very socially inappropriate? Tick the corresponding box in the answer sheet in front of you.

You will receive Rs 250 for this question only if your answer matches that of a randomly selected person in the other room, different from your spouse. 


\section{Question 2}

I will now tell you about another situation, also dealing with a decision that a woman might have to make. Again, I would like you to think whether making that choice is very socially inappropriate, somewhat socially inappropriate, somewhat socially appropriate, or very socially appropriate. To indicate your response, you would place a check mark on the corresponding symbol on the decision sheet.

Imagine that a woman is running a business from her home. At the end of the month, she has some profits to re-invest. She can ask her husband to re-invest them for her, or she can choose herself, without consulting him. She decides to re-invest her profits in what she thinks best, without consulting her husband.

How appropriate do you think it is for the woman to make the investment decision on her own? Do you think her decision is very socially appropriate, somewhat socially appropriate, somewhat socially inappropriate or very socially inappropriate? Tick the corresponding box in the answer sheet in front of you.

You will receive Rs 250 for this question only if your answer matches that of a randomly selected person in the other room, different from your spouse.

\section{Question 3}

We will now describe another situation. This situation is the same as the first one, only this time your payment for this question is determined in a different way, so pay attention.

Imagine that a woman can buy a piece of clothing for herself, using money she has been given by her parents as a gift. She wants to buy a scarf. Her husband offers to go and buy the scarf for her. She can let the husband go shopping for her, or she can go herself. She decides to go shopping by herself.

How appropriate do you think it is for the woman to buy the scarf by herself? Do you think her decision is very socially appropriate, somewhat socially appropriate, somewhat socially inappropriate or very socially inappropriate? Tick the corresponding box in the answer sheet in front of you.

You will receive Rs 250 for this question only if your answer matches that of your spouse in the other room. So note the difference with respect to the first question: there, you would get paid if your answer matched that of a randomly selected person in the other room, different from your spouse. Now, you will get paid for this question if your answer matched that of your spouse in the other room.

\section{Question 4}

We will now describe another situation. This situation is the same as the second one, only this time your payment for this question is determined in a different way, so pay attention. 
Imagine that a woman is running a business from her home. At the end of the month, she has some profits to re-invest. She can ask her husband to re-invest them for her, or she can choose herself, without consulting him. She decides to re-invest her profits in what she thinks best, without consulting her husband.

How appropriate do you think it is for the woman to make the investment decision on her own? Do you think her decision is very socially appropriate, somewhat socially appropriate, somewhat socially inappropriate or very socially inappropriate? Tick the corresponding box in the answer sheet in front of you.

You will receive Rs 250 for this question only if your answer matches that of your spouse in the other room. So note the difference with respect to the first question: there, you would get paid if your answer matched that of a randomly selected person in the other room, different from your spouse. Now, you will get paid for this question if your answer matched that of your spouse in the other room.

\section{Final Instructions}

We have now completed all the tasks. We will now draw one number from this bag to determine which task will be paid [ask one participant to draw a number in front of all other subjects. If task 2, 3 or 4 is drawn, then toss a coin to determine whether they will be paid as Player 1 or 2].

We will now call you one by one to give you your payment. Then you are free to leave.

Thank you all very much for participating in today's activities! Please don't hesitate to ask us questions if you have doubts before you leave. 


\section{A2. Second Laboratory Experiment}

The study population differs from that of LAB1, in that the experiments were carried out in rural villages in Faisalabad, Punjab (Pakistan). This sample represents agriculturedependent, low-income households. We conducted 30 lab-in-field sessions in 15 rural villages across Faisalabad. At the time of invitation, all couples were given basic information on the experiment and details on the time, date, and expected duration of the session (2-3 hours). ${ }^{20}$

Each married couple was also informed of the compensation and expected earnings from participation: a participation fee of Rs. 500 (\$5) (i.e., Rs. 1000 per couple), provided that they stayed for the entire duration of the session; and additional earnings of at most Rs. $1000(\$ 10)$. Informed consent was collected from all participants before the start of each session, and payments were made individually and privately at the end. Individual surveys were conducted at the end of the experiment session. The sequence of events at participant arrival was as follows:

\section{Sequence of events during experiment sessions}

- Upon arrival, subject pairs are assigned to their respective gender-specific room.

- No contact is allowed between subjects during the entire experiment. Men and women are seated in separate rooms. Respondents in the same room are seated in compartments separated by cardboard sheets. Contact between subjects in the same room is strongly discouraged but not impossible.

- Each subject in the stranger matching treatment is assigned a partner; this is done without replacement, which means that all subjects in the stranger treatment have one partner and one partner only; by construction, the partner is not the household member they came with

- Subjects in each session played each task one with the spouse and once with a 'stranger' as the partner. The stranger could be of three types - stranger of the opposite gender, stranger of the same gender, or paired with a 'computer' that uses numbers generated from a random number generating program. 'Strangers' were randomly allocated at the session level as follows:

\begin{tabular}{ll} 
Stranger type & Session No. \\
\hline Stranger: opposite gender & $3,10,11,12,13,15,16,17,18,28$ \\
Stranger: same gender & $1,2,19,20,21,22,24,26,29,30$ \\
Computer & $5,6,7,8,9,14,23,25,27$
\end{tabular}

\footnotetext{
${ }^{20}$ Each experimental session was held in a central location, at less than 10 minutes drive via public transport
} 
- Dictator task is always conducted first, with individuals playing as Player 1 or Player 2 in random order. The dictator task has two rounds - one played with the spouse as a partner, one played with a 'stranger'. In each round, Player 1 allocates a share of a $\operatorname{Rs} 1000(\approx \$ 10)$ endowment received from the research team to Player 2 . The order of rounds is randomised as follows:

\begin{tabular}{ll} 
Order of round & Session No. \\
\hline Spouse round, then stranger round & $1,2,5,9,10,12,14,15,16,17$, \\
& $18,19,20,23,24,26,27,29$ \\
Stranger round, then spouse round & $3,4,6,7,8,11,13,21,22$,
\end{tabular}

$25,28,30$

- Preferences task is always played second. The task is played twice, once with the spouse as a partner and once with a stranger as the partner, with stranger type randomised on at a session level as summarized above. The following steps are taken in each round:

1. Participants are given a menu of three food - biryani, chicken tikka boti and zarda (sweet rice), and three drink item - water, soft drink (coke), rooh afza (local sweet drink), to choose from for their lunch at the end of the session. Participants were asked to both highlight one food and one drink item they would like to consume and cross out the food and drink items that they do not want to consume.

2. Participants are asked to guess their partner's preferences, earning Rs 50 if they guess either the food or the drink correctly and Rs 100 if they guess both.

3. Participants are asked to select a food and drink item for their partners to consume at lunch. Half of the subjects are randomly assigned to the information treatment, done by pair ID codes assigned at the start of the treatment. [This step is not conducted with those paired with a 'computer'.]

4. Participants are asked to select from two options: either consume the food and drink the partner has selected for you OR pay a nominal cost (Rs 5/20/50, randomly drawn out) from their participation fee to consume their own choice for sure.

5. One round - spouse or stranger pairing, will be selected at random and participant's final choice will be implemented for serving lunch at the end of the session.

- A norms elicitation task is conducted. Respondents are asked to mark hypothetical decisions regarding spouse and others, against a scale of "appropriateness". The order of questions is randomised.

- Participants are served lunch.

- Individual surveys are conducted 
- One round of the dictator task is randomly selected for payment via a coin toss. Participants receive a fixed participation fee + earnings from the dictator task. 
We reproduce below the full protocol used in the experiment. The text below was read in Urdu to all participating subjects during the experiment. Square brackets [] contain instructions for enumerators.

\section{Introduction to the community}

Thank you all for taking the time to be here today. My name is [experimenter's name], and I will be facilitating this meeting. Helping me today, we also have here [introduce everyone]. Before we start, we would like to remind you that we will give you compensation for your time, if you decide to participate. This _--- is not a part of the activity and is yours to keep. We will give you _-_- at the end of the meeting, together with any other sum you will earn through the activities.

Purpose: Today, we will conduct several activities in your community. The purpose of these activities is to better understand how people in this community make decisions. The results of the study may eventually be published or part of a book. It is not part of a development project of any sort. Your community and other communities around Faisalabad were selected to participate from a large group of potential communities.

\section{Activities}

We will perform several tasks here today. For these activities, we will select 24 participants. In a moment, I will explain how we will select the participants. Before that, I want to make some general comments. The participants will be performing some tasks in exchange for real money that they will be able to take home. You should understand that this is not my money. It is money given to me by Lahore School, to use to conduct a research study. As we told you when we invited you to come here, the meeting may take 3 hours, so if you think you will not be able to stay that long without leaving please let us know now. [Couples who cannot stay for the length of the meeting should leave before they enter the lottery to participate. They do not get paid, as stated in the invitation] Those of you who cannot stay can leave now. Thank you all for taking the time to come today.

- We only need 24 individuals to participate in these tasks. Thus, unfortunately, not all of you will be able to participate.

- We will have a lottery to determine who will participate.

- To complete the lottery, we will take the coupon you came with today, which has your name on, and fold the coupon in half.

- Next, we will place your folded coupon of paper in this bag.

- This means that we need one coupon for each couple present here today. 
- We will then ask one of you to draw 12 pieces of paper from this bag containing your coupons.

- Those whose names will be drawn will stay here and participate in the tasks, while the others will go home.

- We will give another coupon to those of you who will not be drawn to participate today: this coupon will guarantee that you will participate, if you come to a future meeting

- When we give you this coupon, we will show you the dates of the future meetings, so that you can tell us when you would like to come again

Is this clear to everyone? Does anyone have any questions on how we will select the 24 participants?

[Set aside the people with the coupons, collecting the coupons from them. Then proceed with the random draw of names.]

Those of you, whose names have not been called, can leave now. Thank you all for taking the time to come today.

[Pay show up fee to all subjects who have to leave (hand out pre-prepared envelopes containing _-_- to each individual in the couple and have them sign a receipt). Then, after people have left, proceed]

We will now ask you to draw a nametag from this bag. This nametag will determine your ID for the activities. You are given an ID to preserve your anonymity: your name will not be kept anywhere in our records, only your ID.

\section{Consent}

- Before we begin, I will explain the basic activities we will do together, and the rules that we will follow.

- Read Consent Statement:

If you wish to participate, please say, "I do. If you do not wish to participate, please advise us. You will be free to leave then. You will not be able to stay in the activity $\operatorname{room}(\mathrm{s})$ if you do not wish to participate.

You will be matched with a partner for some of the tasks that you will perform today. We will explain more about your partner later.

We will now take all women to one room, and all men to another room. Please follow [Assistant's name] if you are a woman, or [Assistant's name] if you are a man.

[Take the selected participants into the rooms and have them sit. The Assistant directs each subject to her allocated seat.]

Welcome, and thank you again. 
- Before we proceed any further, let me stress something that is very important. Many of you were invited here without understanding very much about what we are planning to do today. If at any time you find that this is something that you do not wish to participate in for any reason, you are of course free to leave at anytime. If you do choose to leave, you won't be able to come back into the activity room(s) until everyone if finished performing all the activities.

- Before we start, please make sure your mobile phones are switched off, to avoid interruptions during the meeting.

- If you have heard about activities that have been conducted here in the past you should try to forget everything that you have been told. These are completely different tasks.

- Please also be advised, there are no right or wrong choices, so you should choose whatever you think is best for yourself and not look at your neighbor's choices. It is important to remember that not everyone will win the same amount in the task. Everyone will still receive the _--- payment for participation, regardless of how much you win in the task

- We are about to begin. It is important that you listen as carefully as possible to the instructions, because only people who understand the tasks will actually be able to perform them. I will run through some examples to make sure you understand.

- You cannot ask questions out loud or talk about the tasks with anyone else while we are here together.

- If you have questions at any time during the meeting, please raise your hand and ask, and we will come to you and answer them in private.

- I will read through a script to explain all the activities that we will perform here today. As you may know, these activities are conducted in other localities beside this one, so it is very important that people in every locality receive exactly the same information, and this is the reason why I must read from this script.

\section{NO TALKING}

- I will now say something very important. You cannot ask questions out loud or talk about the tasks with anyone else while we are here together.

- If you need to ask a question at any time, please raise your hand and I will come to you so I can answer your question privately.

- I will explain the tasks, do demonstrations, and let you practice the tasks before we perform them for real. These demonstrations and practices are to help you understand the rules and clarify any questions. 
- Please be sure that you obey these rules because it is possible for one person to spoil the tasks for everyone by talking in front of the group. If this happens, we will not be able to continue forward with the tasks today and you will not be paid for the tasks.

- Is this clear to everyone? Does anyone have any questions so far about what will go on today?

[If anyone asks a question out loud, explain again that all questions must be asked in private].

REAL PAYMENT

- In today's activities, you will have the opportunity to receive a cash payment. The amount that you will receive depends on your decisions and on the decisions of others. It also depends on what task is selected to be paid.

- Remember that at the end of all the activities, we will draw a number from a hat. That number will determine for which task you will be paid. This means that each task that you perform has the same chance of being selected to be paid.

- Remember also, that in addition to what you will earn from the activities, each of you will receive Rs 150 for participating in today's meeting. This money is yours, regardless of what happens during the activities. It will be paid to you in cash together with your earnings from the activities.

- It is real money, which you will be allowed to keep for yourself or do what you wish. This money will paid to you in cash at the end of the meeting.

- During the activities you will make your decisions using paper slips [show slips], each representing 100 Rs. These paper slips will be converted into cash when you get paid at the end of the meeting.

\section{CONFIDENTIALITY}

- Your decisions and your payment are private and confidential. Nobody, apart from a member of our team will know what you earned, and he/she will not tell anyone.

- We will put up these partitions between you every time you have to take a decision. You will make your decisions behind the partitions, so that nobody else can see what you decide.

\section{Instructions for dictator game, round 1 (Task 1)}

We are now ready to begin the first task. Let me remind you that you may not ask questions or talk while you are here in the group. If you have any questions, you may 
raise your hand and I (the enumerator) or my assistant(s) will come answer your question privately.

\section{INTRODUCTION}

- This task is performed by pairs of individuals. Each pair is made up of a Player 1 and a Player 2.

- Researcher [name] will provide Rs 1000 to Player 1 in each pair of players.

- Player 1 must decide how to divide this money between him or herself and Player 2. Player 1 must allocate between Rs 0 and the total Rs 1000 to Player 2.

- Player 2 takes home whatever Player 1 allocates to him or her, and Player 1 takes home whatever he or she does not allocate to Player 2.

- If spouse matching performed first: In this task, your spouse will be your partner.

- If stranger matching performed first: In this task, your partner will be the [stranger of the same gender/stranger of the opposite gender/computer $\hat{\mathrm{a}} €$ " as randomized for the session] you were paired with in the previous task.

- Notice, your partner will also be making a decision for the allocation of this money.

- This means that you will all perform one round as Player 1 and one round as Player 2. You will first perform the task as Player 1, and then perform the task as Player 2 .

- How will we choose whether to pay you for this task, and whether to pay you as Player 1 or Player 2? After we have finished performing all the tasks, we will first draw a number from the hat [show again numbers and hat] to determine which task will be paid. If we draw the number 1 from the hat, then it means that this task is the one selected for payment. If so, we will toss a coin: if heads come up then you will be paid as Player 1; if tails come up, we will pay you as Player 2.

- Is this clear to everyone? Please raise your hands if you have any questions and I will come and answer them privately.

We will now run through 5 examples to show you how the task might be performed.

[Notes: the researchers and assistants work through the examples and test questions with paper slips, each representing a Rs 100 note. They also take from and place the paper slips into two envelopes identical to the ones to be given to subjects, so as to demonstrate fully what subjects have to do. Each of the examples presented below is presented either as an example or used as a test question as required. If more test questions are needed the researcher or assistant begin again with the first example above. The script below is written assuming that 6 more examples were given, 3 presented as test scenarios/practice rounds, i.e., the subjects are asked questions about the amounts the subjects would take home. The 11 examples/tests, 5 above, 6 below, cover the full set of possible choices for Player 1.] 
1. Here is the Rs1000. Imagine that Player 1 chooses to allocate Rs900 to Player 2. Then, Player 2 will go home with Rs900 and Player 1 will go home with Rs100 (Rs1000 minus Rs900 equals Rs100).

2. Here is another example. Imagine that Player 1 chooses to allocate Rs200 to Player 2. Then, Player 2 will go home with Rs200 and Player 1 will go home with Rs800 (Rs1000 minus Rs200 equals Rs800).

3. Here is another example. Imagine that Player 1 chooses to allocate Rs500 to Player 2. Then, Player 2 will go home with Rs500 and Player 1 will go home with Rs500 (Rs1000 minus Rs500 equals Rs500).

4. Here is another example. Imagine that Player 1 chooses to allocate Rs700 to Player 2. Then, Player 2 will go home with Rs700 and Player 1 will go home with Rs300 (Rs1000 minus Rs700 equals Rs300).

5. Here is another example. Imagine that Player 1 chooses to allocate zero to Player 2. Then, Player 2 will go home with zero and Player 1 will go home with Rs1000 (Rs1000 minus zero equals Rs1000).

[The experimenter and assistants hand out two envelopes for each subject. Each envelope features the subject's ID. The two envelopes are of different color. Moreover, Player 1's] envelope has a 1 [2] written on it.]

We will now practice the task together. You will first practice the task as Player 1. You have been handed two envelopes. The red [or other color] one with 10 paper slips in it is the one that determines Player 1's payment. The other envelope, the white [or other color] one, is empty and the paper slips you put in it will determine the payment to Player 2. As we work through the following examples, please put the paper slips into the empty envelope as indicated by the examples. We will walk around the room to check if your allocation matches the one from the example. This is important; because it allows us to make sure that everyone understands the task and how to make the decision.

Here are some more examples [The experiment assistants go around the room to check that subjects correctly place the paper slips into the envelopes. The experimenter explains the task again if mistakes are discovered]:

1. Imagine that Player 1 chooses to allocate Rs1000 to Player 2. Please place the paper slips into the blue envelope corresponding to this decision. How much will Player 2 go home with? And how much will Player 1 go home with? [Player 2 will go home with Rs1000 and Player 1 will go home with zero (Rs1000 minus Rs1000 equals zero).]

2. Here is another example. Imagine that Player 1 chooses to allocate Rs400 to Player 2. Please place the paper slips into the blue envelope corresponding to this decision. How much will Player 2 go home with? And how much will Player 1 go home with? [Player 2 will go home with Rs400 and Player 1 will go home with Rs600 (Rs1000 minus Rs400 equals Rs600).] 
3. Here is another example. Imagine that Player 1 chooses to allocate Rs600 to Player 2. Please place the paper slips into the blue envelope corresponding to this decision. How much will Player 2 go home with? And how much will Player 1 go home with? [Player 2 will go home with Rs600 and Player 1 will go home with Rs400 (Rs1000 minus Rs600 equals Rs400).]

4. Suppose that Player 1 chooses to allocate Rs100 to Player 2. Please place the paper slips into the blue envelope corresponding to this decision. In this case, how much will Player 1 go home with? [Rs900] And how much will Player 2 go home with? [Rs100]

5. Now try this one. Suppose that Player 1 chooses to allocate Rs800 to Player 2. Please place the paper slips into the blue envelope corresponding to this decision. In this case, how much will Player 1 go home with? [Rs200] And how much will Player 2 go home with? [Rs800].

6. Now try this one. Suppose that Player 1 chooses to allocate Rs300 to Player 2. Please place the paper slips into the blue envelope corresponding to this decision. In this case, how much will Player 1 go home with? [Rs700]. And how much will Player 2 go home with? [Rs300].

We will now conduct the task for real. You will now perform the task as Player 1. Remember, your partner in this round is:

- If spouse matching performed first: your spouse

- If stranger matching performed first: the [stranger of the same gender/stranger of the opposite gender/computer as randomized for the session] you were paired with in the previous task.

You have been handed two envelopes. The yellow [or other color] one with 10 paper slips in it is the one that determines your payment. The other envelope, the blue [or other color] one, is empty and the paper slips you put in it will determine the payment to Player 2. Please put the paper slips you want to give to Player 2 in the empty envelope. Please make sure your choice is not observed by others in the room.

You must now wait while the rest of the players, finish performing the task. Then we will play the second round of this task, where you are Player 2. [The experimenter and assistants collect the envelopes.]

[For Player 2s] You will now perform the task as Player 2. As Player 2, you have no decision to make. Player 1 who has been matched with you has allocated a sum of money to you. After we finish performing all the activities, if this task and the role of Player 2 is the one selected to be paid I will pay you what Player 1 has allocated to you. 


\section{Instructions for dictator game, round 2}

We will now perform another task. This task is the same as the previous one, except that your partner for this task is:

- If spouse matching performed second: your spouse

- If stranger matching performed second: the [stranger of the same gender/stranger of the opposite gender/computer as randomized for the session] you were paired with in the previous task.

Again, you will all perform one round as Player 1 and one round as Player 2. You will first perform the task as Player 1, and then perform the task as Player 2.

How will we choose whether to pay you for this task, and whether to pay you as Player 1 or Player 2? After we have finished performing all the tasks, we will first draw a number from the hat [show again numbers and hat] to determine which task will be paid. If we draw the number 2 from the hat, then it means that this task is the one selected for payment. If so, we will toss a coin: if heads come up then you will be paid as Player 1; if tails come up, we will pay you as Player 2.

Do you have questions on the task? [If there are questions: repeat instructions from introduction of task 1, and provide examples as needed].

Let's play the task for real. You have been handed two envelopes. The yellow [or other color] one with 10 paper slips in it is the one that determines your payment. The other envelope, the blue [or other color] one, is empty and the paper slips you put in it will determine the payment to Player 2. Please put the paper slips you want to give to Player 2 in the empty envelope.

Please make sure your choice is not observed by others in the room.

You must now wait while the rest of the players, finish performing the task. Then we will play the second round of this task, where you are Player 2.

[The experimenter and assistants collect the envelopes.]

[For Player 2] You will now perform the task as Player 2. As Player 2, you have no decision to make. Player 1 who has been matched with you has allocated a sum of money to you. After we finish performing all the activities, if this task and the role of Player 2 is the one selected to be paid I will pay you what Player 1 has allocated to you.

\section{Instructions for preferences game (Task 2)}

We are now ready to begin with the second task. Let me remind you that you may not ask questions or talk while you are here in the group. If you have any questions, you may raise your hand and I (the enumerator) or my assistant(s) will come answer your question privately. Please be sure to listen to the instructions carefully. This is NOT the same task that you just performed, so be sure to listen to the instructions carefully. 
- This task is performed by pairs of individuals.

- Each of you will perform this task twice, once with your spouse (or your household member) and once with an anonymous partner.

[Enumerator: There are three types of anonymous partners. Each session will have only one kind. Please give instructions for the partner type according to the type specified for that session.]

- Stranger - other room treatment: You will be paired with a stranger in the other room i.e. of the opposite gender. None of you will know exactly with whom you are paired. Only [researcherâ€s name] knows who is matched with whom, and she/he will never tell anyone.

- Stranger - same room treatment: You will be paired with a person in this room i.e. another male/female. Only [researcherâ€s name] knows who is matched with whom, and she/he will never tell anyone.

- Computer treatment: You will be paired with the computer. This means that the partnerâ€s decisions will be the result of a random draw by the computer, which will appear on the computer screen and be communicated to the researcher.

Do you have questions on who your partner will be in this task? If you have questions, please raise your hand and I will come to you to answer your question privately.

The decisions that you will take as part of this task concern what you would like to have for lunch. We will be serving you lunch at the end of the session, to thank you for spending part of your day with us.

\section{PART 1:}

I have three different food items here today: biryani (savory), chicken tikka boti and zarda (sweet rice). I also have three different types of drinks: soft drink (coke), rooh afza and water. Before we begin this task, please have a look at these food items (without tasting) and select what kind of rice you would most like to eat and what you would like to drink at lunch today. Please circle the food item and drink you would most prefer to have for lunch today, and cross out the food item and drink that you would least prefer to have for lunch today. You cannot rank two items equally. Once you have had a look at the items, we will ask you record your ranking on the sheet we will provide you. Remember, you may get for lunch the items that you circle. Distribute a sheet with pictures of the 3 (or as many) food items] Does anyone have any questions? Please raise your hand and my assistant or I will come and address your query.

[Subjects should circle $=$ most preferred, cross-out=least preferred. The assistants collect the ranking sheets. While the experimenter proceeds with Part 2, the assistant(s) enters the rankings.]

ROUND 1: Spouse preferences (randomize order between spouse and anonymous): Your partner in this round is your family member, who you came with today. Your 
partner in the other room has also been asked to pick what food item and drink $\mathrm{s} / \mathrm{he}$ would like to have for lunch. We would like you to guess your partnerâ€s pick. We will now distribute a sheet, where you can write your guess. Circle what you guess is your partnerâ€s preferred food item and drink for lunch today. We will give you Rs. 50 for correctly guessing the food or drink ranked as most preferred by your partner and Rs 100 if you guess both food and drink item preferred by your partner correctly. This money will be paid to you at the end of all activities, on top of your other earnings from the other tasks.

[Distribute another sheet with pictures of the 2 food items and 3 drinks. Subjects should circle $=$ most preferred. The assistants collect the guessed partnerâ $€_{\mathrm{S}}$ ranking sheets. While the experimenter proceeds with Part 3, the assistant(s) enter the guessed rankings.]

PART 2 [KNOW PARTNERâ€S RANKING treatment only]: Now, we will distribute to you a sheet, containing the ranking given by your partner, capturing his or her own preferences for the 3 foods items and 3 drinks.

[The experimenter and assistants distribute to participants the partnerâ€ $€_{\mathrm{s}}$ ranking sheet. Provide this information to each participant with an odd number ID.]

PART 3: Now I would like for you to:

- Choose a food item and a drink for your partner to consume. It does not have to be the same items that you chose for yourself. [Say to KNOW PARTNERâ€S RANKING treatment individuals only:] It also need not be the items your partner selected for him/herself, if you know them.

- In the other room, your partner is being asked to do the same.

- Your preferred food and drink are what you circled earlier.

- Neither you nor your partner will be able to exchange the food item and drink you are given with anyone else.

Shall we begin? Does anyone have any questions? Please raise your hand and my assistant or I will come and address your query.

We will now distribute a decision sheet, where you can mark your choice of what food item and drink that you would like your PARTNER to consume

[Distribute a decision sheet, with space to record one choice for food and one choice for drink for the partner].

Please circle the food item and the drink that you would like your PARTNER to consume in the sheet of paper in front of you and fold it to let us know you are done. My assistants and I will come and collect your decision sheet.

ROUND 2- Anonymous partner preferences: 
We will now repeat the activities we performed in round 1, only with a different partner. Remember, your partner in this round is (Enumerator: please announce according to the partner specified for that session),

- Stranger other room treatment: a person sitting in the next room. We will never reveal to you who this person is, and we will never reveal to this person that you have been matched with them. This will be kept completely secret.

- Stranger other room treatment: a person sitting in this room. We will never reveal to you who this person is, and we will never reveal to this person that you have been matched with them. This will be kept completely secret.

- Computer treatment: the computer, whose decisions are determined by a program generating random numbers.

[Computer treatment] The computer generated a random ranking of the food items and drinks, selecting at random one most preferred food and drink and one least preferred food item and drink. We have recorded that ranking.

[Other matching treatments] Recall that in the previous round, we asked each participant to rank the food items and drinks from most preferred to least preferred. We have kept those rankings.

We now would like you to guess your partnerâ€s ranking. We will distribute a sheet, where you can write your guess. Circle what you guess is your partnerâ€s preferred food item and drink. We will give you Rs. 50 for correctly guessing the food item or drink ranked as most preferred by your partner and Rs 100 if you guess both food and drink item preferred by your partner correctly. This money will be paid to you at the end of all activities, on top of your earnings from the other tasks.

[Distribute another sheet with pictures of the 3 food items and three drinks. Subjects should circle $=$ most preferred, cross-out=least preferred. The assistants collect the guessed partnerâ $€_{\mathrm{s}}$ ranking sheets. While the experimenter proceeds with Part 3, the assistant(s) enter the guessed rankings. These guesses are compared with the actual partnerâ€s ranking at the end of the session, when computing the payments]

PART 3: Now I would like for you to:

- For STRANGER SAME or OTHER ROOM ONLY: Choose a food item and a drink for your partner to consume. It does not have to be the same items that you chose for yourself. [KNOW PARTNERâ€S RANKING treatment individuals only:] It also need not be the items your partner selected for him/herself, if you know them.

- Your partner is being asked to do the same.

- Your preferred food and drink are what you circled earlier.

- Neither you nor your partner will be able to exchange the food item and drink you are given with anyone else. 
Shall we begin? Does anyone have any questions? Please raise your hand and my assistant or I will come and address your query.

[For STRANGER SAME or OTHER ROOM ONLY:] We will now distribute a decision sheet, where you can mark your choice of what food item and drink that you would like your PARTNER to consume [Distribute a decision sheet, with space to record one choice for food and one choice for drink for the partner]. Please circle the food item and the drink that you would like your PARTNER to consume in the sheet of paper in front of you and fold it to let us know you are done. My assistants and I will come and collect your decision sheet.

\section{PART 4}

- We will now ask you to choose between two options: either you receive the food item and drink that your partner from round 1 or round 2 has picked for you; or you pay [Enumerator: this amount is randomized across sessions]. Rs. (5/20/50)from your show-up fee and get your own choice of food and drink. We will do this twice. First, we will first ask you to make this choice with your partner from round 1 , that is, the household member with whom you came/anonymous partner. Second, we will ask you to make this choice for the partner assigned to you in round 2. The person you came with will be asked to make similar decisions, but we will not reveal to that person or anyone else any of the choices you make.

- When you have made your choice for your partner in rounds 1 and 2, we will then select one of the two rounds at random and implement what you have decided. If the selected round is round 1, you will receive the food item and drink that your accompanying household member has selected for you, unless you agreed to pay Rs. $(5 / 20 / 50)$ from your show-up fee to receive your own choice. If the selected round is round 2, you will receive the food item and drink that your unknown partner has selected for you, unless you agreed to pay Rs. (5/20/50) from your show-up fee to receive your own choice.

- You will only need to pay Rs. (5/20/50) for the selected round. For instance, suppose that you selected to pay Rs. (5/20/50) to get your own choice only with the round 1 partner AND round 2 is selected. In this case, you will receive what the round 2 partner selected for you and you will pay nothing. Alternatively, if you selected to pay Rs. (5/20/50) for round 1 and round 2 partners, you will pay Rs. $(5 / 20 / 50)$ and you will receive your own choice for sure.

- We will not reveal to anyone the outcome of the coin toss that selects between your final decisions between round 1 and round 2 .

We will now call you one by one to the back of the room to record your final decisions in privacy.

[At individual meetings. The experimenter has two decision sheets in front of him: the one with the subjectâ€s own pick (face up) and the one with the round 1 partnerâ€s 
pick for him/her (face down, folded to conceal id)]. Here I have the sheet with your most preferred and least preferred food item and drink, and another sheet with what was selected for you by your partner from round 1 (your spouse). You can either choose to have what your partner picked for you, or you can give Rs. (5/20/50) from your show-up fee of Rs. 500 and have your own choice. What is your decision?

Enumerator: Write down Decision 1

Now I will tell you what your partner has picked for you. What do you think your partner has picked for you? Your partner picked _---- and ---- for you. Would you like to change your earlier decision?

Enumerator: Note revised decision as Decision 2

[Repeat explanation of options if necessary. Record decision for Round 1. ]

Now, I will ask you about Round 2, where you were matched to a random stranger. At the end we will toss a coin to decide whether we implement your decision for round 1 or round 2 .

[The experimenter now has two decision sheets in front of him: the one with the subjectâ€s own pick (face up), as before; and the one with the round 2 partnerâ€s pick for him/her (face down, folded to conceal id)] Here I have the sheet with your most preferred and least preferred food item and drink, and another sheet with what was selected for you by your randomly assigned partner from round 2. You can either choose to have what your partner picked for you, or you can give Rs. (5/20/50) from your show-up fee of Rs. 500 and have your own choice. What is your decision? [Enumerator: Please refer to the session randomization list to find out what the cost is for each participant.]

Enumerator: Write down Decision 3 (own or partner choice)

Now I will tell you what your partner has picked for you. What do you think your partner has picked for you? Enumerator: Note guess 2 of partnerâ€s choice of food item ---- and drink

Your partner picked _--- and _-_- for you. Would you like to change your earlier decision?

Enumerator: Note revised decision as Decision 4 (yes/no)

[Repeat explanation of options if necessary. Record decision for Round 2. ].

[Enumerator: If decision 2 and 4 are the same, then Skip the coin toss]. Coin toss: Now we will toss a coin to select between the 2 rounds of this task. If the coin toss falls on heads, we will implement your final decision for round 1. If the coin toss falls on tails, we will implement your final decision for round 2 .

Enumerator: Note outcome of coin toss.

Some of our team members will now prepare the food items based on the decisions. Meanwhile we will continue with the rest of the planned activities.

[Record decision for Round 1 and Round 2. When all subjects have made their decision, the assistant enters the coin toss data] $\mathrm{a} €$ 


\section{Instructions for Norm Elicitation game (Task 3)}

For this task, I will read to you descriptions of a series of situations. These descriptions correspond to situations in which a person must make a decision. For each situation, you will be given a description of the decision faced by an individual. After I read to you the description of the decision, I will describe a choice that the individual might have made, and you should decide whether making that choice would be "acceptable" and "consistent with proper social or moral behavior" or "unacceptable" and "inconsistent with proper social or moral behavior.â€ By acceptable, we mean behavior that most people agree is the "correct" or "ethical" thing to do. Another way to think about what we mean is that, if someone were to make an unacceptable choice, then someone observing this behavior might get angry at the person who made the choice for acting in that manner.

In each of your responses, we would like you to answer as truthfully as possible, based on your opinions of what constitutes socially appropriate or socially inappropriate behavior.

To give you an idea of how the experiment will proceed, we will go through an example and show you how you will indicate your responses. I will now read to you an example of a situation. These cards that I am holding illustrate the situation and the decision sheet. [Experimenter illustrates the situation using a vignette, to make it easier for subjects to understand the situation].

Someone is at a local grocery store. While there, the person notices that someone has left a wallet/bag on the counter. How appropriate would it be to take the wallet?

If this were the situation we asked you about in the study, you would indicate the extent to which you believe taking the wallet would be "acceptable" and "consistent with proper social or moral behavior" or "unacceptable" and "inconsistent with proper social or moral behavior". Recall that by socially appropriate we mean behavior that most people agree is the 'correct' or 'ethical' thing to do.

You should indicate your choice by filling the decision sheet [Hold up a reproduction of the decision sheet, where the answers are pictured using thumbs up or down]. As you can see, the decision sheet has four symbols on it:

- 2 thumbs down, corresponding to "very unacceptable"

- 1 thumb down, corresponding to "somewhat unacceptable"

- 1 thumb up, corresponding to "somewhat acceptable"

- 2 thumbs up, corresponding to "very acceptable".

This is to help you recognize and remember what each of these options mean. For example, suppose you thought that taking the wallet was very unacceptable. Then, you would indicate your response by selecting the first symbol, the one with the two thumbs down on the decision sheet. 
Are there any questions about this example situation or about how to indicate your responses? I will now read to you several situations, all dealing with decisions that you may have to make regarding your spouse, strangers or the researchers. I will illustrate these situations using vignettes. For each of the choices, I would like you to think whether making that choice is very unacceptable, somewhat unacceptable, somewhat acceptable and very acceptable. To indicate your response, you would place a check mark on the corresponding symbol on the decision sheet [Hold up reproduction of decision sheet again].

Participants have to answer ALL questions regardless of who they are matched with.

[Randomize order of 1, 2,3,4; randomize order of a and b]

Question 1a: (Spouse) "Is it acceptable to pick a snack for your spouse that is different from what you know they prefer.â€

[The assistants hand out the decision sheet, with a short description of the situation (picking a snack) and the appropriateness rating]

[After participants have noted their opinions, read out the next statement and ask them rate it]

Question 1b: (Spouse) "Is it acceptable for you to pick for yourself a snack that is different from what your spouse picked for you.â€

[The assistants hand out the decision sheet, with a short description of the situation (picking a snack) and the appropriateness rating]

[After participants have noted their opinions, read out the next statement and ask them to rate it]

Question 2a: (non-household members/strangers of opposite gender). "Is it acceptable to pick a snack for a man/woman (opposite gender) in the other room from outside your household that is different from what you know they prefer"

[The assistants hand out the decision sheet, with a short description of the situation (picking a snack) and the appropriateness rating.]

[After participants have noted their opinions, read out the next statement and ask them rate it.]

Question 2b: (non-household members/strangers of opposite gender). "Is it acceptable for you to pick for yourself a snack that is different from what a man/woman (opposite gender) in the other room from outside your household has picked for you".

[The assistants hand out the decision sheet, with a short description of the situation (picking a snack) and the appropriateness rating.]

[After participants have noted their opinions, read out the next statement and ask them rate it.]

Question 3a: (non-household members/strangers of the same gender). "Is it acceptable to pick a snack for a man/woman (same gender) in the this room from outside your household that is different from what you know they prefer" 
[The assistants hand out the decision sheet, with a short description of the situation (picking a snack) and the appropriateness rating.]

[After participants have noted their opinions, read out the next statement and ask them rate it.]

Question 3b: (non-household members/strangers of the same gender). "Is it acceptable for you to pick for yourself a snack that is different from what a man/woman (same gender) in the this room from outside your household has picked for you".

[The assistants hand out the decision sheet, with a short description of the situation (picking a snack) and the appropriateness rating.]

[After participants have noted their opinions, read out the next statement and ask them rate it.]

$\hat{a} €$

\section{Final Instructions}

This was the last activity. We will now compute your earnings and distribute them to you. While you are distributed your lunch, we will ask you a short questionnaire.

In order to compute your payment, we have to determine whether you will be paid for Task 1 or Task 2, and whether you will be paid for your decisions as Player 1 or Player 2. Recall that we said we would draw a number from a bag to determine which task you will be paid for, and would toss a coin to decide whether you would be paid as Player 1 or Player 2.

We will therefore ask the enumerator outside to draw the number and then toss a coin: if heads come up then you will be paid as Player 1; if tails come up, we will pay you as Player 2. We will also use a coin toss to determine if you get payment from round 1 or round 2 of task 1 . We will inform each of you the outcome of the coin toss as we provide you your earnings in privacy.

[Enumerator: Please refer to the randomization lists provided to you to determine the color of the tag that will get payment for the spouse round and the color that will be paid for the stranger round. Also refer to the randomization list to find out whether each individual is paid as player 1 or player 2.]

Your final payment will therefore be determined by

- Your decision/Your partner's decision in task 1/2 (task that dictator was on that day).

- On top of these earnings, you will also receive the participation fee

- Also in addition, you will receive the money you earned in the first activity we performed, when we asked you to guess your partner's ranking of the food items flavors. Recall that we promised you we would give you Rs 50 if you guessed your 
partner's favorite food item or drink, and Rs 100 is you guessed both food item and drink preferred by your partner. If you guessed correctly, those earnings will be also included in your total payment.

[When distributing the payment envelopes]: Thank you very much for your participation! Please enjoy your lunch and don't hesitate to ask us questions if you have doubts before you leave. 


\section{A3. Field experiment}

The details of the randomized controlled trial are given in Afzal et al. (2018). The specific part of the endline questionnaire dealing with the gift experiment is reproduced below, together with the instructions for enumerators.

\section{GIFT FOR PARTICIPATION}

Thank you for answering our survey and being a part of our research.

Before we start with a small exercise, we would like to give you Rs. 300 as a compensation for your time in participating in this survey. These Rs. 300 are not a part of the activity and are yours to keep.

I would like to have brief conversation with your husband regarding our research. Can you please call him and give us 5 minutes alone in this room?

[ENUMERATOR: If husband is available and willing to talk to us, proceed with step 1 and step 2. If husband not available or unwilling to talk to us, ask if it is possible to call him and agree with him on a time to talk. If husband not available to talk on the phone, agree with the wife on a time to visit the household again when the husband will be present.]

[Enumerator: If the respondent is unmarried or her husband does not live with her/is not a part of the household roster, then ask for the oldest male household member. Step 1 is then to be administered to this male individual.]

If there is no husband and/or an adult male household member in the household then record 77 :

section_9

\section{STEP 1: Husband}

1. You may remember that 8-9 months back we asked you to make a choice between three household items (a male wallet, a female wallet and children's pencil case). Your choice was [report Item selected at baseline]

\{ENUMERATOR: if he did not make a choice at baseline, we ask him to choose right now and note

a.Item selected: 1: male wallet, 2 : female wallet, 3 ; child's pencil case._--_ choice_1a

b.Recipient. i.e who is the item for?

choice_1b

c. What initials should appear on it?

choice_1c\}

2. Your wife was also asked to choose an item when we visited her 8-9 months back. As we explained last time, we will toss a coin to decide, between your choice and your wife's choice, which item your household will receive.

However, you can let your spouse choose in your stead, in which case, we will not toss a coin and simply select the gift according to your wife's choice.

Would you like to let your wife choose in your stead? — $—$ Yes/No] choice_2 


\section{If YES to 2[ENUMERATOR: Skip to 4]}

3. If NO to 2: Would you be willing to let your wife choose in your stead if we offered you a voucher worth a certain amount of money? The value of this voucher is determined by a random draw and it can be either Rs. X or Rs. XX. The value of the voucher is written in this sealed envelope [ENUMERATOR: Show the envelope to the respondent without opening the seal]. Before I open this envelope and reveal the value of the voucher, I will ask you whether you would be willing to let your wife choose the gift instead of you in exchange for the voucher, for each of the two possible values of the voucher. Once I open the envelope and reveal the value of the voucher, we will implement your choice corresponding to that value of the voucher. The voucher can be redeemed at the NRSP office three-four weeks from today, and we will send an SMS to inform you when the gift or voucher is ready to be collected.

Before we proceed, do you have any questions on this? [ENUMERATOR: Answer any questions before proceeding.]

a. Would you let your wife choose the gift if the voucher were worth Rs. X? - $[\mathrm{Yes} / \mathrm{No}] \quad$ choice_3a

b. Would you let your wife choose the gift if the voucher were worth Rs. XX? choice_3b

- YYes/No] [ENUMERATOR: Ask this question regardless of the answer to 3a]

c. What is your best guess of your wife's choice among the three gift options? [_-_-_- item] choice_3c

d. Suppose you knew for sure that your wife's choice was the male wallet, how much money should the voucher be worth to induce you to let your wife choose the gift? [_-_- Rupees] choice_3d

e. Suppose you knew for sure that your wife's choice was the child's pencil case, how much should the voucher be worth to induce you to let your wife choose the gift? [_-_ Rupees] choice_3e

f. Suppose you knew for sure that your wife's choice was the female wallet, how much should the voucher be worth to induce you to let your wife choose the gift? Rupees] choice_3f

g. Now we will find out the value of the voucher. [ENUMERATOR: Give the sealed envelope to the respondent to open.]

h. Earlier you said that you would/would not [report respondent's answer to 3a or $3 \mathrm{~b}$, depending on the voucher value] let your wife choose the gift in exchange for a voucher of this value. So we will now implement your choice.

i. [ENUMERATOR: If answer to $3 \mathrm{a}$ or 3b, is 'YES' to taking the voucher]

Take this voucher receipt of $\mathrm{Rs}_{----_{-}}$voucher_male

Please keep it safe. You will have to bring this voucher receipt with you to NRSP 
office to collect your money. We will now ask your wife to choose the gift.

[ENUMERATOR: If answer to $3 \mathrm{a}$ or $3 \mathrm{~b}$, is 'NO' to taking the voucher]

You will not receive the voucher, and your household's gift will be decided after we interview your wife.

[ENUMERATOR: Now go to step 2]

4. What is your best guess of your wife's choice among the three gift options? (1:

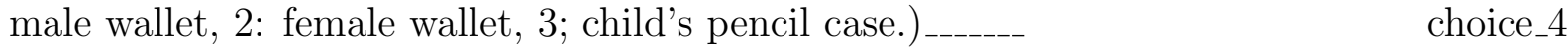

5. Suppose that I was willing to give you a voucher worth a certain amount of money if you let your wife choose the gift instead of you.

a. Suppose also that you knew for sure that your wife's choice was the male wallet, how much money should the voucher be worth to induce youto let your wife choose the gift in your stead?

[-_-_ Rupees] choice_5a

b. Suppose you knew for sure that your wife's choice was the child's pencil case, how much should the voucher be worth to induce you to let your wife choose the gift in your stead?

[----- Rupees] choice_5b

c. Suppose you knew for sure that your wife's choice was the female wallet, how much should the voucher be worth to induce you to let your wife choose the gift in your stead? [_-_ Rupees] choice_5c

We also have a voucher in this envelope as a thank you for participating in our short questionnaire today. I will now/you may now open the envelope to see what the amount of this voucher is. This voucher can be redeemed at the NRSP office three-four weeks from today, and we will send an SMS to inform you when the gift and voucher are ready to be collected.

[Enumerator: Now go to step 2]

STEP 2: [ENUMERATOR: Go back to the female respondent.]

1. You may remember that 8-9 months back we asked you to make a choice between three household items (a male wallet, a female wallet and children's pencil case). Your choice was [report Item selected at baseline]

\{ENUMERATOR: if she did not make a choice about the initials to appear on the gift, ask now

a. What initials should appear on it? choice_2_1\}

2. Your husband was also asked to make a choice at that time and we have just asked him to confirm his choice.

3. As we explained last time, we will toss a coin to decide, between your choice and your husband's choice, which item your household will receive. 
We will also give you a voucher for either Rs. 50 or Rs. 200. The value of the voucher is written in this sealed envelope [ENUMERATOR: Show the envelope to the respondent without opening the seal].This voucher can be redeemed at the NRSP office three-fourweeks from today, and we will send an SMS to inform you when the gift and voucher are ready to be collected.

Before I toss the coin to decide if you will get your choice or your husband's choice of gift, you can choose to forfeit the voucher and get your choice of the gift for sure -i.e. you can skip the coin toss and guarantee you get your choice for sure, in exchange for the voucher. Before I open this envelope and reveal the value of the voucher, I will ask you whether you would be willing to get your choice for sure in exchange for the voucher, for each of the two possible values of the voucher. Once I open the envelope and reveal the value of the voucher, we will implement your choice corresponding to that value of the voucher.

4. Would you forfeit the voucher to get your choice for sure if the voucher were worth Rs. Y? $[$ Yes/No] choice_2_4

5. Would you forfeit the voucher to get your choice for sure if the voucher were worth Rs. YY? [Yes/No] [ENUMERATOR: Ask this question regardless of the answer to 4] choice_2_5

6. What is your best guess of your husband'schoice among the three gift options?(1:

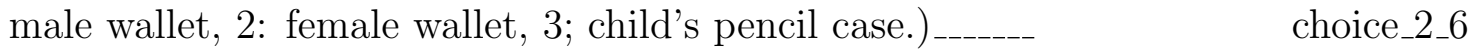

7. Suppose you knew for sure that your husband's choice was the male wallet, how much money would you be willing to give up to avoid the coin toss and make sure you got your choice for sure? [-_-_-_- Rupees] $\quad$ choice_2_7

8. Suppose you knew for sure that your husband's choice was the female wallet, how much money would you be willing to give up to avoid the coin toss and make sure you got your choice for sure? [_-_- Rupees] choice_2_8

9. Suppose you knew for sure that your husband's choice was the child's pencil case, how much money would you be willing to give up to avoid the coin toss and make sure you got your choice for sure? [-_--_-- Rupees] choice_2_9

10. Now we will find out the value of the voucher. [ENUMERATOR: Give the sealed envelope to the respondent to open]

11. Earlier you said that you would/would not [report respondent's answer to 4 or 5, depending on the voucher value] forfeit a voucher of this value in order to get your choice of gift for sure. So we will now implement your choice.

[If she has chosen to keep the voucher for the actual voucher value] For this value of the voucher you chose to toss the coin instead of forfeiting the voucher. Please toss the coin to determine whether you will get your choice or your husband's choice of gift. If the coin toss yields Head you will get your choice, if it yields Tails you will get your husband's choice. [Observe and record the outcome of the coin toss] The coin toss has come out -[Head/Tails].

coin_toss 
[If she has chosen to forfeit the voucher and get her own choice for sure for the actual voucher value] For this value of the voucher you chose to forfeit the voucher instead of tossing the coin. You will thus receive your choice of gift.

[If her husband had delegated the choice to her in step 1] For your information, your husband chose [report item chosen by husband] _._-_ as a gift. He also chose to let you choose the gift instead of him. Therefore, you will receive the gift of your choice and you will not have to forfeit the voucher/ toss a coin.

12. For your information, your husband chose [report item chosen by husband] as a gift. He also chose to not let you choose the gift instead of him.

13. To summarise, according to your choices today, you will receive [report item that the respondent will receive as gift(1: male wallet, 2 : female wallet, 3 ; child's pencil case.)] --_-_-_as a gift. final_gift

It will have [report initials that will have to be put on the gift that the respondent is to receive] _-__-_ initials inscribed on it. final_initials

This receipt records the gift that you are entitled to receive [Hand receipt].

[If applicable] This also has the voucher of Rs _-_... voucher_female

Please keep it safe. You will have to bring this receipt with you to NRSP office to collect your gift and/or money, once you receive an SMS telling you that they are ready to be collected, in about 3-4weeks' time. 


\section{Online Appendix B: Agency questions}

\begin{tabular}{|c|c|c|c|}
\hline Question & Description & Answer codes & Sample \\
\hline household_12 & $\begin{array}{l}\text { Do you need to ask someone's permission for making the } \\
\text { following decisions, and if yes from whom? (a) Purchasing } \\
\text { ice cream for children, (b) Purchasing grocery, (c) Purchas- } \\
\text { ing medicine for myself (d) Purchasing personal cosmet- } \\
\text { ics/clothing (e) Taking a child to a doctor (f) Purchasing } \\
\text { childrenâ€s books / clothes, (g) Purchasing furniture (h) } \\
\text { Purchasing refrigerator / TV (i) Sale of personal jewelry }\end{array}$ & $\begin{array}{l}\text { 1: Nobody, 2: Hus- } \\
\text { band, 3: Mother- } \\
\text { in-law/father-in- } \\
\text { law, 4: Son, 5: } \\
\text { Daughter, 6: Other } \\
\text { male, 7: Other } \\
\text { female }\end{array}$ & $\begin{array}{ll}\text { Field ex- } \\
\text { periment } \\
\text { (women } \\
\text { only) and } \\
\text { LAB1 }\end{array}$ \\
\hline p_1 & $\begin{array}{l}\text { Do you need to ask someone's permission for making the } \\
\text { following decisions, and if yes from whom? (a) Purchasing } \\
\text { ice cream for children, (b) Selecting food or drink for myself, } \\
\text { (c) Purchasing grocery for the household, (d) Purchasing } \\
\text { personal cosmetics/clothing, (e) Buying a snack or drink } \\
\text { from a street vendor, (f) Taking a household member to the } \\
\text { doctor, (g) Meeting a friend in town, (h) Purchasing clothes } \\
\text { for our children, (i) Inviting a friend to visit our house, } \\
\text { (j) Purchasing furniture for the household, (k) Selling my } \\
\text { personal jewelry }\end{array}$ & 0: No, 1: Yes & LAB2 \\
\hline $\begin{array}{l}\text { consump- } \\
\text { tion_8 }\end{array}$ & $\begin{array}{l}\text { Are your preferences/opinion taken into consideration when } \\
\text { making the following types of decisions within your house- } \\
\text { hold? (a) Decisions regarding boysâ€ schooling, (b) De- } \\
\text { cisions regarding girls' schooling, (c) Decisions regarding } \\
\text { your children's marriage, (d) Decision regarding your med- } \\
\text { ical care, (e) Decision regarding your childrenâ€s medical } \\
\text { care, (f) Decision regarding family planning, (g) Social vis- } \\
\text { its to your family, (h) Decisions regarding purchase of cloth- } \\
\text { ing/cosmetics (j) Decision to work for earned income, (k) } \\
\text { Decision to borrow money from an MFI, (l) Purchase of } \\
\text { HH appliances (refrigerator, TV, etc), (m) Decision about } \\
\text { house sale/purchase, (n) Decision regarding sale of personal } \\
\text { jewelry }\end{array}$ & $\begin{array}{l}\text { 1: Always, 2: Most } \\
\text { of the time, } 3: \\
\text { Some of the time, } 4 \text { : } \\
\text { Rarely, } 5: \text { Never }\end{array}$ & $\begin{array}{l}\text { Field ex- } \\
\text { periment } \\
\text { (women } \\
\text { only) }\end{array}$ \\
\hline
\end{tabular}

